INTERACTIVE DIPOLE-DIPOLE RESISTIVITY AND IP MODELING

OF ARBITRARY TWO-DIMENSIONAL STRUCTURES

(IP2D USERS GUIDE AND DOCUMENTATION)

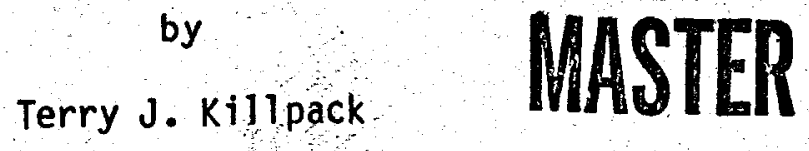

Gerald W. Hohmann

January, 1979

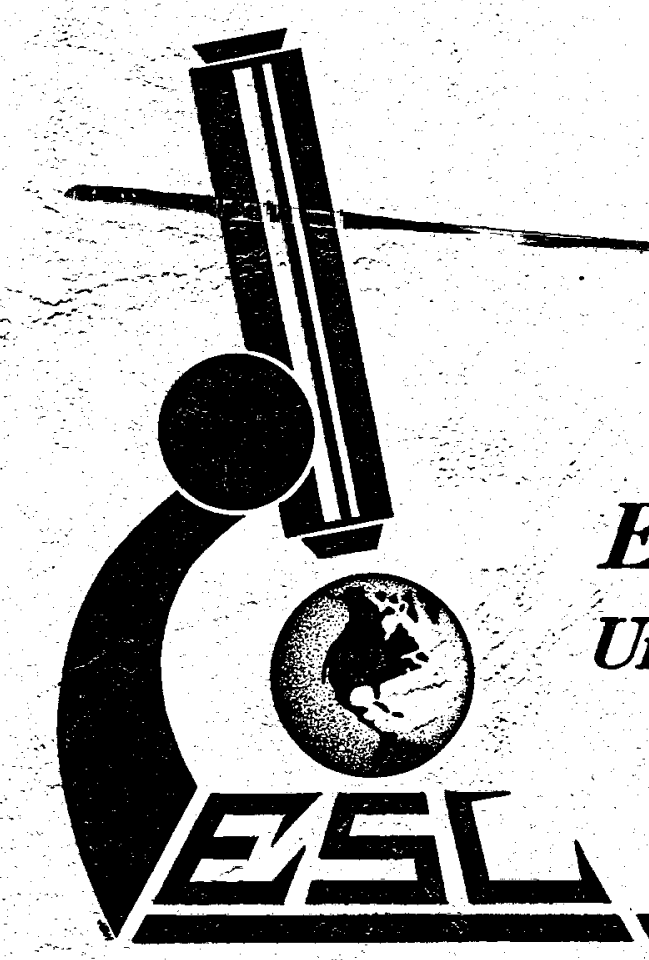

Work performed under Contract No. EG-78-C-07-1701

EARTH SCIENCE LABORATORY University of Utah Research Institute Salt Lake City, Utah

Prepared for

U.S Department of Energy

Division of Geothermal Energy

DISTRIBUTION OF THIS DOCUMENT IS UNLMMITES 


\section{DISCLAIMER}

This report was prepared as an account of work sponsored by an agency of the United States Government. Neither the United States Government nor any agency Thereof, nor any of their employees, makes any warranty, express or implied, or assumes any legal liability or responsibility for the accuracy, completeness, or usefulness of any information, apparatus, product, or process disclosed, or represents that its use would not infringe privately owned rights. Reference herein to any specific commercial product, process, or service by trade name, trademark, manufacturer, or otherwise does not necessarily constitute or imply its endorsement, recommendation, or favoring by the United States Government or any agency thereof. The views and opinions of authors expressed herein do not necessarily state or reflect those of the United States Government or any agency thereof. 


\section{DISCLAIMER}

Portions of this document may be illegible in electronic image products. Images are produced from the best available original document. 


\section{NOTICE}

This report was prepared to document work sponsored by the United States Government. Neither the United States nor its agent, the United States Department of Energy, nor any Federal employees, nor any of the ir contractors, subcontractors or their employees, makes any warranty, express or implied, or assumes any legal liability or responsibility for the accuracy, completeness, or usefulness of any information, apparatus, product or process disclosed, or represents that its use would not infringe privately owned rights.

\section{NOTICE}

Reference to a company or product name does not imply approval or recommendation of the product by the University of Utah Research Institute or the U.S. Department of Energy to the exclusion of others that may be suitable. 


\title{
Interactive Dipole-Dipole Resistivity and IP Modeling of Arbitrary Two-Dimensional Structures (IP2D Users Guide and Documentation)
}

\section{by}

\author{
Terry J. Killpack
}

Gerald W. Hohmann

\author{
EARTH SCIENCE LABORATORY \\ UNIVERSITY OF UTAH RESEARCH INSTITUTE \\ 420 Chipeta Way \\ Suite 120 \\ Salt Lake City, Utah 84108 \\ Date Published - January, 1979
}

Prepared for the DEPARTMENT OF ENERGY

DIVISION OF GEOTHERMAL ENERGY UNDER CONTRACT EG-78-C-07-1701

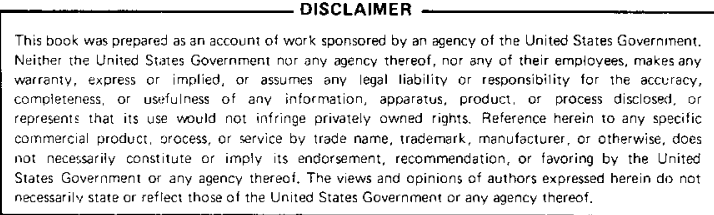


E. The Element Matrix Equation ............ C-12

F. Assemblage of the Global Matrix Equation ......... C-14

Computational Aspects ............... C-16

A. Incorporation of the Dirichlet Boundary Conditions . . . - C-17

B. Solution of the System of Equations ........... . C-17

C. Computation of the Inverse Transform for the

IP-Resistivity Problems .................. C-18

D. Computation of the IP Response.....................

Appendix D

Sample Computer Sessions.............. D-1 Appendix E

Batch Modeling Users Guide . . . . . . . . . . . E-1

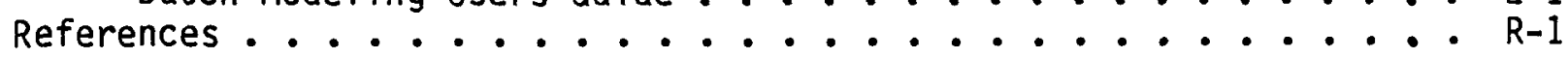




\section{List of Figures}

Page

Figure 1-1 Interactive Modeling System Flow Chart . . . . . . 1-3

Figure 1-2 Batch Modeling System Flow Chart . . . . . . . . 1-5

Figure 2-1 Finite-Element Mesh .............. 2-4

Figure 2-2 Finite-Element Mesh, Middle Portion . . . . . . . . 2-6

Figure 2-3 Finite-Element Mesh Triangular Elements . . . . . . . 2-8

Figure 2-4 Finite-Element Mesh, Middle Portion, Triangular Elements............. 2-9

Figure C-1 An arbitrary element . . . . . . . . . . . C-8

Figure D-1 Resistivity and Ratio Page . . . . . . . . . . D-25

Figure D-2 PFE and Difference Page . . . . . . . . . . D-26

Figure D-3 Resistivity Section of a Topographic Model . . . . . D-42 


$$
\text { List of Tables }
$$

Page

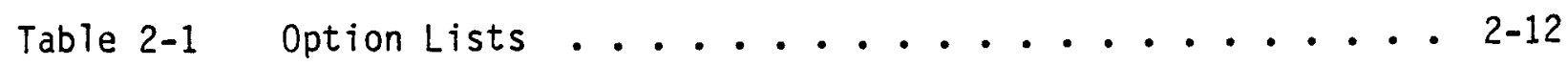

Table $\mathrm{C}-1$ Mathematical Notation............ C-2 
ABSTRACT

An interactive IP-resistivity modeling computer program has been developed at the Earth Science Laboratory. This program can be used to model arbitrary two-dimensional IP-resistivity structures for comparison with data from dipole-dipole surveys. The program computes the potential difference between the two potential electrodes of a conventional dipole-dipole array using a finite-element approach. The original program was developed by Luis Rijo at the University of Utah. Additional software has been written around Rijo's program to provide interactive input and output functions. This report is a users guide and documentation for the interactive program called IP2D. 
Abstract

Forward

I. Introduction .......................... 1-

A. System Structure and Overview .............. 1-1

B. Interactive Modeling System ................ 1-2

C. Batch Modeling System .............. . 1-4

II. Users Guide .................... . 2-1

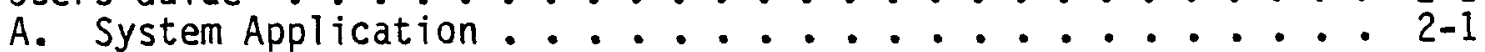

B. Model Description and Definitions .......... 2-2

C. Option system . . . . . . . . . . . . . . . 2-10

D. TERM options .................... 2-11

E. MASTR options ................... $2-11$

F. INPUT options ................... 2-16

G. MESH options .................... 2-16

H. EDIT options ................ . . 2-17

I. TRI options .................... . . 2-18

J. EGEO options .................. . . 2-19

K. PLOT options ................... . . 2-20

L. PAGE options................... 2-21

M. RADIF options ................... . . 2-22

N. FMAIN options ................. 2-22

0. LIST options .................. 2-23

P. SECT options........................ 2-24

Q. Interactive Modeling Examples . . . . . . . . . 2-25

III. System Implementation . . . . . . . . . . . . 3-1

Appendix $A$

Calcomp Plotter Routines used by IP2D System . . . . . . A-1

Appendix B

Tektronix Subroutines used by IP2D System . . . . . . . B-1

Appendix C

Theory for Resistivity and Induced-Polarization Modeling

in Terms of a Helmholtz Equation .............. C-1

A. The General Maxwell Equations and Boundary Conditions . - C-1

B. Coupling-free Induced Polarization and Resistivity . . . . C-4

Finite Element Theory of the Helmholtz Equation . . . . . . C-6

A. Subdomains.................... C-7

B. Function Description over Subdomains . . . . . . . C-7

C. The Element Equations .............. C-10

D. The Boundary Condition .............. C-12 
FORWARD

Software Availability

Copies of the FORTRAN software for this program can be obtained either on magnetic tapes or as a paper listing from the Earth Science Laboratory (ESL) at our cost. ESL is neither funded nor staffed to provide implementation of this software on another computer system. The program is presently operational on the University of Utah's UNIVAC 1108 which has a time-sharing service available. 


\section{INTRODUCTION}

An IP-resistivity modeling program was developed at the University of Utah by Luiz Rijo (1977) while he was a doctoral candidate in the Department of Geology and Geophysics. Rijo's program computes the potential difference between the two potential electrodes of a conventional dipole-dipole IP array using a finite-element approach. The program is restricted in its application to two-dimensional resistivity and topographic structures and is also restricted to batch usage.

This report describes an IP-resistivity interactive modeling system developed at the Earth Science Laboratory that incorporates Rijo's program. The modeling system provides the user with interactive model manipulation and data presentation functions. The system makes use of two data files: (1) a work data file where model parameters and pseudosections are stored, and (2) a merge file where copies of the work file may be stored for future recall and analysis. The interactive system allows on-line model parameter input and editing. Model parameters and computed results can be printed on demand terminals or main site line printers. The interactive system has access to Tektronix and Calcomp plotting packages that provide the capability of plotting mesh geometries and pseudosection results.

System Structure and Overview

The interactive modeling system has two modes that can be implemented from remote terminals: (1) interactive modeling and (2) interactive model setup with batch execution. The interactive modeling mode allows the user to: 
1) input an earth cross-section model, 2) list the input model parameters for verification, 3 ) execute the finite-element program which produces computed pseudosections, 4) update the model parameters, and 5) continue this process indefinitely. Once the model has reached its final form the user can 1) list the model and resulting pseudosections, 2) store the model on the merge file for future reference, and/or 3) plot mesh geometry and pseudosections on a Tektronix terminal or a Calcomp plotter. The interactive model setup with batch execution allows the user to interactively set up a number of different models which are stored on the merge file. The user can then start a batch run that will access the merge file, execute the finite-element program for each of the models specified, and store the results in the merge file for future examination. This capability was developed to allow the user to set up a series of models in the merge file and then to execute the finite-element program at lower computer costs in a batch run.

Interactive Modeling System

The interactive modeling system consists of seven programs that can pass program control back and forth through option selections. The programs also access the two data files mentioned above. Figure 1-1 shows the organization of the interactive system. Program control is shown in solid lines while data flow is shown in dashed lines. System entry is obtained through a program called TERMS. The type of terminal in use is recorded in the work file by TERMS and then program control is passed to the program called MASTER. Program MASTER acts as an executive for the system, and program control is passed to other programs by option selection. Program MASTER provides data 
Figure $1-1$ Interactive Modeling System Flow Chart

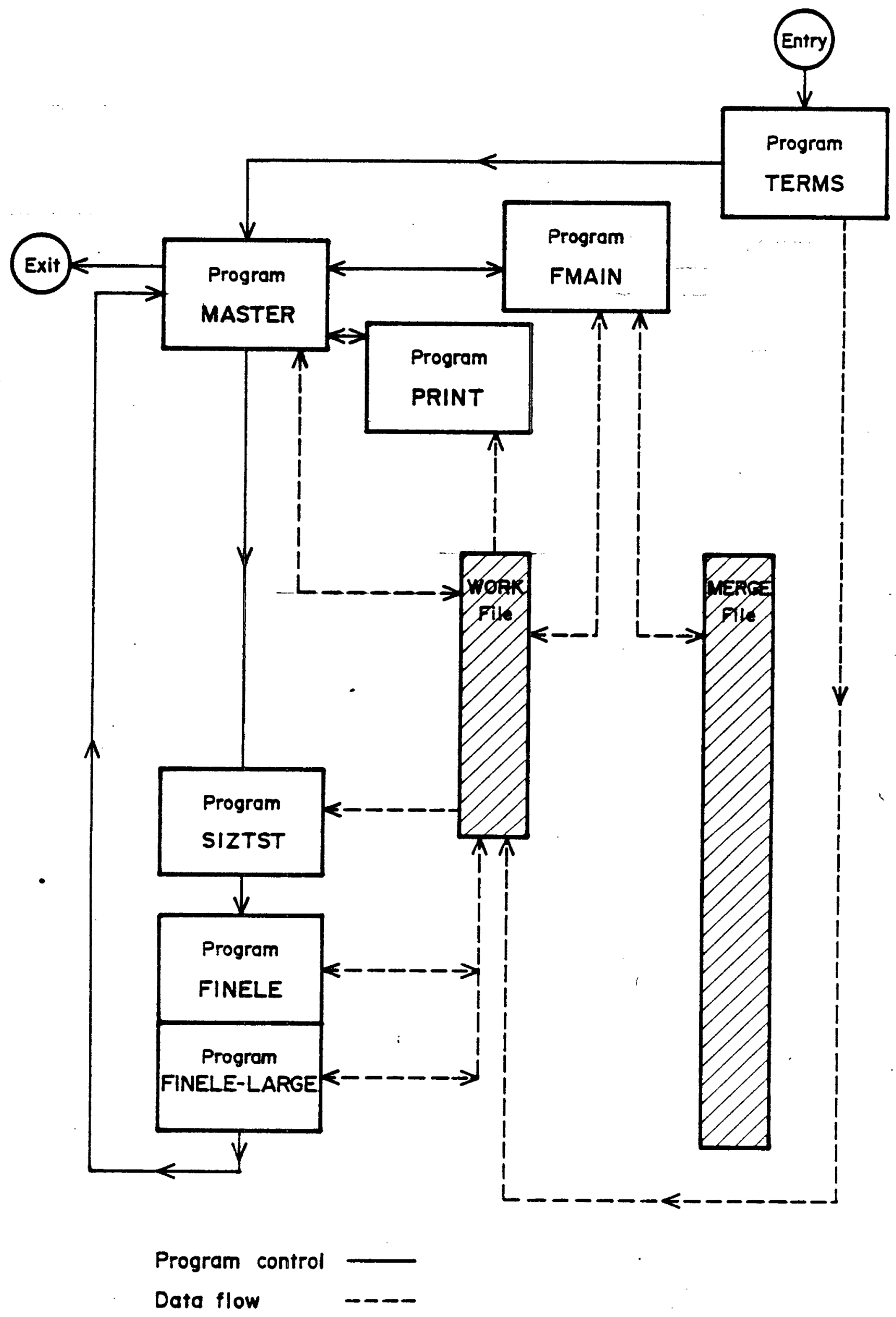


input, editing, listing, and plotting functions. After a model has been set up on the work file using MASTER, the finite-element program can be executed by passing control to the program called SIZTST. If the mesh geometry is small enough in terms of number of $z$-nodes, SIZTST passes control to the program called FINELE; if the mesh is larger, control is passed to the program called FINELE-LARGE. FINELE or FINELE-LARGE read the model parameters from the work file and execute the finite-element program. After the computed pseudosections are printed and stored, control is passed back to MASTER. PRINT is a program that is used to send listings of the parameters and pseudosections in the work file to the main site line printer. FMAIN is a file maintenance program that is used to initialize the two data files and to perform maintenance on the merge file. FMAIN is also used to store the work file in the merge file or to recall a copy of a previous work file from the merge file.

\section{Batch Model ing System}

The batch modeling system consists of five programs that communicate with two data files and are driven by a small data file on cards. Figure 1-2 is a flow chart of the batch modeling system. Programs SIZTST, FINELE, and FINELE-LARGE are the same as those used in the interactive modeling system. The batch system is put into operation by using the interactive system to form a number of models which are then stored on the merge data file. A small batch deck is then set up which will call out the models from the merge file, execute the finite-element program, and store the results in the merge file.

Entry to the batch system is gained through execution of BATIN. A 
Figure 1-2 BATCH MODELING SYSTEM FLOW CHART

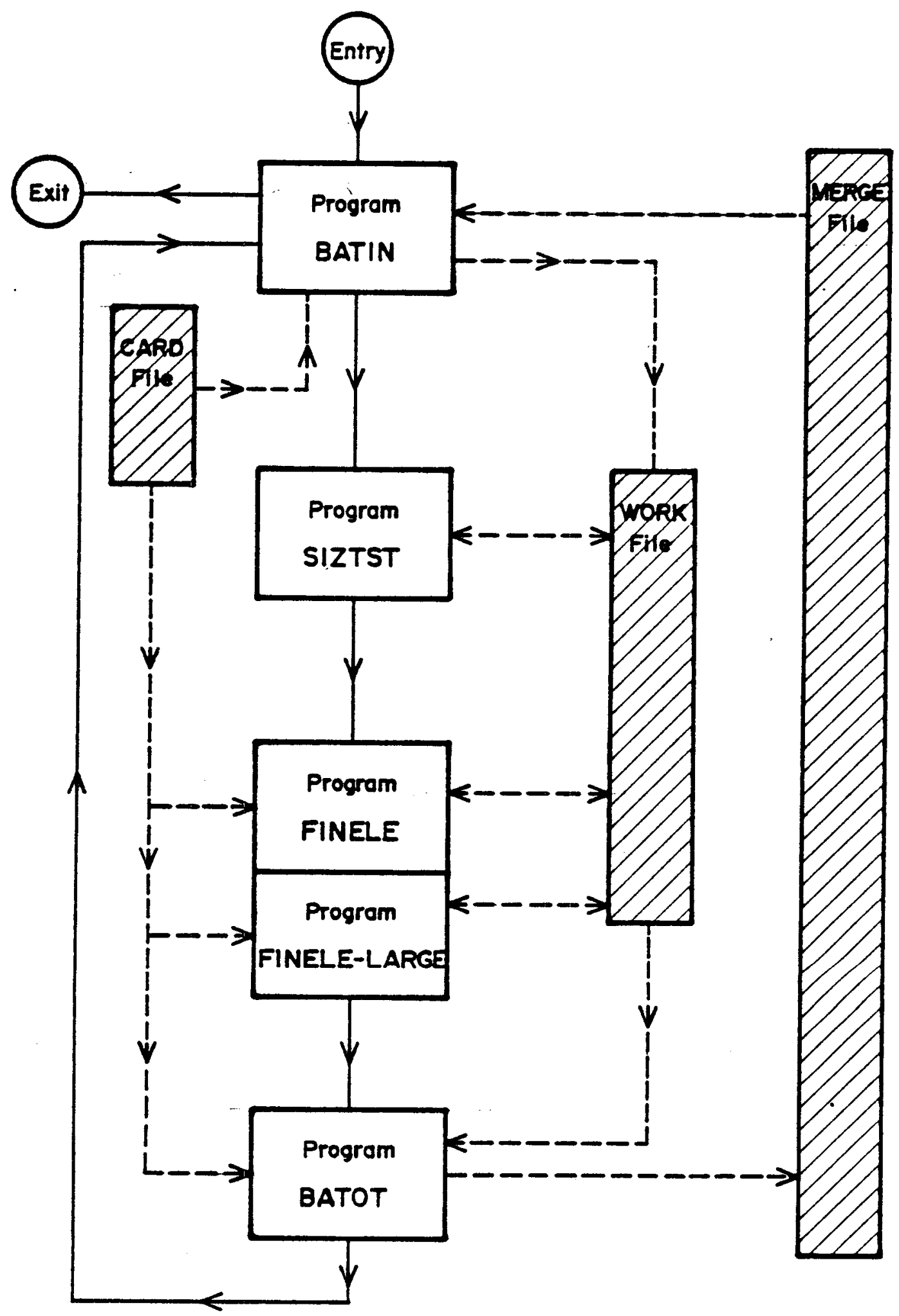

Program control

Data flow

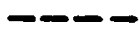


subfile number is read from the card file by BATIN. If the subfile number is zero, exit is obtained from the system. If the subfile number is not zero, the subfile indicated is read from the merge file and is placed in the work file. Control is then passed to SIZTST. The mesh size is read from the work file and control is passed to FINELE or FINELE-LARGE, depending on the number of $z$-nodes in the finite-element mesh. FINELE or FINELE-LARGE reads the model parameters from the work file, executes the finite-element algorithm, prints the resistivity and IP pseudosections, and writes the pseudosections into the work file. Control is then passed to BATOT which reads a subfile number from the CARD file and writes a copy of the work file into the merge file according to the subfile number that has been read. Program control is then returned to BATIN and the process is repeated until BATIN reads a subfile number of zero from the card file. 


\section{USERS GUIDE}

\section{System Application}

The finite-element technique used in both the interactive and the batch systems is restricted to two-dimensional models with irregular topography. The ideal earth environment that could be modeled by this system is an area where both the resistivity structure and the topography have a strike direction over which their values remain constant. The dipole-dipole array al so must be perpendicular to the strike direction. The cross section perpendicular to the strike and containing the electrode array is then modeled by dividing the section into a large number of finite elements. The solution that is obtained using the finite-element model is a good approximation of the analytical solution.

Obviously the ideal earth environment never exists and the interpretation is always degraded by three-dimensional effects. The difference between three-dimensional and two-dimensional responces is greater at higher resistivity contrasts.

The modeling system allows great flexibility in model definition, but some parts of the model have been fixed to reduce the amount of input required. The dipole-dipole array is fixed so that most of the array parameters can be set up internally and the output of pseudosections can be standardized. Onty six dipole separations are allowed. From the formula

$$
R E S=(X K+D V) / I
$$


it can be seen that a different geometric factor (XK) is needed for each seperation. The geometric factors for $N=1$ to $N=6$ are set internally in the finite-element program. Seventeen electrode positions are allowed, and the middle seven electrode positions are always taken as the transmitter electrodes. This results in a standard seven-spread pseudosection. The only information that is required from the user are the locations of the seventeen electrodes.

The finite-element program solves for the potential $V(x, y, z) ; V$ is independent of $y$ for two-dimensional geometries, and is symmetrical about a vertical plane containing the transmitter electrodes. To conserve computer storage the problem is solved in Fourier transform space for $V^{\prime}(x, s, z)$ where $s$ is the Fourier transform variable in the $y$ direction. The finite-element program computes $V^{\prime}(x, s, z)$ at several values of $s$ and inverse fourier transforms to obtain $V(x, y, z)$. It has been found that seven judiciously selected critical values of $s$ are sufficient to represent the potential in Fourier space. The critical values of $s$ are set internally in the program. Since all transmitter and receiver electrodes are coplanner in the $x z$ plane, $y=0$ and the program solves for $V(x, 0, z)$.

\section{Model Description and Definitions}

The finite-element model is set up by dividing an earth cross section into a large number of rectangular elements. For most models the number of rectangular elements is between 1000 and 1,500. Figure 2-1 is an example of such a mesh. The circular symbols near the top of the mesh are the electrode positions. The coordinate system used throughout this report is defined as 
$x$-axis positive to the right, $z$-axis positive down, and $y$-axis parallel to strike which is positive out of the page in Figure $2-1$. Figure $2-2$ is a larger view of the middle portion of the mesh in Figure 2-1. The elements in the mesh are defined by specifying various mesh geometry parameters.

The first two parameters that define the mesh size are the number of $x$ nodes and number of $z$ nodes. Nodes are located at each corner of all the rectangular elements in the mesh. The mesh shown in Figure 2-1 has $77 \times$ nodes and $12 \mathrm{z}$ nodes. The number of rectangular elements along the $x$ axis is always one less than the number of $x$ nodes and the number of elements along the $z$ axis is likewise always one less than the number of $z$ nodes.

It can be seen from the mesh in Figure 2-1 that there is some duplication in the rectangular element dimensions in both the $x$ and the $z$ directions. Rather than specify the $x$ and $z$ dimension of each rectangular element individually, the common element dimensions are grouped together in both the $x$ and $z$ directions. An examination of the mesh in Figure 2-1 shows that the $x$ dimension of the rectangular elements from left to right has the following pattern: one element $30 \mathrm{~A}$ wide, one element $15 \mathrm{~A}$ wide, one element $2 \mathrm{~A}$ wide, seventy elements $0.25 \mathrm{~A}$ wide, one element $2 \mathrm{~A}$ wide, one element $15 \mathrm{~A}$ wide, and one element $30 \mathrm{~A}$ wide where $\mathrm{A}$ is the electrode spacing. The element widths can be placed in 7 element groups in the $x$ direction with all elements in a group having the same width. An examination of the mesh in Figure 2-1 also shows that the rectangular elements have a $z$ dimension or height pattern with one element $0.1 \mathrm{~A} \mathrm{high,}$ one element $0.2 \mathrm{~A}$ high, one element $0.3 \mathrm{~A} \mathrm{high}$, one element $0.4 \mathrm{~A}$ high, two elements $0.5 \mathrm{~A}$ high, two elements $1 \mathrm{~A}$ high, one element $2 \mathrm{~A}$ high, 


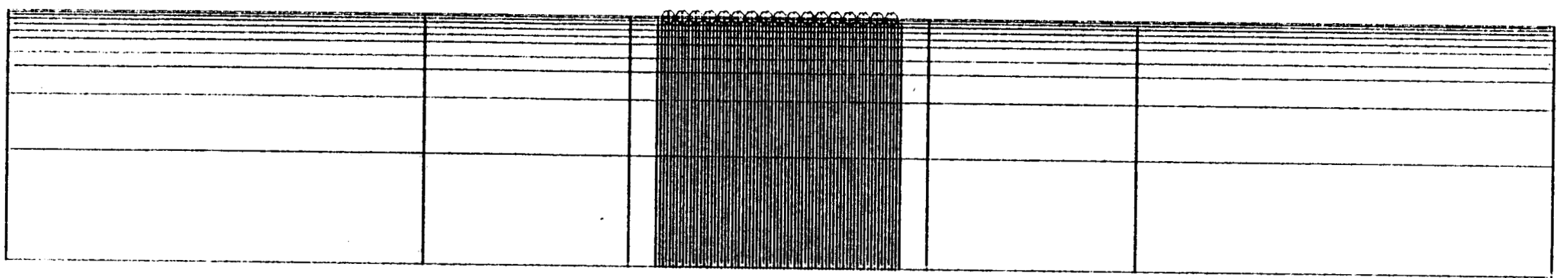

Figure 2-1 Finite Element Mesh 
one element $4 \mathrm{~A} \mathrm{high,} \mathrm{and} \mathrm{one} \mathrm{element} 8 \mathrm{~A}$ high from top to bottom. The element widths may be placed in 9-element groups in the $z$ direction. The groups 7 and 9 are referred to as "\# of $x$ element groups" and "\# of $z$ element groups" respectively in the interactive modeling system.

After the number of element groups has been defined in each of the two dimensions, an element group number and an element group spacing must be assigned to each group. The element group number defines the number of elements in each group and the element group spacings define the width or height of the elements in each group. The element group spacings are in multiples or fractions of the dipole spacing, A. It is assumed that group numbers and spacings are ordered from left to right and from top to bottom.

The electrode locations are specified by $x$-node number and $z$-node number. $X$ nodes begin at the left with one and are numbered sequentially to the right. The $z$-node numbers begin with one at the top of the mesh and monotonically increase to the bottom. The finite-element program assigns a unique node number to each node in the mesh by beginning in the upper left-hand corner of the mesh with the number one and counting down the column ( $z$ dimension), then continuing across the columns in the mesh. This counting is automatically done by a subroutine so that the user need only specify the $x$ - and $z$ - node numbers of an electrode position.

The next parameters required to define the model are resistivity and PFE (Percentage Frequency Effect) values of individual elements assigned through an index number to define individual element characteristics. The user assigns to each element in the mesh an index number associated with a 


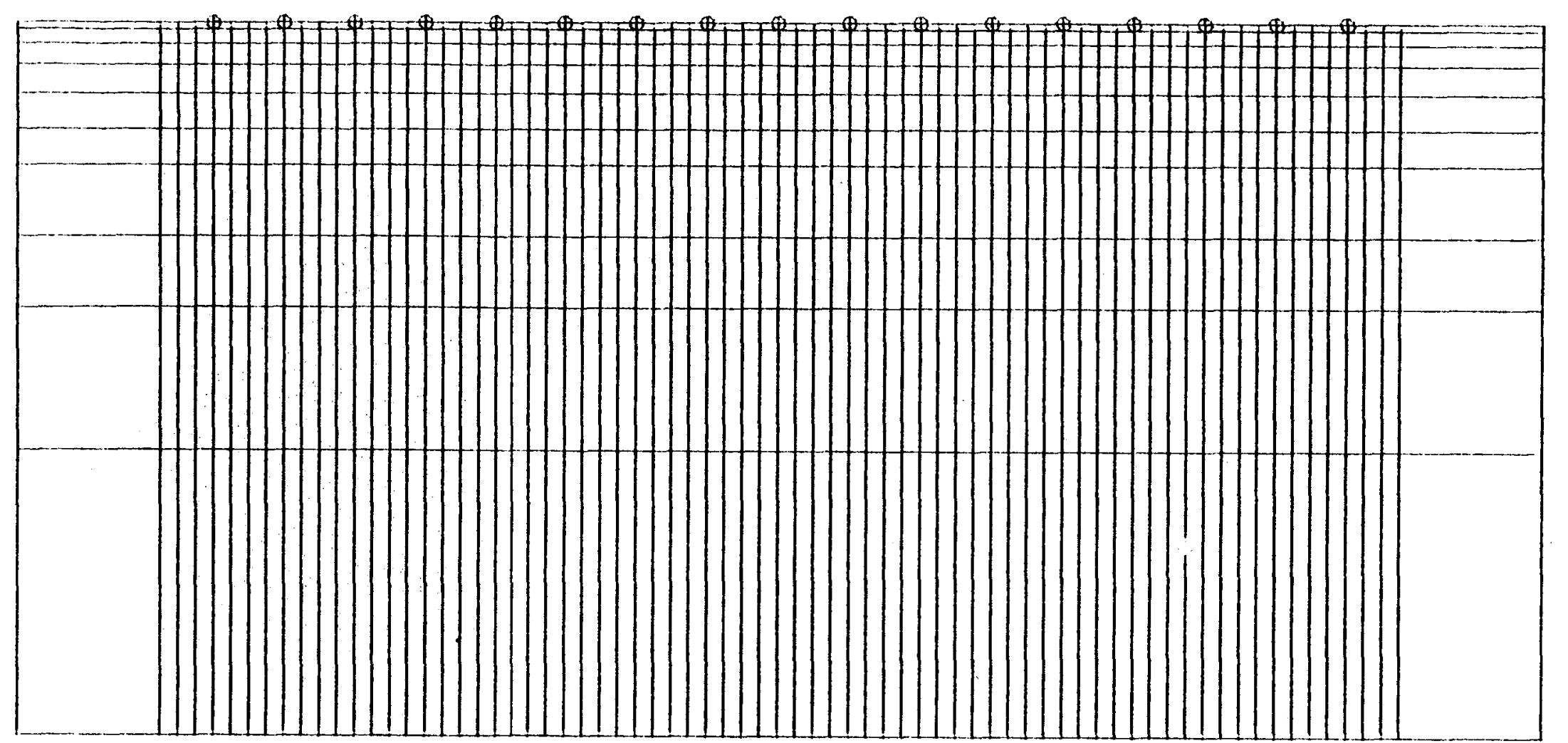

Figure 2-2 Finite Element Mesh, Middle Portion 
specified resistivity and PFE value. Thus elements that have the same characteristics have the same index number. The index numbers have a range of one to nine and the total number of distinct media throughout the mesh can be no more than nine.

The media characteristics are defined by first specifying the total number of distinct media that will be encountered in the mesh. The program then requests resistivity and PFE values for each of the distinct media. Elements that have an index code of one will be assigned the resistivity and PFE values of the first medium. Elements that have an index code of two will be assigned the resistivity and PFE value of the second medium and so forth.

Once the media characteristics have been defined, the mesh can be coded by assigning a media index number to each element of the mesh. The finite-element program actually uses triangular elements rather than the rectangular elements that the mesh geometry parameters define. Each rectangular element is divided into four triangular elements by drawing boundaries along the diagonals of the rectangular elements. Figures 2-3 and 2-4 show the mesh triangular elements. Each triangular element is assigned a single media index number and triangular elements within the same rectangular element need not have the same index number. To simplify input, the program accepts index numbers for rectangular elements and automatically assigns the rectangular index to each triangular element within it. Greater smoothness and detail in media boundaries can be implemented by individually coding the triangular elements. The editing options provide this capability.

The program provides the user with the capability of coding only a 

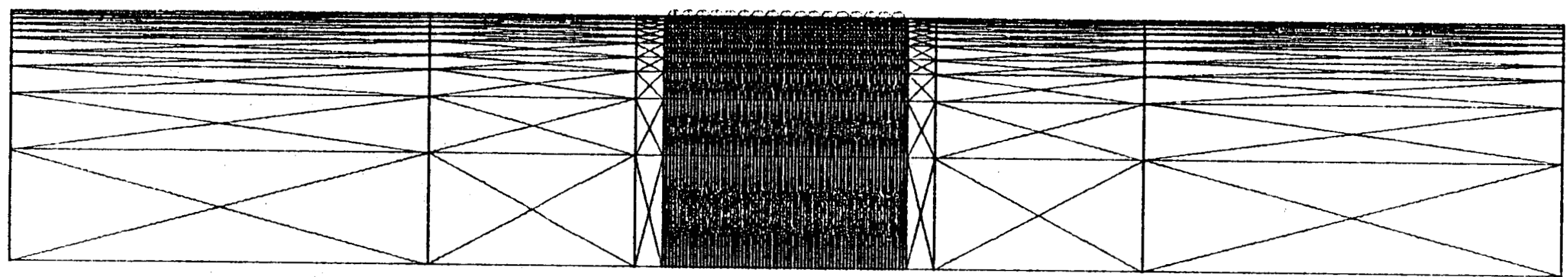

Figure 2-3 Finlte Element Mesh Triangular Elements 


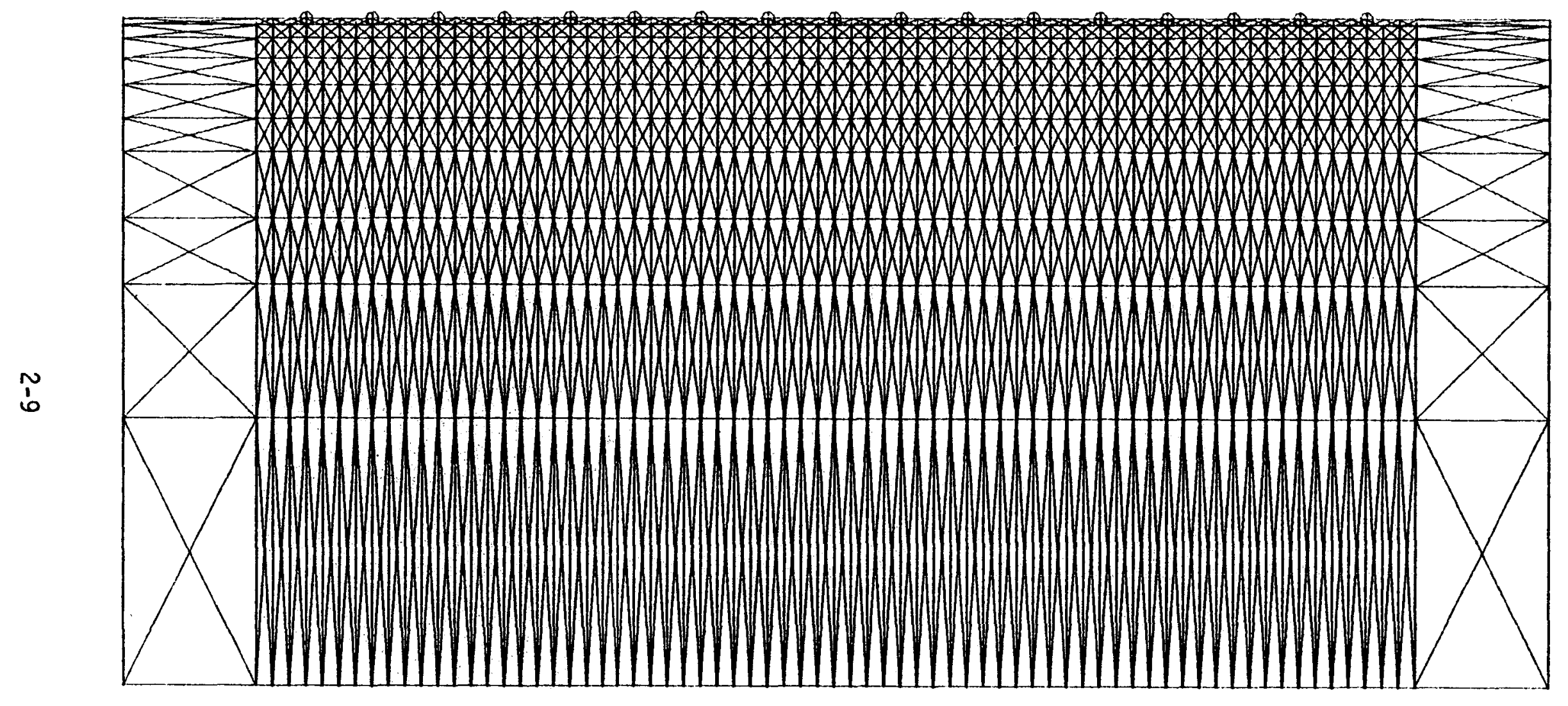

Figure 2-4 Finife Element Mesh, Middle Portion, Triangular Elements 
selected rectangular portion of the mesh. Mesh code is then extended to the left and right and then to the top and bottom of the full mesh area.

Option System

The interactive modeling system is controlled by an option selection system which works in the following manner. The option list that the user is dealing with is identified by a six-letter designator. An option number (integer) is requested by the option selection subroutine. If the user knows the option number of the function that is to be executed, the number may be specified directly. If the option number is not known the user can answer the number request with a zero. Any option number answer that is outside of the range of options for the designated list will cause an options list to be printed. Zero will always be outside because all option numbers are greater than or equal to one. After the list is printed, the option selection system will again designate the option 1 ist name and will again request an option number.

Option lists are set up in option levels. The selection of an option at one level may lead to another option list and option selection level. Each lower option list is printed with an indentation from the higher level list. The first option number is always a return to the next higher level options and in the case of the master options the first option causes the user to exit from the system. Thus the user can always return back up through the option levels and eventually out of the system by answering one to each option request. 
Table 2-1 is a complete 1ist of the options that are contained in the interactive system. The option lists appear in Table 2-1 just as they do when printed by the computer. The indentations are indicative of the level of the option 1ist. An explanation of each option of the interactive system in the order in which they are encountered in the Table 2-1 options list follows.

\section{TERM Options}

The terminal option selection is used to identify the type of terminal that is being used.

(1) HARD COPY means that the user is on line with a terminal that produces continuous hard copy like a teletype or a Texas Instruments Silent 745 .

(2) TEKTRONIX means that the user is on line with a Tektronix terminal that has plotting capabilities.

(3) CRT means that the user is on line with a cathode-ray-tube terminal that continuously scrolls the text off the top of the page.

\section{Master Options}

(1) EXIT FROM SYSTEM is selected when the user desires to terminate the modeling session.

(2) INPUT MODEL PARAMETERS is selected when a new model is to be input into the system.

(3) EDIT MODEL PARAMETER FILE is selected to change the model 
Table 2-1 Option Lists

TERM --OPTIONS

$$
\begin{array}{ll}
\# & \text { OPTION } \\
1 & \text { HARD COPY } \\
2 & \text { TEKTRONIX } \\
3 & \text { CRT }
\end{array}
$$

MASTR - OPTIONS
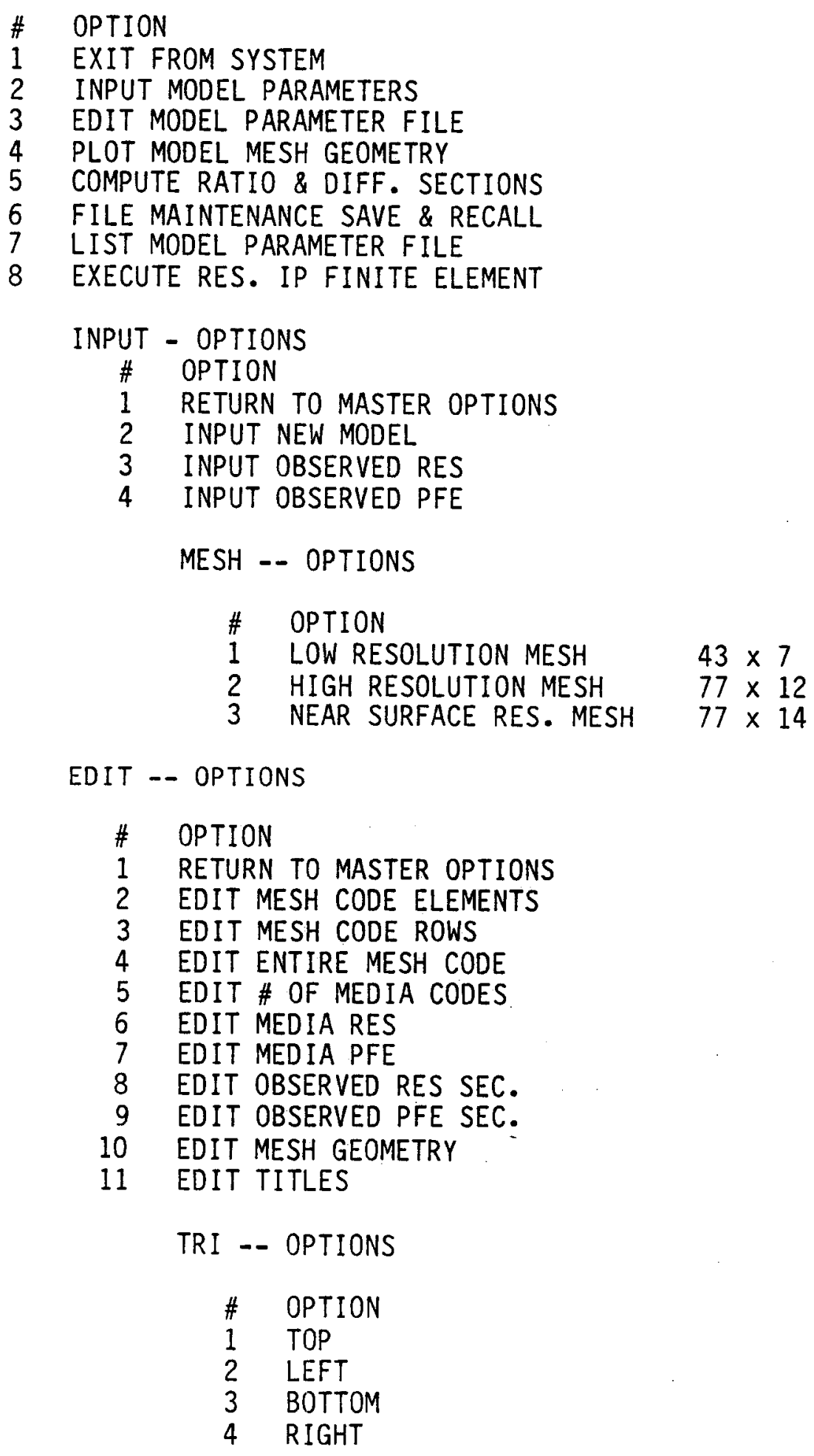
5 ALL

6 ENTER

EGEO -- OPTIONS

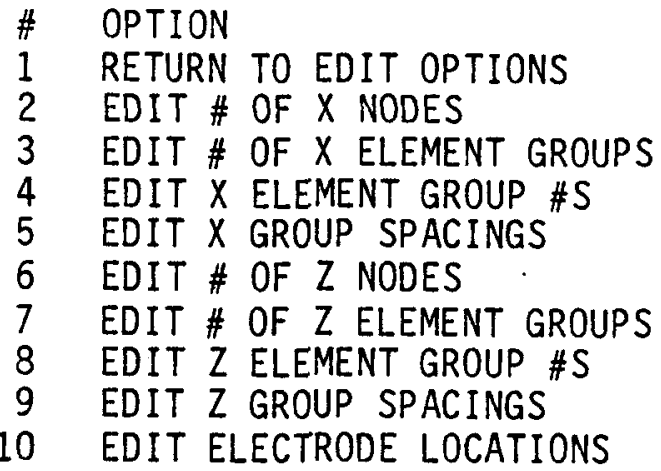

PLOT -- OPTIONS

\# OPTION

1 RETURN TO MASTER

2 TEK MESH PLOT

3 TEK SECTION PLOT

4 CALCOMP MESH PLOT

5 CALCOMP SECTION PLOT

6 CALCOMP REPORT PAGE PLOT

7 CALCOMP SCALED PAGE

8 CALCOMP SCALED PSEUDO S.

PAGE -- OPTIONS

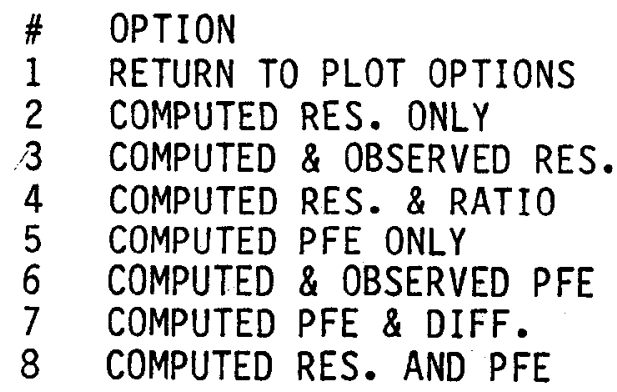

RADIF - OPTIONS

\# OPTION

1 RETUR.N MSTR

2 RES. RATIO

3 PFE DIFF

FMAIN - OPTIONS

$\begin{array}{ll}\# & \text { OPTION } \\ 1 & \text { RETURN TO MASTER PROGRAM } \\ 2 & \text { LIST MERGED FILE DIRECTORY } \\ 3 & \text { SAVE WORK FILE ON MERGED FILE } \\ 4 & \text { RESTORE WORK FILE FROM MERGED FILE } \\ 5 & \text { DELETE AND PACK MERGED FILE } \\ 6 & \text { INITIALIZE WORK FILE } \\ 7 & \text { INITIALIZE MERGE FILE }\end{array}$




$$
\begin{aligned}
& \text { LIST -- OPTIONS } \\
& \text { \# OPTION } \\
& 1 \text { RETURN TO MASTER OPTIONS } \\
& 2 \text { LIST TITLES } \\
& 3 \text { LIST GEOMETRY PARAMETERS } \\
& 4 \text { LIST MEDIA CHARACTER . } \\
& 5 \text { LIST MESH CODE TRI. ELE. } \\
& 6 \text { LIST MESH CODE SQR. ELE. } \\
& 7 \text { LIST PSEUDO SECTIONS } \\
& 8 \text { LIST FILE CONTENTS } \\
& 9 \text { SEND FILE CONTENTS TO PR } \\
& \text { SECT -- OPTION } \\
& \begin{array}{ll}
\# & \text { OPTION } \\
1 & \text { RETURN TO LIST OPT } \\
2 & \text { CALCULATED RES } \\
3 & \text { CALCULATED PFE } \\
4 & \text { OBSERVED RES } \\
5 & \text { OBSERVED PFE }
\end{array}
\end{aligned}
$$


parameters. This option could be selected to correct a model parameter that has been entered incorrectly, to update a model prior to the next iteration of finite-element solving, or to assign index numbers to triangular elements.

(4) PLOT MODEL MESH GEOMETRY is an option that is selected to produce plotted output of the model and the pseudosection results. The plotting option contains the capability of plotting on both a Tektronix terminal or on a Calcomp pen plotter.

(5) COMPUTE RATIO AND DIFF. SECTIONS is selected after the user has input observed resistivity and PFE pseudosections and after the finite-element program has been executed. This option can then be used to produce a ratio of resistivity sections and a difference of PFE sections.

(6) FILE MAINTENANCE SAVE \& RECALL is selected when the user desires to save the work file on the merge file, to recall a copy of the work file from the merge file, to pack the merge file, or to initialize the work or merge file after their creation.

(7) LIST MODEL PARAMETER FILE is selected to list the model parameters, mesh code, or pseudosections.

(8) EXECUTE RES. IP FINITE ELEMENT is selected to solve for the calculated resistivity and PFE pseudosections using the finiteel ement program. 
(1) RETURN TO MASTER OPTIONS returns the user to the MASTER option selection point.

(2) INPUT NEW MODEL allows the user to input a new model into the work file.

(3) INPUT OBSERVED RES is selected to input an observed resistivity pseudosection that can later be used to produce a ratio pseudosection.

(4) INPUT OBSERVED PFE is analagous to the observed res. but allows the user to input an observed PFE pseudosection that can be used to produce a difference pseudosection.

\section{MESH Options}

The mesh option provides the user with the capability of selecting a default mesh geometry.

(1) LOW RESOLUTION MESH $43 \times 7$ is a mesh that is used for program debugging. Its resolution is generally too poor to be used for actual modeling applications.

(2) HIGH RESOLUTION MESH $77 \times 12$ is the standard mesh used at the Earth Science Laboratory for modeling areas with relatively flat topography.

(3) NEAR SURFACE RES. MESH $77 \times 14$ is a mesh that is used when there are a 
lot of fine near-surface resistivity structures.

\section{EDIT Options}

(1) RETURN TO MASTER OPTIONS returns the user to the MASTER option selection point.

(2) EDIT MESH CODE ELEMENTS is selected when the user desires to change some or all of the triangular elements within a specified rectangular element.

(3) EDIT MESH CODE ROWS is selected to change all or some of the triangular elements across an entire row of the mesh.

(4) EDIT ENTIRE MESH CODE allows the user to recode the mesh in the same manner as during initial input of a model. A portion of the mesh is selected for coding and the user is able to code the rectangular elements of the selected area. The remainder of the mesh is coded by the program by first extending the index number to the right and left boundaries and then by extending the rows to the top and bottom of the mesh.

(5) EDIT \# OF MEDIA CODES is used to change the number of distinct media that will be encountered in the mesh.

(6) EDIT MEDIA RES is selected to change the resistivities that are assigned to each element index number.

(7) EDIT MEDIA PFE is selected to change the PFE values that are 
assigned to each element index number.

(8) EDIT OBSERVED RES SEC. allows the user to correct any of the observed resistivities that have been entered in error.

(9) EDIT OBSERVED PFE SEC. allows the user to correct any of the observed PFE values that have been entered in error.

(10) EDIT MESH GEOMETRY allows the user to redefine the mesh geometry. Redefining the mesh geometry necessitates a recoding of the mesh el ements.

(11) EDIT TITLES allows the user to change the model and project titles that were input at the time of new model selection.

\section{TRI Options}

TRI options refer to the triangular elements within a rectangular element. The four options are elements at the top of the rectangle, at the left, right, and bottom. This option selection is used by the EDIT functions which allow the user to change the mesh coding of triangular elements.

(1) TOP allows the updating of the top element index.

(2) LEFT allows the updating of the left element index.

(3) BOTTOM allows the updating of the bottom element index.

(4) RIGHT allows the updating of the right element index.

(5) ALL updates all four triangular elements with one new index 
specification.

(6) ENTER allows the rectangular element to be entered into the parameter file after all the selected triangular elements have been updated.

EGEO Options

(1) RETURN TO EDIT OPTIONS returns the user to the EDIT option selection point.

(2) EDIT \# OF $X$ NODES allows the updating of the number of $x$-nodes in the mesh.

(3) EDIT \# OF $X$ ELEMENT GROUPS allows the updating of the number of $x$ element groups in the mesh.

(4) EDIT $X$ ELEMENT GROUP \#S allows the regrouping of $x$ elements.

(5) EDIT $X$ GROUP SPACINGS allows the changing of the spacing assigned to each $x$ element group.

(6) EDIT \# OF $Z$ NODES is analogous to option 2.

(7) EDIT \# OF Z ELEMENT GROUPS is analogous to option 3.

(8) EDIT $Z$ ELEMENT GROUP \#S is analogous to option 4.

(9) EDIT Z GROUP SPACINGS is analogous to option 5.

(10) EDIT ELECTRODE LOCATIONS allows the user to move the location of 
the electrodes by updating the $x$ and $z$ node location numbers.

\section{PLOT Options}

(1) RETURN TO MASTER returns the user to the MASTR selection point.

(2) TEK MESH PLOT allows the user to plot selected portions of the mesh on the Tektronix screen. The triangular elements are not plotted.

(3) TEK SECTION PLOT allows the user to plot selected portions of the model cross section on a Tektronix terminal.

(4) CALCOMP MESH PLOT allows the user to plot a scaled portion of the mesh on the Calcomp plotter. Both rectangular and triangular elements may be plotted.

(5) CALCOMP SECTION PLOT allows the user to plot a scaled portion of the resistivity structure on the Calcomp plotter.

(6) CALCOMP REPORT PAGE PLOT provides the capability to plot various collections of mesh geometry, resistivity sections, and pseudosections in an eight and one-half by eleven format.

(7) CALCOMP SCALED PAGE provides the capability to plot a mesh with cross section overlay and the resistivity and PFE pseudosections all to scale on a Calcomp plotter.

(8) CALCOMP SCALED PSEUDO S. allows the user to plot any of the four possible pseudosections on a Calcomp plotter to any scale. 


\section{PAGE Options}

The PAGE option selection allows the user to choose various formats and combinations of mesh plotting with pseudosections.

(1) RETURN TO PLOT OPTIONS returns the user to the PLOT option selection point.

(2) COMPUTED RES. ONLY produces a mesh with cross section overlay and the computed resistivity pseudosection only on a report page.

(3) COMPUTED \& OBSERVED RES. produces a mesh with cross section overlay and both the computed and observed resistivity pseudosections on a report page.

(4) COMPUTED RES. \& RATIO produces a mesh with cross section overlay and the computed PFE pseudosection only on a report page.

(6) COMPUTED \& OBSERVED PFE produces a mesh with cross section overlay with both the computed and observed PFE pseudosections on a report page.

(7) COMPUTED PFE \& DIF. produces a mesh with a cross section overlay and both a computed and differenced PFE pseudosection on a report page.

(8) COMPUTED RES. AND PFE produces a mesh with a cross section overlay and both a computed resistivity and P.FE pseudosection on a report page. 


\section{RADIF Options}

(1) RETURN MSTR returns the user to the MASTR option selection point.

(2) RES. RATIO causes the ratio section to be computed and printed.

(3) PFE DIFF causes the difference section to be calculated and printed.

\section{FMAIN Options}

(1) RETURN TO MASTER PROGRAM returns the user to the MASTR option selection point.

(2) LIST MERGED FILE DIRECTORY will produce a list of the subfile numbers and the titles associated with each copy of the work file that exists on the merge file.

(3) SAVE WORK FILE ON MERGED FILE allows the user to store a copy of the contents of the work file on the merge file. The copy is written in the next available subfile location and the subfile number is printed after the transfer is complete. The contents of the work file remain unchanged under this operation.

(4) RESTORE WORK FILE FROM MERGED FILE allows the user to recall a stored subfile from the merge file by specifying the subfile number and to overwrite the contents of the work file.

(5) DELETE AND PACK MERGED FILE allows the user to designate certain subfiles for deletion. The merged file is then packed by moving all subfiles with higher numbers than those that have been flagged for 
deletion into the positions of the deleted subfiles. A password is required to access this option.

(6) INITIALIZE WORK FILE is an option used after creating the work file and consists of writing into each of the records in the file and also of initializing the observed resistivity records with floating point ones and initializing the observed PFE records with floating point zeros.

(7) INITIALIZE MERGE FILE is an option used after creating the merge file and consists of specifying the record and file lengths and total allowed subfiles, setting the number of subfiles written to zero, and setting an alphanumeric descriptive array. This information is then written into the first record of the merge file.

\section{LIST Options}

(1) RETURN TO MASTER OPTIONS returns the user to the MASTR option selection point.

(2) LIST TITLES causes the project name and the model name to be printed on the terminal.

(3) LIST GEOMETRY PARAMETERS causes the mesh geometry parameters to be printed on the terminal.

(4) LIST MEDIA CHARACTER. causes the media resistivities and PFE values to be printed on the terminal. 
(5) LIST MESH CODE TRI. ELE. causes the mesh index numbers to be printed out for each triangular element in the mesh. The code numbers are printed in blocks of four lines each. The top line of each block corresponds to the top triangular elements in the row, the second line corresponds to the left triangular elements in the row, the third line as the bottom elements, and the fourth line as the right elements.

(6) LIST MESH CODE REC. ELE. causes a list of the rectangular element codes to be printed on the terminal. Rectangular elements that have triangular elements of different codes are flagged with an asterisk in the listing.

(7) LIST PSEUDOSECTIONS causes the user to be transferred to a pseudosection selection point. The user may use this option to obtain listings of the observed or calculated pseudosections that have been stored in the work file.

(8) LIST FILE CONTENTS causes a listing of all the data in the work file to be printed on the terminal. The rectangular element format is used for the mesh code printing and the calculated pseudosections are the only ones printed.

(9) SEND FILE CONTENTS TO PR will cause the contents of the work file to be sent to the on-site line printers at the UUCC.

SECT Options 
(1) RETURN TO LIST OPT returns the user to the LIST option selection point.

(2) CALCULTED RES causes the calculated resistivity pseudosection to be printed on the terminal.

(3) CALCULATED PFE causes the calculated PFE pseudosection to be printed on the terminal.

(4) OBSERVED PFE causes the observed PFE pseudosection to be printed on the terminal.

\section{Interactive Modeling Examples}

Two modeling examples have been prepared in this report. The first is a simple modeling exercise that is a terminal listing of the user-computer conversation that was generated during a modeling session. The second is a terminal listing of the user-computer conversation that was generated during the setup and execution of a more complex topographic model. The two modeling examples are contained in appendix $D$. 


\section{SYSTEM IMPLEMENTATION}

It may be desirable to implement the interactive modeling system on computers that are not strictly compatible with the UNIVAC 1108 system at the University of Utah. The first problem that may be encountered is that of fitting the system into a minicomputer. The system is fairly modular at present and the MASTER program could be broken down even further. Most minicomputer systems have mechanisms for passing program control from one program to another as is required for the operation of this system. The finite-element program can be made smaller by reducing the number of $x$ and $z$ nodes in the dimension parameters called IP1 and IP4. There is a limit as to how much these parameters may be reduced, beyond which it is not possible to obtain the required resolution for the modeling process.

The interactive modeling system requires the capability of passing program control from one program to another after certain option selections are made. This function is provided by the subroutine CONTRL in the UNIVAC 1108 program library at the University of Utah Computer Center. There are equivalent subroutines in most minicomputer libraries. For example the subroutine CALL RUN in DEC (Digital Equipment Corporation) systems accomplishes the same thing. Computers that have virtual memory capability would allow the user to consolidate the system into a single large program rather than implementing a passage of control. In any case the implementation of the interactive modeling system on any other computer system will probably require the modification of program control functions. The programs and subroutines where CONTRL is used are BATIN, BATOT, FINELE, FINELE-LARGE, 
FMAIN, MASTER, SIZTST, TERMS, and MLIST.

The interactive system makes use of random access files which may or may not be available on other computers. The DEFINE FILE statement and the READ and WRITE statements may have to be modified to conform to the particular random access file capabilities of the system that the program is to be implemented on. The DEFINE FILE statement is used in the following programs and subroutines: BATIN, BATOT, FINELE, FINELE-LARGE, FMAIN, MASTER, SIZTST, and TERMS. The random access read and write statements are encountered in the following programs and subroutines: BATIN, BATOT, FINELE, FINELE-LARGE, FMAIN, SIZTST, TERMS, CODEX, DEFALT, DEPACK, EDIT, EMGEO, EMPFE, EMRES, ENMC, EPFE, ERES, INGEOM, INMED, INPFE, INPUT, INRES, INTM, MPRT, RCODE, RDB1, RE, and RWP.

The interactive system also makes use of some functions and statements that are not FORTRAN IV standard. The program uses the PARAMETER statement to set dimension limits. The PARAMETER statement can be removed but the dimensions must be replaced with actual numbers. The programs or subroutines that use the PARAMETER statement are FINELE, FINELE-LARGE, GAUSS1, and GAUSS1-LARGE.

The DECODE and ENCODE statements are also used and are not FORTRAN IV standard but are found on many extended FORTRANS. A computer system that lacks the ENCODE and DECODE statements presents a more difficult problem. The statements could be replaced with calls to other subroutines, but it would require some system programing to implement the proper functions. The DECODE and ENCODE statements are used in FINELE, FINELE-LARGE, CODEX, MPRT, RADIF, 
and OPTION.

Another extended FORTRAN function that is used is the $\$$ control passage from subroutine. For example consider the following code:

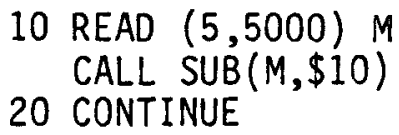

If a RETURN 2 is used to return to the calling program from SUB, control is passed to statement 10 rather than to statement 20 . If a RETURN is used to return the calling program, the control would continue on to statement 20 . The \$ control subroutine passage is used to print error messages and to allow the re-input of some parameter that is in error. There are other ways to program the same function. Computers that do not have the capability metioned above would require the modification of code in the following subroutines in the interactive modeling system: ECODE, EMES, EMES1, EMGEO, ENMC, INCODE, INGEOM, INMED, RCODE, SETMA, and SETSCL.

A problem that the user might encounter in implementing the interactive system on another computer is that of incompatible alphanumeric data storage. The UNIVAC 1108 uses an internal six-bit field data code for the storage of alphanumeric data. The word length of the 1108 is 36 bits, so six field data characters may be stored in each word. The program has data statements where character strings are multiples of six characters long and the dimension of the string array may not be large enough if a different alphanumeric code is used. The programs and subroutines that have alphanumeric strings in data statements are FMAIN, MASTER, TERMS, CRPLT, DEFALT, ECODE, EDIT, EMGEO, INPUT, MLIST, MPLOT, PSESCL, RCODE, RDSEC, and OPTION. There are also places in the 
model ing system where the $A 6$ formats should be replaced with an $A 4$ or an $A 8$, depending on the system on which the modeling programs are to be implemented. The programs and subroutines where A6 format is used are FINELE, FINELE-LARGE, FMAIN, INPUT, and MPRT.

The only other problems of implementation that the user may encounter are those of non-compatible Tektronix or Calcomp plotter software packages. Most Tektronix packages are compatible with the Plot 10 package used on the 1108 . It is possible that a Tektronix package would not be available on other systems. The modeling system will operate without the Tektronix capability, but mesh plotting and cross section plotting would be possible only on a pen plotter. Most systems have pen-plotting software but there is some variation in the form of the subroutine calls. Most of the deviations can be overcome with a minimum of programming since most plot packages provide the basic plotting functions that the modeling system requires even if the details are different. 
Appendix A

Calcomp Plotter Routines used

by IP2D System 
FINI must be the last plot subroutine called by a plot program. It writes the final buffer onto the plot tape and writes a calcomp end-of-file mark and a UNIVAC 1108 hardware tape mark on the plot tape. Its call statement looks like this:

\section{CALL FINI}

Several plots may be generated by one program simply by making several calls to IDPLOT and FINI. The user should be warned, however, that all plots must begin with a call to IDPLOT and end with a call to FINI. A call to FINI before a call to IDPLOT will result in error termination as will a second call to IDPLOT without an intervening call to FINI.

IDPLOT

IDPLOT must be the first plot subroutine called. It sets up the desired page size and initializes some of the other plot subroutines. It is called by the statement

CALL IDPLOT (XM, YM)

where $X M$ is the desired $X$ dimension and $Y M$ is the desired $Y$ dimension in inches of the plot page. The origin $(0,0)$ of all plots is assumed to be the lower left-hand corner. IDPLOT draws identification information on the side of the plot. If $X M$ or $Y M$ is not valid, the following error message is printed and the program terminated:

PLOTTING SIZE SPECIFIED AS $\mathrm{nn} . \mathrm{nn} \times \mathrm{mm} . \mathrm{mm}$ IS EITHER TOO LARGE OR TOO SMALL--MAX SIZE IS $100.0 \times 33.0--$ MIN SIZE $4.0 \times 1.0$.

NUMBER, NUMBRF, and NUMBRE

NUMBRF, NUMBRE, and NUMBRI are all entry points in a subroutine used to draw numbers in various formats to label points, display input parameters, etc.

CALL NUMBER ( $X, Y$, HEIGHT, FPNUM, ANGLE, NDIG)

CALL NUMBRF ( $X, Y$, HEIGHT, FPNUM, ANGLE, NDIG)

CALL NUMBRI $(X, Y, H E I G H T$, INTGR, ANGLE)

where $X, Y$, HEIGHT, and ANGLE have the same meaning as described for subroutine SYMBOL, and

FPNUM ( $f$ ) is the floating point number to be drawn by the routine called.

NDIG (i) is the number of digits to the right of the decimal point in the number. If NDIG $=-1$, no decimal point will be drawn. NDIG has a range of -1 to 9 . If the range of NDIG is exceeded, NDIG will be set to 5 .

Subroutine NUMBRF draws the floating point argument aligned on the decimal point in a field of ten character positions, formatted as if the FORTRAN "F" format editing code were used.

Subroutine NUBMRE draws the floating point argument with an exponent and 
a mantissa in a field of ten character positions, as though the FORTRAN "E" format editing code were used.

When using the entry point NUMBRE, NDIG has a range of 1 to 9 inclusive. PENSEL

PENSEL allows the selection of pens during a plot. Three pens are allowed in the turret and may be selected before the plot is done.

CALL PENSEL (PEN)

where:

\begin{tabular}{ll}
\multicolumn{1}{c}{ Description } & Type \\
PEN & is the number of the pen in \\
& the turret $(1,2$, or 3$)$.
\end{tabular}

PLOT

The PLOT subroutine is used to move the pen in a straight line to a new position, with the pen either up or down during the movement. Optionally, a new origin may be established at this new point.

$$
\text { CALL PLOT (X, Y, IPEN) }
$$

where:
$X \quad(f)$ is the desired $X$ coordinate in inches, relative to the last established origin (lower left corner of the plot window, initially),
Y (f) is the desired $Y$ coordinate in inches, relative to the last established origin.

IPEN

(i) is the pen position command, defined as follows: IPEN $=1$ causes no change in the vertical pen position from the previous call to PLOT; IPEN = 2 causes the pen to be lowered onto the paper before moving; and IPEN $=3$ causes the pen to be raised off of the paper before moving to $(X, Y)$. If IPEN is negative, the absolute value is used, and the logical origin is reset to the destination $(X, Y)$.

The plot package checks to make sure that the destination of each plot call lies within the window defined by IDPLOT. If this window is violated, the line leaving the window is truncated at the edge of the window, and the position of the pen is "remembered". by the package until the pen again moves within the window, and that movement is picked up at the point where it crosses back into the window. This feature can be used to great effect to create plots which are physically larger than the plotter can handle. One simply sets the window to a convenient size, positions the origin to the proper place to leave only a part of the total plot visible in the window, and generates the entire plot. By appropriate positioning of the origin, ali pieces of the total plot can be generated, and then the pieces cut-and-pasted to construct the complete plot. 
SYMBOL

The SYMBOL subroutine produces plot annotation at any angle and in practically any size. There are two symbol call formats: 1) the "standard" call, which can be used to draw text such as titles, captions, and legends; and 2) the "special" call, which is used to draw special centered symbols such as a box, octagon, triangle, etc., for plotting data points.

$$
\begin{aligned}
& \text { For the "standard" call: } \\
& \text { CALL SYMBOL (X,Y, HEIGHT, IBCD, ANGLE, +NCHAR) }
\end{aligned}
$$

where:

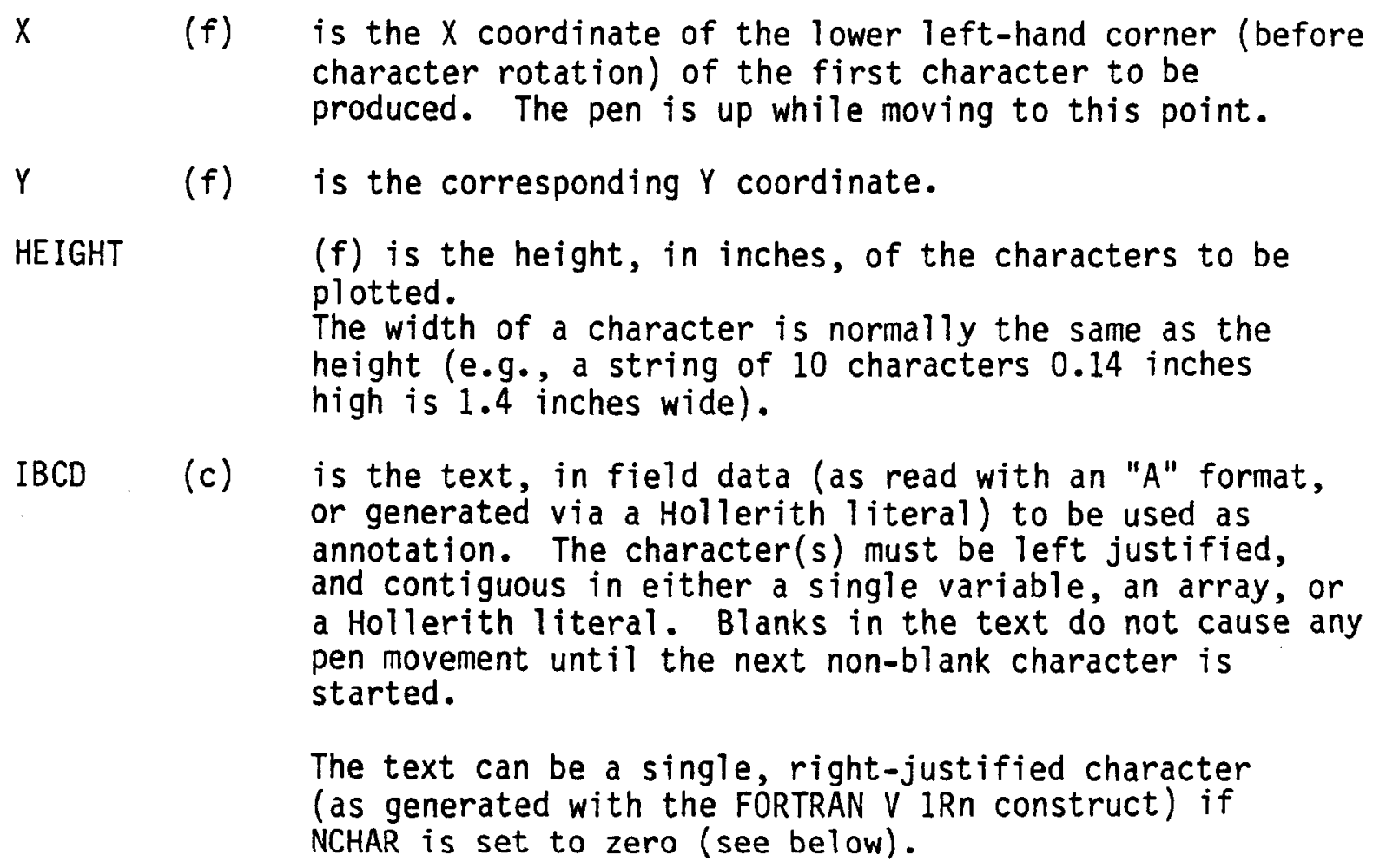

ANGLE (f) is the angle, in degrees from the positive $X$-axis, at which the annotation is to be plotted. If $A N G L E=0.0$, the characters will be plotted right side up and parallel to the $X$-axis.

+ NCHAR (i) is the number of characters to be plotted from IBCD. If $N C H A R=0$, the data must be left-justified in the first element of IBCD; If NCHAR $=0$, one alphanumeric character is produced, using a single character which is right-justified in the first element of IBCD (as generated by the FORTRAN $V$ IRn construct).

For the "special" call:

CALL SYMBOL ( $X, Y$, HEIGHT, INTEQ, ANGLE, -ICODE)

where $X, Y$, and ANGLE have the same meanings as in the "standard" call. If the symbol to be plotted is one of the centered symbols (e.g., INTEQ is less than 16), $X$ and $Y$ represent the geometric center of the character produced. In addition: 
HEIGHT ( $f$ ) is the height (and width), in inches, of the centered symbol to be drawn.

INTEQ (i) is the integer equivalent of the desired symbol. If INTEQ is 0 through 15 , a centered symbol is produced.

-ICODE (i) is negative and determines whether the pen is up or down during the move to $(X, Y)$. If ICODE $=-1$, the pen is up during the move, after which a single symbol is produced. If ICODE $<-1$, the pen is down during the move, after which a single symbol is produced.

Annotation may be continued from the position following that at which the last annotation ended by setting $X$ and/or $Y$ to 999.0. This feature may be applied to $X$ or $Y$ independently.

Caution should be used when plotting symbols near the edge of the window defined by IDPLOT, since any character which lies wholly or partially outside that window is not drawn at all. This is because the symbols are generated by the plotter itself, and it is not able to draw only part of a character. 
Appendix B

Tektronix Subroutines used

by IP2D System 


\section{Subroutine ANMODE}

At times the user may wish to output $A / N$ data other than through the Terminal Control system. In such cases it is the user's responsibility to insure that the Terminal is in $A / N$ mode. This can be done by using ANMODE. It is not necessary to call ANMODE when using the Terminal Control system routines as they will automatically call it whenever necessary.

CALLING SEQUENCE:

\section{CALL ANMODE}

Subroutines MOVEA and DRAWA

MOVEA, and DRAWA, are analogous to MOVABS and DRAWABS but they allow points outside the virtual window to be referenced. Only those points or portions of bright vectors (line segments) which fall within the window boundaries, however, will be displayed; this is known as "clipping."

CALLING SEQUENCE:

CALL MOVEA $(X, Y)$

CALL DRAWA $(X, Y)$

Parameters Entered:

$X$ - the horizontal virtual (real) coordinate to which a bright dark vector is drawn or at which a point is displayed.

$Y$ - the vertical virtual (real) coordinate to which a bright or dark vector is drawn or at which a point is displayed.

Subrout ine ERASE

The Terminal screen may be erased without changing the mode or beam position. The Terminal Control System will prevent generation of additional output until the erase is completed.

CALLING SEQUENCE:

CALL ERASE 
When terminating a program which uses the Terminal Control System, it may be desirable to return the Terminal to alphanumeric mode and move the cursor the small floating square which indicates the position where writing will occur to a point that will not interfere with any previous output. All output to the terminal is buffered, or stored, until the user calls a routine that dumps the buffer, or until the buffer is full.

FINITT automatically performs these functions. It terminates the program and outputs the contents of the buffer. Its arguments designate the position of the alphanumeric cursor upon program termination. FINITT should be used, depending on the computer system, either in conjunction with or in place of a FORTRAN STOP statement.

CALLING SEQUENCE:

$$
\text { CALL FINITT (IX, IY) }
$$

Parameters Entered:

IX - the screen $x$-coordinate of the position to which the beam is moved before program termination.

IY - the screen $y$-coordinate of the beam termination position.

Subroutine HOME

Moves the alphanumeric cursor to the upper left corner of the screen.

CALL HOME

\section{Subroutine INITT}

Initialization of the Terminal and the Terminal Status Area must be accomplished as the first step in the use of Terminal Control System routines. This may be done by calling the initializing routine INITT. When INITT is called, the following events occur:

(a) The screen is erased and the cursor moves to the HOME position in the upper left hand corner of the screen.

(b) The Terminal is set to alphanumeric mode.

(c) The margin values are set to the left and right screen extremes.

(d) The window is defined so that the portion of the virtual space will be displayed which is equivalent in coordinates with the screen

in (i.e., $(275,763)$ in user coordinates is equivalent to $(275,763)$

screen coordinates).

INITT requires the rate of character transmission from the computer to the Terminal as an input parameter in order that appropriate delays may be produced during screen erasure and hardcopy generation. This will prevent loss of data on remotely connected Terminals while they are not ready.

CALLING SEQUENCE: 


\section{CALL INITT (IBAUD)}

Parameter Entered:

IBAUD - the transmission (baud) rate in characters per second.

Subroutine MOVABS

The argument of MOVABS is the pair of coordinates of the point to which a move is desired. Outcrop starts at the stored current beam position. This position is updated after every line draw or other output command. In addition, all drawings are buffered.

CALLING SEQUENCE:

CALL MOVABS (IX, IY)

Example:

CALL MOVABS $(100,150)$

This call generates a move to $(100,150)$ so that drawing can proceed there.

Subroutine SWINDO

CALLING SEQUENCE:

CALL SWINDO (MINX, LENX, MINY, LENY)

Parameters Entered:

MINX - the minimum horizontal screen coordinate.

LENX - the horizontal extent of the rectangle.

MINY - the minimum vertical screen coordinate.

LENY - the vertical extent of the rectangle.

Subroutine TOUTPT

TOUTPT outputs a single ADE* character. This routine does not update the graphic beam position within the Terminal Control System nor does it put the Terminal into alphanumeric mode. TOUTPT should be used only when outputting a control character which is not otherwise handled by the Terminal Control System.

CALLING SEQUENCE:

CALL TOUTPT (ICHAR)

Parameter Entered:

ICHAR an ADE* character to be output. 
It is often useful to be able to retieve virtual rather than screen coordinates with the graphic cursor. The routine VCURSR allows the user to enable the graphic cursor. After the cursor has been positioned, its screen coordinates may be transmitted to the computer by striking a keyboard character. VCURSR transforms the input data into virtual coordinates according to the current window definition. The virtual cursor does not affect the beam position.

The tranformation which VCURSR affects assumes that all of the screen is a continuation of virtual space with the scale implied by the current window.

CALLING SEQUENCE:

CALL VCURSR (ICHAR, $X, Y$, )

Parameters Returned:

ICHAR - a keyboard character, 7-bit ASCII, right-adjusted.

$x$ - the virtual $x$-coordinate of the graphic cursor.

$Y \quad$ - the virtual $y$-coordiate of the graphic cursor.

The following example of VCUSRS allows the user the capability of interactive line drawing. When a character is struck, a line segment is drawn or a move is made from the current beam position to the coordinates specified by the graphic cursor.

\section{Subroutine VWINDO}

The Terminal Control System uses one of two subroutines to define the virtual window. The first is VWINDO.

CALLING SEQUENCE:

CALL VWINDO (XMIN, XRANGE, YMIN, YRANGE)

Parameters Entered:

XMIN - the minimum horizontal user coordinate.

XRANGE - the horizontal extent of the rectangle.

YMIN - the minimum vertical user coordinate.

YRANGE - the vertical extent of the rectangle. 
APPENDIX C

Finite-Element Theory 
The General Maxwell Equations and Boundary Conditions

In the frequency domain ( $e^{i \omega t}$ time dependence) Maxwell's equations are:

$$
\begin{aligned}
\nabla X \vec{E} & =-\hat{z} \vec{H}, \\
\nabla X \vec{H} & =\hat{y} \vec{E}+\vec{J}, \\
\nabla \cdot \vec{B} & =0,
\end{aligned}
$$

and

$$
\nabla \cdot \vec{D}=q,
$$

where the terms are explained in the mathematical notation table, $\mathrm{C}-1$.

A boundary condition is associated with each Maxwell's equation. They are as follows:

$$
\begin{aligned}
& \vec{n} \times\left(\vec{E}_{1}-\vec{E}_{2}\right)=0 \text {, or tangential } \vec{E} \text { is continuous, } \\
& \vec{n} \times\left(\vec{H}_{1}-\vec{H}_{2}\right)=\vec{J}_{s} \text {, or there is a discontinuity } \\
& \text { in the tangential } \vec{H}, \\
& \vec{n} \cdot\left(\vec{B}_{1}-\vec{B}_{2}\right)=0 \text {, or normal } \vec{B} \text { is continuous, }
\end{aligned}
$$

and

$$
\vec{n} \cdot\left(\vec{D}_{1}-\vec{D}_{2}\right)=q_{s} \text {, or there is a discontinuity }
$$

The term $\vec{n}$ is the surface normal to the boundary between two different media, and $\vec{j}_{s}$ and $q_{s}$ are surface current density and surface charge density, respectively. 
The MKS system, $e^{i \omega t}$ time dependence, and the following notations are used in appendix $C$.

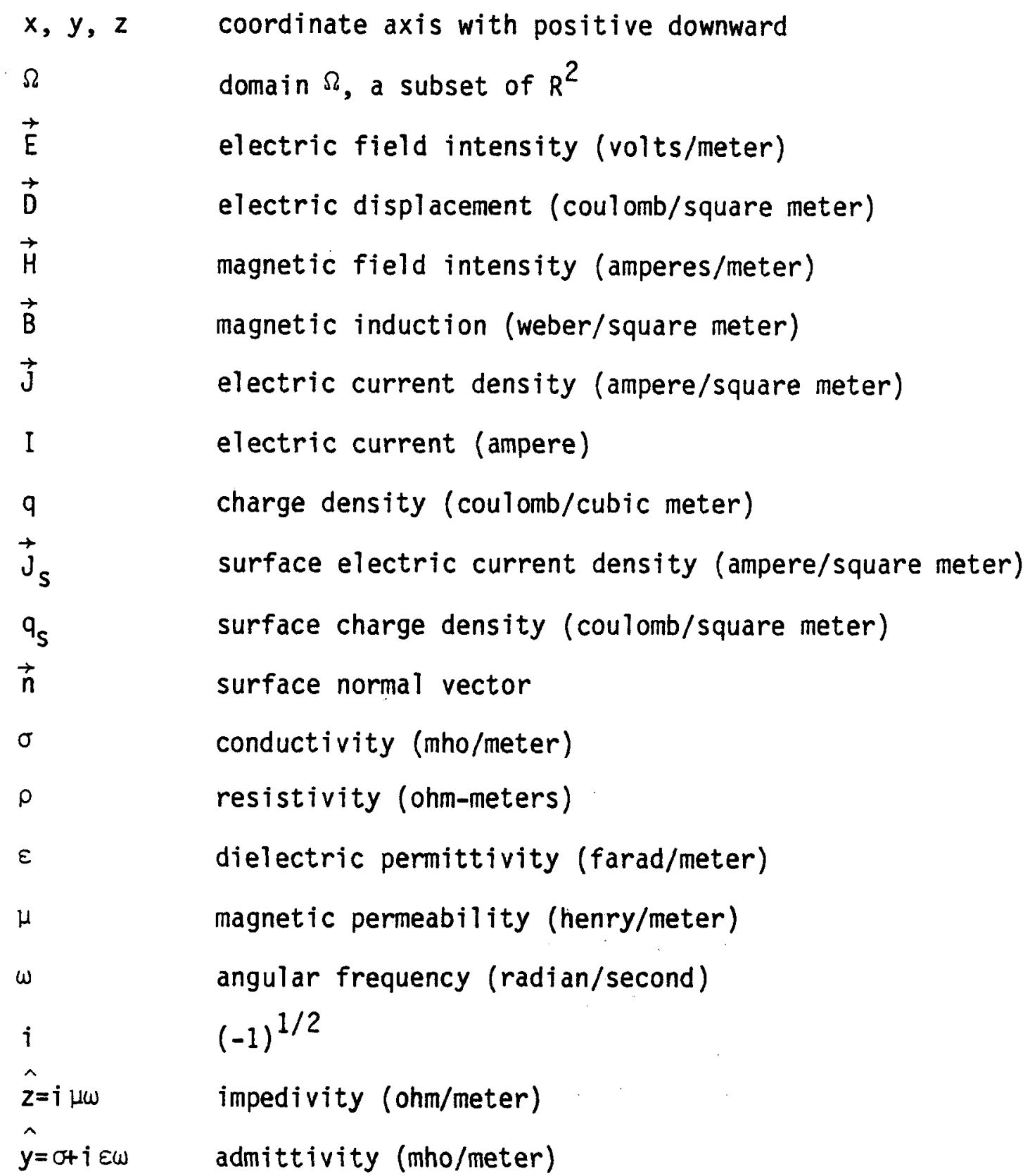


(Table C-1 cont.)

$\begin{array}{ll}\delta(x) & \text { Dirac delta function (1/meter) } \\ f & \text { field or potential function } \\ s & \text { arbitrary source function } \\ (e) & \text { "element" } \\ \partial e & \text { boundary of the element (e) } \\ f^{(e)}(x, z) & \text { finite element approximation of } f \\ f_{n}(e) & \text { nodal values of } f(e){ }^{(x, z)} \\ N_{i}(e) & \text { shape function or basis function } \\ f^{\top}(e) & \text { the vector }\left[f^{i}(e)^{j}(e) f^{k}(e)\right]\end{array}$

$\boldsymbol{N}_{(\mathrm{e})}$

the vector $\left[N_{j}(e) N_{j}(e) N_{k}(e)\right]$

G the global finite element matrix

$f$ vector containing the value of the approximating function at the nodes of the finite element mesh source vector containing all source information 
The boundary conditions take the same form as Maxwell's equations with the curl operator replaced by $\vec{n}, \hat{z}$ and $\hat{y}$ by zero, the fields by their differences across the boundary, and $\vec{j}$ and $q$ by surface current and charge density, respectively:

\section{Coupling-free Induced Polarization and Resistivity}

Although the mathematical formulation for the coupling-free induced polarization and resistivity problems can be derived directly from equations (1) through (4), a different process will be used because of the inherently static nature of the problem. (inductive coupling is ignored in order to make the problem tractable).

Start with the continuity equation

$$
\nabla \cdot \vec{j}=\frac{\partial \rho}{\partial t}=I \delta(x) \delta(y) \delta(z),
$$

for a localized current source I $\delta(x) \delta(y) \delta(z)$ and 0 hm's law,

$$
\vec{j}=\sigma \vec{E} \text {. }
$$

Substituting (10) into (9) results in

$$
\nabla \cdot(\sigma \vec{E})=I \delta(x) \delta(y) \delta(z) \text {. }
$$

For time-independent phenomena, the first Maxwell equation (1) implies the relation

$$
E=-\nabla \phi
$$

where $\phi$ is a scalar potential.

Equation (11) then may be written,

$$
\nabla \cdot(\sigma \nabla \phi)=-I \delta(x) \delta(y) \delta(z) \text {. }
$$

Assuming again a two-dimensional earth model with the $y$-axis parallel to 
strike, a one-dimensional Fourier transform defined by

$$
\hat{\phi}(x, \lambda, z)=\int_{-\infty}^{\infty} \hat{\phi}(x, y, z) e^{-i \lambda y} d y,
$$

and

$$
\phi(x, y, z)=\frac{1}{2 \pi} \int_{-\infty}^{\infty} \hat{\phi}(x, \lambda, z) e^{i \lambda y} d \lambda,
$$

is applied giving

$$
\hat{\nabla} \cdot(\sigma \nabla \hat{\phi})=-\hat{I} \delta(x) \delta(z),
$$

where $\hat{\phi}(x, \lambda, z), \hat{I}(x, \lambda, z)$ and $\hat{\nabla}$ are the Fourier transforms of $\phi(x, y, z)$, $I(x, y, z)$, and $\nabla$ respectively.

Transforming out the $y$ dependence allows a three-dimensional problem solution by using the simple two-dimensional model. The problem must be solved for many different $\lambda$ values in order to recover $\phi(x, y, z)$ from $\phi(x, \lambda, z)$ by means of the inverse Fourier transfer, (15).

Equation (16) can be written as

$$
\frac{\partial}{\partial x}\left(\frac{1}{\rho} \frac{\partial \hat{\phi}}{\partial x}\right)+\frac{\partial}{\partial z}\left(\frac{1}{\rho} \frac{\partial \hat{\phi}}{\partial z}\right)-\frac{\lambda^{2}}{\rho} \hat{\phi}=-I \delta(x) \delta(z),
$$

in which $\rho=\sigma^{-1}$ is the resistivity.

Equation (17) has the following form:

$$
\frac{\partial}{\partial x}\left(\frac{1}{k} \frac{\partial f}{\partial x}\right)+\frac{\partial}{\partial y}\left(\frac{1}{k} \frac{\partial f}{\partial y}\right)+p f=s,
$$

which is the well known two-dimensional Helmholtz equation (Zienkiewicz, 1971). 
The finite-element theory of the Helmholtz equation is well documented in the literature. In particular, Zienkiewicz (1971) gives a detailed description of the finite element technique as a whole.

For completeness, a brief description of the technique is given here.

The finite-element formulation is constructed as follows:

a) The region is divided into a finite number of subdomains selected here as triangular elements. These elements are connected at common nodal points and collectively approximate the shape of the region.

b) The continuous unknown function $f$ is approximated over each element by polynomials, selected here as linear polynomials, that are defined using the nodal values of the continuous function $f$. The value of a continuous function $f$ at each nodal point is denoted as a variable which is to be determined.

c) The equations for behavior of fields or potentials over each element are derived from the Helmholtz equation using the linear polynomials defined as above and the Galerkin criterion.

d) The regions of applicability of Newmann and Dirichlet boundary conditions are established.

e) The element equations are converted to the element matrix equations.

f) The matrix element equations are assembled to form the global matrix equation. Also, the source vector is assembled.

g) The Dirichlet boundary condition is introduced.

h) The system of linear equations is solved. 
The first six of these steps will be discussed now and the remaining two will be discussed in later sections.

\section{Subdomains}

One important aspect of the finite element method is the design of the discretized model, i.e., the construction of a finite element mesh. The first step in the construction of the mesh is to decide the extent, or the domain $\Omega$, of the finite model chosen to represent the actual given infinite continuous region. The objective is to select a region large enough so that the calculated values along the external boundary agree with those existing in the actual continuous problem. These values along the boundary represent the Dirichlet boundary conditions for the finite discretized model.

The ease of varying the element size is an important aspect of the finite element method; because near discontinuities of the media it is always necessary to have a fine texture in the mesh.

\section{Function Description over Subdomains}

Select an arbitrary triangular element (e) of the finite domain $\Omega$ with nodes at the vertices of the triangles as in Figure $\mathrm{C}-1$. With this type of domain discretization $f$ can be allowed to vary linearly over each element.

The plane passing through the three nodal values of $f$ associated with element (e) is described by the equation

$$
f^{(e)}(x, z)=\alpha_{1}^{(e)}+\alpha_{2}^{(e)} x+\alpha_{3}^{(e)} z \text {. }
$$

Therefore at the three nodes the values of $f$ are 


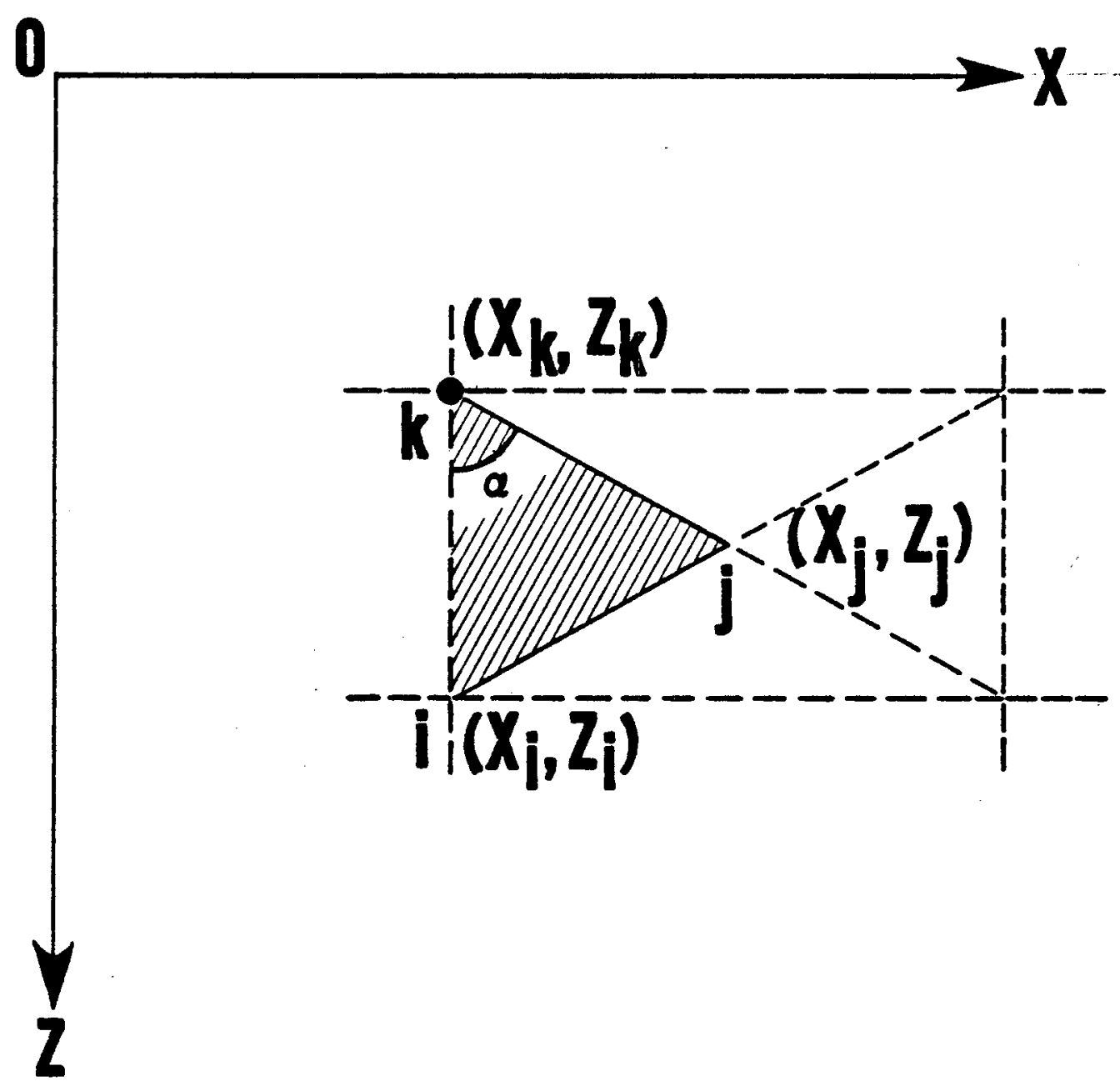

Figure $\mathrm{C}-1$ An arbitrary element. The dot represents an impressed source located at node $k$. 


$$
\begin{aligned}
& f_{i}{ }^{(e)}=\alpha_{1}{ }^{(e)}+\alpha_{2}{ }^{(e)} x_{i}+\alpha_{3}{ }^{(e)} z_{i}, \\
& f_{j}{ }^{(e)}=\alpha_{1}{ }^{(e)}+\alpha_{2}{ }^{(e)} x_{j}+\alpha_{3}{ }^{(e)} z_{j},
\end{aligned}
$$

and

$$
f_{k}(e)=\alpha_{1}^{(e)}+\alpha_{2}(e) x_{k}+\alpha_{3}^{(e)} z_{k} \text {. }
$$

We solve equations (20) through (22) for $\alpha_{1}^{(e)}, \alpha_{2}{ }^{(e)}$, and $\alpha_{3}^{(e)}$ and insert these values in (19) to obtain

$$
f^{(e)}=N_{i}(e)_{f}(e)+N_{j}(e)_{f}(e)+N_{k}(e)_{f_{k}}(e) \text {, }
$$

in which

$$
N_{i}(e)=\frac{1}{2 \Delta}\left(a_{i}+b_{i} x+c_{i} z\right)
$$

where

$$
\begin{aligned}
& a_{i}=x_{j} z_{k}-x_{k} z_{j}, \\
& b_{i}=z_{j}-z_{k}, \\
& c_{i}=x_{k}-x_{j},
\end{aligned}
$$

and $\Delta$ is the area of the triangular element (e).

Likewise the terms $N_{j}(e)$ and $N_{k}(e)$ are obtained through a cyclic permutation of the subscripts $i, j$ and $k$. The functions $N_{n}$ are called shape funcitons, interpolation functions, or basis functions.

Equation (23) can be described by the matrix expression

$$
f^{(e)}=\mathbf{N}_{(e)} \mathbf{f}_{(e)}^{\top}
$$


in which

$$
N_{(e)}=\left[N_{i}(e) N_{j}(e) N_{k}(e)\right]
$$

and

$$
f_{(e)}^{T}=\left[f_{i}(e) f_{j}(e) f_{k}(e)\right]
$$

If the domain $\Omega$ contains $M$ triangular elements, the complete representation of the unknown function $f$ over the whole domain is given by

$$
f(x, z) \cong \sum_{e=1}^{M} f^{(e)}(x, z)=\sum_{e=1}^{M} N_{(e)} f^{\top}(e)
$$

Now that the function $f$ is defined over the whole domain the element equations will be derived.

The Element Equations

Equation (18) may be written in a concise form as follows:

$$
\text { Lf }=s \text {, }
$$

in which

$$
L+\frac{\partial}{\partial x}\left(\frac{1}{k} \frac{\partial}{\partial x}\right)+\frac{\partial}{\partial y}\left(\frac{1}{k} \frac{\partial}{\partial y}\right)+p
$$

Inserting the approximate value of $f(x, z)$ given by (31) into (32), results in

$$
L\left(\sum \mathbf{N}_{(e)} \mathbf{f}_{(e)}^{\top}\right)-s=\varepsilon \text {, }
$$

in which, $\varepsilon$ is a residual or error because the solution is only approximate. It is desirable to make $\varepsilon$ as small as possible. One way to accomplish this objective is to invoke the inner product

$$
\left\langle N_{j}(e), \varepsilon>=\iint_{(e)} N_{n}(e)_{\varepsilon d x d z=0}\right.
$$

for each of the basis functions $N_{n}(e)$. This integral mathematically states 
that the basis functions must be orthogonal to the error over the element (e). This method is known as the Galerkin method.

Using (31), (32), (33) and (34), equation (35) can be expressed as

$$
\iint_{(e)} N_{n}(e)\left[\frac{\partial}{\partial x}\left(\frac{1}{k} \frac{\partial f}{\partial x}^{(e)}\right]+\frac{\partial}{\partial z}\left(\frac{1}{k} \frac{\partial f}{\partial z}^{(e)}\right)+p f^{(e)}-s d x d z=0\right. \text {, }
$$

in which, (e) is the triangular region, and $n=i, j$, and $k$.

Since the interpolation function $f^{(e)}(x, z)$ is linear, the second derivatives in (36) present a serious obstacle. This restriction can be avoided by reducing the order of the derivatives in (36) by using integration by parts.

Focusing attention on the first term of (36), integration by parts yields

$$
\begin{aligned}
\iint_{(e)} N_{n}(e) \frac{\partial}{\partial x}\left(\frac{1}{k} \frac{\partial f}{\partial x}^{(e)}\right) d x d z= & -\iint \frac{1}{k} \frac{\partial f}{\partial x}^{(e)}{\frac{\partial N_{n}}{\partial x}}^{(e)} d x d z+ \\
& \oint_{(\partial e)} \frac{1}{k} \frac{\partial f}{\partial x}^{(e)} n_{x} N_{n}^{(e)} d l,
\end{aligned}
$$

in which $n_{x}$ is the $x$-component of the unit normal to the boundary, dl is a differential arc length along the boundary, (дe), of the triangular element $(e)$. When the second term in $(36)$ is treated in the same manner, the equation (36) takes the form

$$
\begin{aligned}
& \iint_{(e)}\left[-\frac{1}{k}\left(\frac{\partial f}{\partial x}(e) \frac{\partial N_{n}(e)}{\partial x}-\frac{\partial f}{\partial z} \cdot \frac{\partial N_{n}}{\partial z}\right)+N_{n}(p f(e)-s)\right] d x d z+ \\
& \oint_{(\partial e)} \frac{1}{k} \frac{\partial f}{\partial n}(e) N_{n}(e) d 1=0,
\end{aligned}
$$

in which

$$
\frac{\partial f}{\partial n}^{(e)}=\frac{\partial f}{\partial x}^{(e)} n_{x}+\frac{\partial f}{\partial z}^{(e)} n_{z} \text {. }
$$


The Boundary Condition

For the boundary of internal elements the surface integral in (38) need not be evaluated because each boundary is traversed twice in opposite directions during integrations. For the elements at external boundaries of the domain $\Omega$, the surface integral in (38) is either zero for a Neumann boundary condition or need not be evaluated for a Dirichlet boundary condition. A Neumann boundary condition of $\frac{\partial \hat{\phi}}{\partial n}=0$ at the air-earth interface and a Dirichlet boundary condition of $\hat{\phi}=0$ at the side and bottom boundaries are applied in the IP-resistivity problem. The bottom and side boundaries are kept far from any inhomogeneity.

\section{The Element Matrix Equation}

The surface integral in (38) is now disposed of via carefully selected boundary conditions. Substituting (28) into (48) gives

$$
\begin{gathered}
\iint_{(e)}-\frac{1}{k}\left(\frac{\partial \boldsymbol{N}(e)}{\partial x} \mathbf{f}_{(e)}^{\top} \frac{\partial N_{n}(e)}{\partial x}+\frac{\partial \mathcal{N}(e)}{\partial z} \mathbf{f}_{(e)} \frac{\partial N_{n}}{\partial z}\right) d x d z+ \\
\iint_{(e)}\left(P N_{(e)} \mathbf{f}_{(e)}^{\top} N_{n}{ }^{(e)} d x d z-{ }_{(e)} \iint s N_{n}{ }^{(e)} d x d z=0,\right.
\end{gathered}
$$

in which $n=i, j$, and $k$. Equation (40) can be rewritten in matrix form

$$
\left.\boldsymbol{K}_{(e)}+\mathbf{P}_{(e)}\right) \mathbf{f}_{(e)}^{\top}=\boldsymbol{S}_{(e)}^{\top},
$$

in which the matrices $\mathbf{K}(e), \mathbf{P}(e)$ and the vector $\mathbf{S}^{\top}(e)$ have the entries

$$
\begin{aligned}
& K_{i j}=-\iint_{(e)} \frac{1}{k}\left(\frac{\partial N_{i}}{\partial x} \frac{\partial N_{j}}{\partial x}+\frac{\partial N_{i}}{\partial z} \frac{\partial N_{j}}{\partial z}\right) d x d z, \\
& P_{i j}=\iint_{(e)} p N_{i} N_{j} d x d z,
\end{aligned}
$$


and

$$
S_{i}=\iint_{(e)} s N_{i} d x d z
$$

Assuming $\rho$ and $\frac{\lambda^{2}}{\rho}$ to be constant within the element (e) and using equations (24) through (27), and the integral (Zienkiewicz, 1971),

$$
\iint_{(e)} N_{i}^{a} N_{j}^{b} N_{k}^{c} d x d z=\frac{2 a ! b ! c ! \Delta}{(a+b+c+2) !}
$$

in which $\Delta$ is the area of the element, (41) through (43) may be written as follows:

$$
\left(\frac{-1}{4 k \Delta}\left[\begin{array}{ccc}
b_{i}{ }^{2}+c_{i}{ }^{2} & b_{i} b_{j}+c_{i} c_{j} & b_{i} b_{k}+c_{i} c_{k} \\
& b_{j}{ }^{2}+c_{j}{ }^{2} & b_{j} b_{k}+c_{j} c_{k} \\
\text { symmetric } & b_{k}{ }^{2}+c_{k}{ }^{2}
\end{array}\right]+\frac{p \Delta}{12}\left[\begin{array}{lll}
2 & 1 & 1 \\
1 & 2 & 1 \\
1 & 1 & 2
\end{array}\right]\right) \mathbf{f}_{(e)}^{\top}=\boldsymbol{s}_{(e)}^{\top}
$$

For IP-resistivity problems, the source vector ${ }^{T}(e)$ is given by equation (44) in which the term $s$ is $-I \delta(x) \delta(z)$.

Assuming that the source is concentrated at node $k$ as illustrated in Figure 1 and noting at node $k, N_{k}=1, N_{j}=0$, and $N_{j}=0$ (this can be easily proved using equations (24) through (25)). Equation (44) may be written as follows:

and consequently

$$
S_{k}=\iint_{(e)} I \delta(x) \delta(z) d x d z=I
$$

$$
\boldsymbol{s}_{(\mathrm{e})}^{\top}=\left[\begin{array}{lll}
0 & 0 & \mathrm{I}
\end{array}\right] .
$$

The magnitude of I must be modified because the source is shared by more 
than one element (Figure $\mathrm{C}-1$ ). The magnitude of the source is divided among all elements joining at the source node. The source is allocated according to the ratio of the angle $\alpha$ in the element to $360^{\circ}$. Therefore, the correct equation for element (e) is given by

$$
\boldsymbol{S}_{(e)}=\frac{\alpha I}{360}\left[\begin{array}{l}
0 \\
0 \\
1
\end{array}\right] .
$$

If the source would be concentrated at nodes $i$ or $j$, the term 1 in (49) would appear at position $i$ or $j$ respectively. The entries of the vector $\boldsymbol{S}_{(e)}$ are identically zero for all other nodes, except that where the source is concentrated.

\section{Assemblage of Global Matrix Equation}

Equation (46) is known as the element matrix equation for the triangular element (e). For each element in the domain, an equation of the form (46) can be derived. These equations can be assembled (summed) into a single matrix equation, known as the global finite element matrix equation. Details of the assemblage of the global element matrix equation are given by Zienkiewicz (1971).

The global matrix equation may be written as

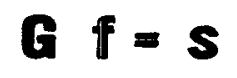

where $\boldsymbol{G}$ is a NXN, symmetric, sparse, banded and diagonally dominant matrix, and $N$ is the total number of nodal points in the entire discretized domain. . The vector $f$ is a column vector of $N$ unknown values of the function $f(x, z)$ at 
each node of the discretized model. The vector $\boldsymbol{S}$ is a column vector that contains the source information given by adding contributions of all source terms given by (49).

Since the vector $\boldsymbol{S}$ in (50) accounts for the impressed sources, the vector $f$ constitutes, by definition, the total solution of the problem. Total solution means the superposition of the primary solution due to a simple layered-earth model (background model) with the secondary solution due to complex inhomogeneities within the background model. 


\section{COMPUTATIONAL ASPECTS}

Incorporation of the Dirichlet Boundary Condition

Equation (50) automatically takes into account the Neumann boundary condition wherever it applies. The Dirichlet boundaries must be inserted where they apply.

In order to minimize computer time and storage, it is desirable during the process of entering the Dirichlet boundary condition to leave the original number of equations unchanged and also to avoid destroying the symmetry, boundedness and sparseness of the original matrix $\mathbf{G}$. This can be accomplished by using a method suggested by Payne and Iron (Zienkiewicz, 1971). According to this method, the diagonal term of $\mathbf{G}$ associated with a node where a Dirichlet boundary condition is specified is multiplied by a large number, say $10^{15}$. The corresponding term in the source vector $\boldsymbol{S}$ is replaced by the specified Dirichlet boundary condition multiplied by the same large factor times the corresponding original diagonal term of a matrix $\mathbf{G}$. This procedure is repeated until all nodes where a Dirichlet boundary condition is specified have been treated. Effectively, this procedure makes the unmodified terms in $\mathbf{G}$ very small compared to the modified terms, i.e., those associated with nodes where a Dirichlet boundary condition is specified.

To illustrate this procedure for entering a Dirichlet boundary condition, consider a simple example with only four system equations, 


$$
\left[\begin{array}{llll}
g_{11} & g_{12} & g_{13} & g_{14} \\
g_{21} & g_{22} & g_{23} & g_{24} \\
g_{31} & g_{32} & g_{33} & g_{34} \\
g_{41} & g_{42} & g_{43} & g_{44}
\end{array}\right] \quad\left[\begin{array}{l}
f_{1} \\
f_{2} \\
f_{3} \\
f_{4}
\end{array}\right]=\left[\begin{array}{l}
s_{1} \\
s_{2} \\
s_{3} \\
s_{4}
\end{array}\right] .
$$

Suppose that for this hypothetical system, the variable $f_{1}$ and $f_{3}$ are specified as

$$
f_{1}=\beta_{1} \text { and } f_{3}=\beta_{3} \text {. }
$$

Now, using the procedure, the system of equations (51) becomes

$$
\left[\begin{array}{lll}
g_{11} \times 10^{15} & g_{12} & g_{13} \\
g_{21} & g_{22} & g_{23} \\
g_{31} & g_{32} & g_{33} \times 10^{15} \\
g_{41} & g_{42} & g_{43}
\end{array}\right]\left[\begin{array}{c}
g_{14} \\
g_{24} \\
g_{34} \\
g_{44}
\end{array}\right]\left[\begin{array}{c}
f_{1} \\
f_{2} \\
f_{3} \\
f_{4}
\end{array}\right]=\left[\begin{array}{c}
\beta_{1} g_{11} \times 10^{15} \\
s_{2} \\
\beta_{3} g_{33} \times 10^{15} \\
s_{4}
\end{array}\right] .
$$

To see that this procedure gives the desired result consider the first equation of the system (52).

$$
g_{11} \times 10^{15} f_{1}+g_{12} f_{2}+g_{13} f_{3}+g_{14} f_{4}=\beta_{1} g_{11} \times 10^{15}
$$

For all practical purposes this equation expresses the fact that

$$
f_{1}=\beta_{1} \text {. }
$$

Solution of the system of equations

Once the Dirichlet boundary conditions have been incorporated, the next step is to solve the system of linear equations. Efficient solution of these equations is a very important aspect of the finite-element method because the system of equations is very large. Approximately $80 \%$ of the computer time 
required for complete solution of a given problem is spent solving this system.

One of the most efficient methods for solving the system of equations associated with the finite-element method is a modification of the Gaussian elimination method. This method transforms the system of equations into a triangular form that is readily solved by using the backward substitution technique.

It is important to note that in the IP-resistivity problems, forward reduction of $\mathbf{G}$ need be done only once, while forward reduction of the source vector $\mathbf{S}$ and backward substitution are done as many times as there are vector sources.

Computation of the Inverse Transform for the IP-Resistivity Problems

If the source is restricted to the plane perpendicular to the strike direction, the potential will be symmetric about this plane and therefore, equation (15) reduces to

$$
\phi(x, y, z)=\frac{1}{\pi} \int_{0}^{\infty} \hat{\phi}(x, \lambda, z) \cos (\lambda y) d \lambda .
$$

Furthermore, if the receivers are located in the same perpendicular plane, we have $y=0$, so that the inverse tranform (54) further reduces to simple integration

$$
\phi(x, y, z)=\frac{1}{\pi} \int_{0}^{\infty} \hat{\phi}(s, \lambda, z) d \lambda
$$

Seven values of $\lambda(.006, .02, .06, .2, .4,1 .$, and 2.$)$ are usually adequate to predict the behavior of the function $\hat{\phi}(x, \lambda, z)$ over the entire range. The 
function $\hat{\phi}(x, \lambda, z)$ so derived is fitted with a cubic spline and inserted into (55). This equation is, then, evaluated analytically. If the transmitters and receivers are not located in the same plane perpendicular to the strike, the complete equation (51) must be evaluated.

\section{Computation of the IP response}

The solution to the resistivity problem is obtained from (52) as an expression for apparent resistivity $\rho_{a}$ derivable from $\phi$, whereas the solution to the induced polarization problem is obtained by combining such solutions according to the following scheme. Polarizable regions are assiged two different resistivities, one higher (value $\rho(1)$ ) and one lower (value $\rho^{(2)}$ ). Two values of $\rho_{a}$ corresponding to two values of $\phi$ associated with the prescribed different values of $\rho$ are computed. Then the quantity "percent frequency effect" (PFE) is formed from

$$
\text { PFE }=\frac{\rho_{a}^{(1)}-\rho_{a}{ }^{(2)}}{\rho_{a}(2)} \times 100 \%
$$

in which $\rho_{a}(1)$ is the apparent resistivity for the 'low frequency' and $\rho_{a}{ }^{(2)}$ is the apparent resistivity for the "high frequency". 
Appendix D

Sample Computer Sessions 


\section{IP2D Computer Session \#1}

Simple Model

D-1 
OADD IP2D.XQT

Ready

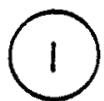

Ready

Ready

Ready

***TERMINAL SELECTION PROGRAM***

TERM-OOPTION\# (I) = $>0$

2

\# OPTION

1 HARD COPY

2 TEKTRONIX

3 CRT

TERM--OPTION\# (I) =

$>1$

NORMAL EXIT.

$\star \star \star$ MASTER PROGRAM***

TIME :

49 MILLISECONDS.

MASTR-OPTION\# (I) =

$>0$

\# OPTION

1 EXIT FROM SYSTEM

2 INPUT MODEL PARAMETERS

3 EDIT MODEL PARAMETER FILE

4 PLOT MODEL MESH GEOMETRY

5 COMPUTE RATIO \& DIFF. SECTIONS

6 FILE MAINTENANCE SAVE \& RECALL

7 LIST MODEL PARAMETER FILE

8 EXECUTE RES. IP FINITE ELEMENT

MASTR-OPTION\# (I) =

$>2$

INPUT-OPTION\# (I)=

$>0$

\# OPTION

1 RETURN TO MASTER OPTIONS

2 INPUT NEW MODEL

3 INPUT OBSERVED RES

4 INPUT OBSERVED PFE

INPUT-OPTION\# (I) =

$>2$

PROJECT NAME $(60 \mathrm{~A})=$

$>$ IP2D DOCUMENTATION

MODEL NAME $(60 \mathrm{~A})=$

>SIMPLE MODEL

USE DEFAULT MESH?

$>Y$

MESH--OPTION\# (I) =

$>2$

\# OF DISTINCT MEDIA (I)= $>2$ 
INPUT 2 MEDIA RESISTIVITIES (F)

$>100$.

$\infty_{>50 .} \# 2=$

INPUT 2
$\# 1=$
1

$>10$.

$>30$. $2=$

DEFINE MESH AREA FOR INPUT

$X$ START NODE \# (I) $=$

30

$Z$ START NODE \# (I) $=$

$X$ END NODE \# (I) $=$

$>35$

$Z$ END NODE \# (I) =

$>12$

MEDIA MESH CODEING

ROW 3 ELEMENT 30 TO 34

3 ...

$>11111$

ROW 4 ELEMENT $30 \quad$ T0 34

3 ....

$>12221$

ROW 5 ELEMENT 30 TO 34

3 ....

$>12221$

ROW 6 ELEMENT 30 TO 34

$3 \ldots$

$>12221$

ROW 7 ELEMENT 30 TO 34

$3 \ldots .$.

$>12221$

ROW 8 ELEMENT 30 TO 34

$3 \ldots$

$>12221$

ROW 9 ELEMENT 30 TO 34

3 ....

$>11111$

ROW 10 ELEMENT 30 TO 34

3 ....

$>11111$ 
ROW 11 ELEMENT 30 TO 34

$3 \ldots$

$>11111$

$\omega_{3}$ INPUT-OPTION\# (I) $=$

*INPUT MEASURED RESISITIVITY SECTION (F)

ROW 1

$>92 ., 59 ., 59 ., 92 \cdot, 103 \bullet, 99 ., 98 ., 97$.

ROW 2

$>89 ., 43 \cdot, 37 ., 43 ., 89,, 111,, 105,, 102,, 101$.

ROW 3

$>87 ., 39 ., 39 ., 39 ., 39 ., 86 ., 115,, 108,, 104 ., 103$.

ROW 4

$>86 ., 39 \cdot, 44 \cdot, 47,, 44 \cdot, 38,, 84,, 118,, 110,, 106,, 105$.

ROW 5

$>39 ., 48,, 53 \cdot, 52 \cdot, 48 \cdot, 38 \cdot, 82,, 120,, 113 ., 109$.

ROW 6

$>53 \cdot, 58 \cdot, 59 \cdot, 58 \cdot, 39 \cdot, 81,, 122,, 116$.

$>4$

$$
\text { INPUT-OPTION\# (I) = }
$$

* INPUT MeAsuREd pFe SECTION (F)

ROW 1

$>10.15,11.44,11.44,10.15,9.82,9.94,9.98,9.99$

ROW 2

$>10.29,13.40,14.97,13.40,10.29,9.67,9.86,9.94,9.97$

ROW 3

$>10.31,13.99,15.37,15.37,13.99,10.32,9.55,9.78,9.89,9.94$

ROW 4

$>10.3,14.16,14.95,14 \cdot 96,14.95,14 \cdot 16,10 \cdot 31,9.45,9.70,9.84,9.91$

ROW 5

$>14.16,14.46,14.40,14.40,14.47,14.16,10.29,9.37,9.64,9.80$

*TM* REBOOT NECESSARY SOON, BE PREPARED TO

*TM* TERMINATE ON SHORT NOTICE.

ROW 6

$>14.03,13.90,13.87,13.91,14.09,10.27,9.31,9.58$.

INPUT-OPTION\# (I)= 
X ELEMENT GROUP SPACINGS IN A-UNITS

$$
\begin{array}{ccccc}
30.00 & 15.00 & 2.00 & .25 & 2.00 \\
15.00 & 30.00 & & &
\end{array}
$$

\# OF Z ELEMENT GROUPS =

9

$Z$ ELEMENT GROUP \#S

Z ELEMENT GROUP SPACINGS IN A-UNITS

$$
\begin{array}{cccc}
.10 & .20 & .30 & .40
\end{array}
$$

ELECTRODE X NODE LOCATIONS

$\begin{array}{ccccccccccccccccc}7 & 11 & 15 & 19 & 23 & 27 & 31 & 35 & 39 & 43 & 47 & 51 & 55 & 59 & 63 & 67 & 71\end{array}$

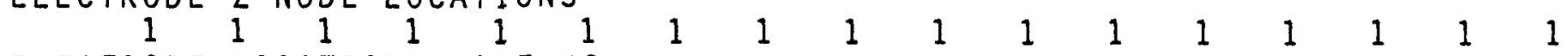
ELECTRODE LOCATIONS NODE \#S

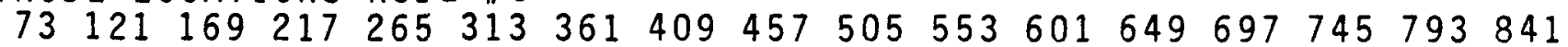

MEDIA RESITIVITY (OHM-METERS)

$100.00 \quad 50.00$

MEDIA PFE $(\%)$
$10.00 \quad 30.00$

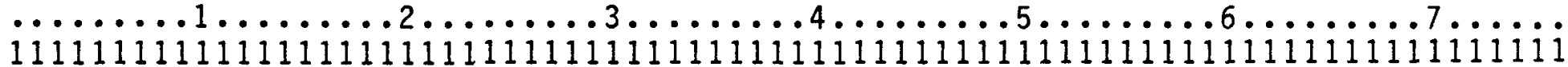
111111111111111111111111111111111111111111111111111111111111111111111111111 1111111111111111111111111111111111111111111111111111111111111111111111111111 1111111111111111111111111111112221111111111111111111111111111111111111111111 111111111111111111111111111112221111111111111111111111111111111111111111111 1111111111111111111111111111112221111111111111111111111111111111111111111111 1111111111111111111111111111112221111111111111111111111111111111111111111111 111111111111111111111111111112221111111111111111111111111111111111111111111 1111111111111111111111111111111111111111111111111111111111111111111111111111 1111111111111111111111111111111111111111111111111111111111111111111111111111 1111111111111111111111111111111111111111111111111111111111111111111111111111

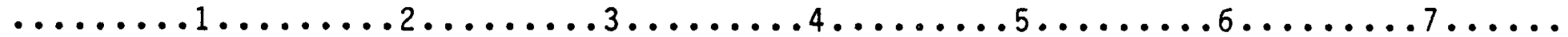

CALCULATED RESISTIVITY (OHM-METERS)

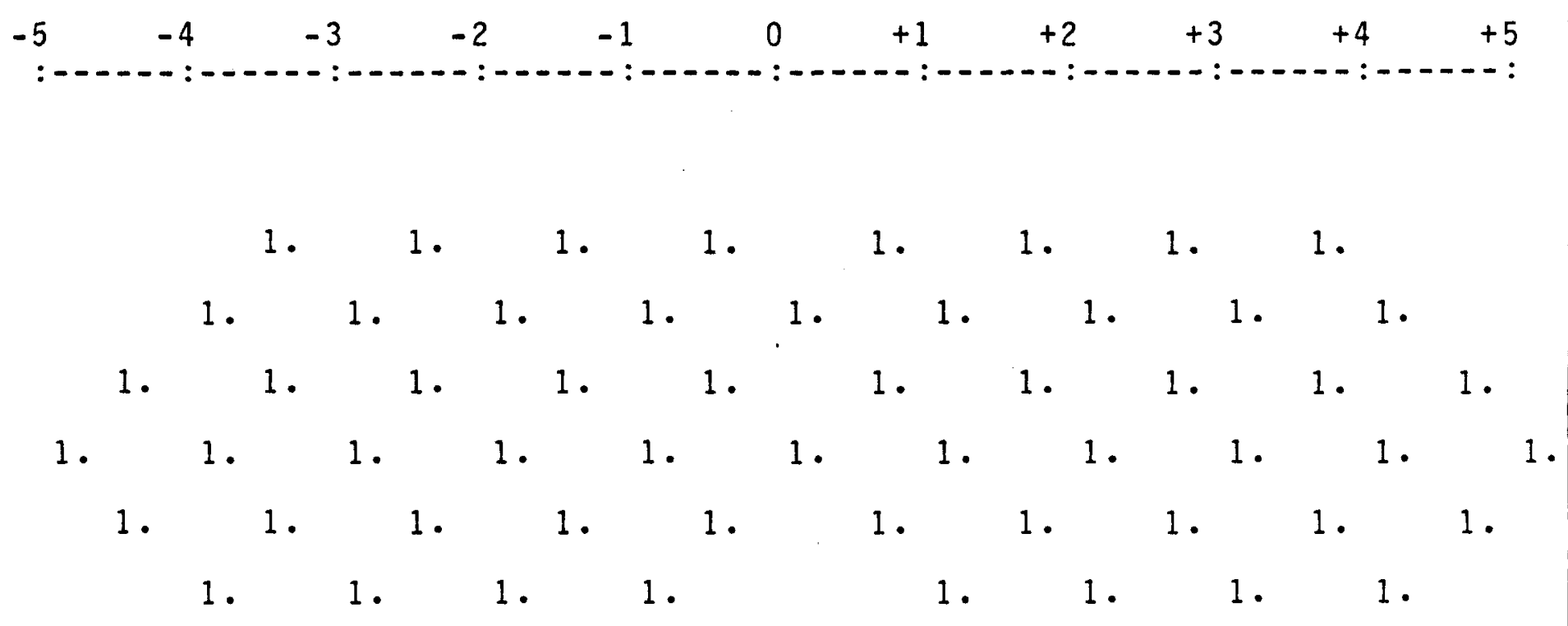




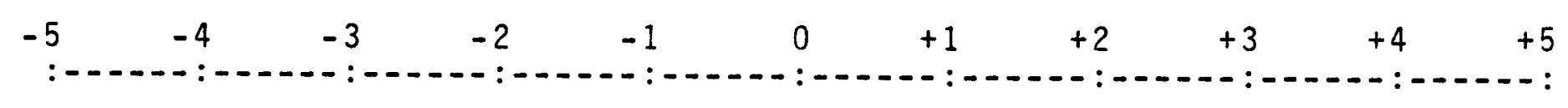

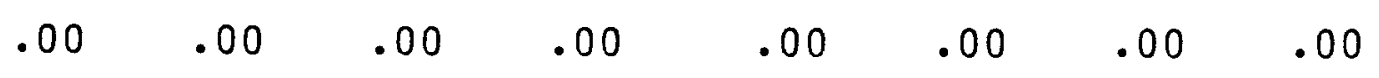

$$
\begin{aligned}
& \begin{array}{llllllll}
.00 & .00 & .00 & .00 & .00 & .00 & .00 & .00
\end{array} \\
& \begin{array}{llllllllll}
.00 & .00 & .00 & .00 & .00 & .00 & .00 & .00 & .00 & .00
\end{array} \\
& \begin{array}{lllllllllll}
.00 & .00 & .00 & .00 & .00 & .00 & .00 & .00 & .00 & .00 & .00
\end{array}
\end{aligned}
$$

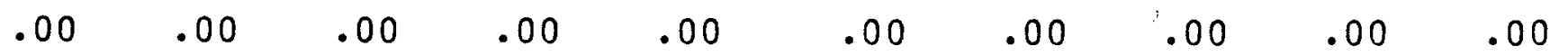

$$
\begin{aligned}
& \begin{array}{lllllll}
.00 & .00 & .00 & .00 & .00 & .00 & .00
\end{array}
\end{aligned}
$$

$>1 \quad$ LIST-OOPTION\# (I) =

MASTR-OPTION\# (I) =

$>8$

NORMAL EXIT. TIME: 1509 MILLISECONDS.

NORMAL EXIT. TIME: 8 MILLISECONDS.

$\star \star \star$ IP2D (IP-RESISTIVITY 2-D) PROG.)

CALCULATE BOTH RESISTIVITY AND PFE?

$>Y$

IP2D DOCUMENTATION

SIMPLE MODEL

APPARENT RESISTIVITY (CALCULATED)

$\begin{array}{lllllllll}-5 & -4 & -3 & -2 & -1 & 0 & +1 & +2 & +3\end{array}$

*TM* PLS TERMINATE ASAP.

98. 92. $\quad$ 86. 95. 98. 97. 97. 97.

102. 92. 88. 87. 95. 102. 101. 101. 101.

103. 91. 89. 91. 88. 94. 103. 102. 102. 102.

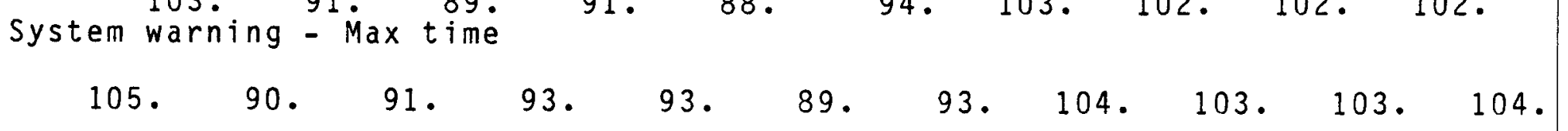


91. 92. 95. 95. 94. 90. 93. 104. 104. 105 . 95. 97. 97. 97. 91. 92. 105. 106.

IP $2 D$ DOCUMENTATION

SIMPLE MODEL

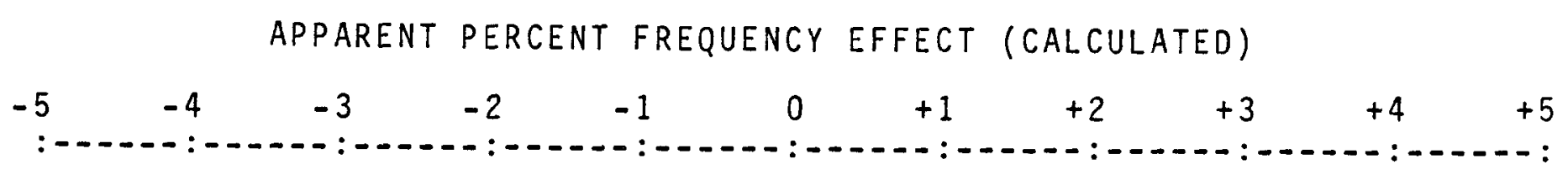

$$
\begin{array}{rrrrrrrrrrrrr}
9.58 & 11.52 & 13.43 & 10.65 & 9.62 & 9.88 & 9.96 & 9.98 \\
9.43 & 12.48 & 14.28 & 14.31 & 11.30 & 9.40 & 9.75 & 9.90 & 9.96 & \\
9.36 & 12.96 & 13.92 & 13.58 & 14.16 & 11.72 & 9.27 & 9.64 & 9.84 & 9.93 \\
9.36 & 13.24 & 13.54 & 12.96 & 13.02 & 13.89 & 12.03 & 9.20 & 9.54 & 9.79 & 9.89 \\
13.44 & 13.20 & 12.50 & 12.40 & 12.58 & 13.63 & 12.27 & 9.18 & 9.47 & 9.74 \\
12.92 & 12.13 & 11.96 & 11.98 & & 13.40 & 12.47 & 9.18 & 9.41 &
\end{array}
$$

\section{NORMAL EXIT. TIME: 60383 MILLISECONDS. \\ $\star \star \star$ MASTER PROGRAM***}

MASTR-OPTION\# (I) =

$>5$

$>0$

$$
\text { RADIF-OPTION\# (I)= }
$$

$$
\begin{aligned}
& \text { \# OPTION } \\
& 1 \text { RETURN MSTR } \\
& 2 \text { RES. RATIO } \\
& 3 \text { PFE DIFF } \\
& \text { RADIF-OPTION\# (I)= }
\end{aligned}
$$

*TM* PLS TERMINATE NOW.

$>2$

$$
\text { RESISTIVITY RATIO SECTION (CALCULATED/MEASURED) }
$$

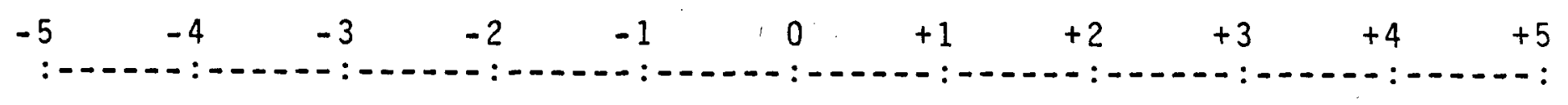

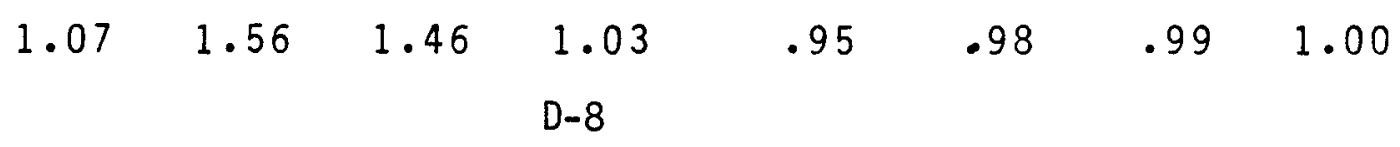




$\begin{array}{lllllllllllllll}1.15 & 2.13 & 2.37 & 2.03 & 1.07 & .92 & .96 & .99 & 1.00 & \\ 1.19 & 2.32 & 2.29 & 2.33 & 2.26 & 1.10 & .90 & .95 & .98 & .99\end{array}$

$\begin{array}{rrrrrrrrrrrrrrrr}1.22 & 2.31 & 2.06 & 1.99 & 2.11 & 2.34 & 1.11 & .88 & .94 & .97 & .99 \\ 2.33 & 1.93 & 1.80 & 1.83 & 1.97 & 2.37 & 1.13 & .87 & .92 & .96 \\ & 1.79 & 1.67 & 1.65 & 1.67 & & 2.33 & 1.14 & .86 & .92 & \end{array}$

RADIF-OPTION\# (I) = $>$ OOTERM

(6) 
An explanation of the program executions taking place near the circled numbers in the computer session is given below.

1 The interactive modeling system is entered with an 1108 add statement. The add element contains statements that assign the work and merge files and unit numbers.

2 And answer of zero to any option request will cause an option list to be generated.

3 The terminal messages (*TM*) are not part of the program. These messages were sent from the operator.

4 If a mistake was made in entering any of the input data, it can be corrected by executing the edit options.

5 It is possible to list the model parameters for checking before execution of the finite-element program.

6 The operators needed the system in order to reboot. All the parameters and results of the first iteration have been saved in the work data file so it is possible to terminate the execution of the program and return later without interrupting the modeling continuity. 
IP2D Computer Session \#2

Simple Model Continued 
QADD IP2D.XQT

Ready

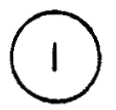

Ready

Ready

Ready

$\star \star \star$ TERMINAL SELECTION PROGRAM***

$>1$

TERM--OPTION\# $(I)=$

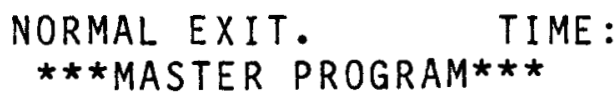

17 MILLISECONDS.

$\star \star \star M A S T E R$
$M A S T R-O P T I O N \#(I)=$

$>5$

RADIF-OPTION\# (I)=

$>3$

PFE DIFFERENCE SECTION (CALCULATED-MEASURED)

$\begin{array}{llllllllll}-5 & -4 & -3 & -2 & -1 & 0 & +1 & +2 & +3 & +4 \\ - & -2 & -5\end{array}$

$\begin{array}{lllllllll}-.57 & .08 & 1.99 & .50 & -.20 & -.06 & -.02 & -.01\end{array}$

$\begin{array}{llllllllll}-.86 & -.92 & -.69 & .91 & 1.01 & -.27 & -.11 & -.04 & -.01\end{array}$

$\begin{array}{lllllllllll}-.95 & -1.03 & -1.45 & -1.79 & .17 & 1.40 & -.28 & -.14 & -.05 & -.01\end{array}$

$\begin{array}{lllllllllll}-.94 & -.92 & -1.41 & -2.00 & -1.93 & -.27 & 1.72 & -.25 & -.16 & -.05 & -.02\end{array}$

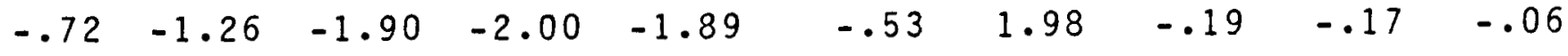

$\begin{array}{llllllll}-1.11 & -1.77 & -1.91 & -1.93 & -.69 & 2.20 & -.13 & -.17\end{array}$

$>1$

RADIF-OPTION\# (I) =

MASTR-OPTION\# (I) $=$

$>3$

$>0$

EDIT--OPTION\# (I) =

\# OPTION

1 RETURN TO MASTER OPTIONS

2 EDIT MESH CODE ELEMENTS

3 EDIT MESH CODE ROWS

4 EDIT ENTIRE MESH CODE

5 EDIT \# OF MEDIA CODES

6 EDIT MEDIA RES

7 EDIT MEDIA PFE

8 EDIT MEASURED RES SEC. 
9 EDIT MEASURED PFE SEC.

10 EDIT MESH GEOMETRY

11 EDIT TITLES

EDIT--OPTION\# (I)=

*EDIT MESH CODE ROWS*

ROW \# (I) $=$

$>4$

$>0$

TRI-- OPTION\# (I)=

$>5$

\# OPTION

1 TOP

2 LEFT

3 BOTTOM

4 RIGHT

$5 \mathrm{ALL}$

TRI--OPTION\# (I) =

ROW 4 ELEMENT 1 TO 76

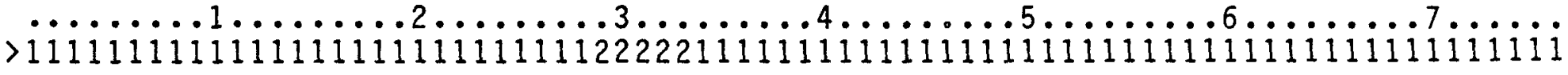

EDIT ANOTHER ROW?

$>Y$

ROW \# (I) =

$>5$

$>5$

TRI-- OPTION\# (I)=

ROW 5 ELEMENT 1 TO 76

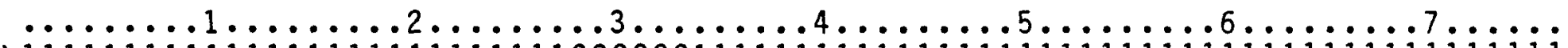

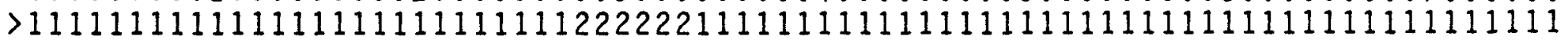

EDIT ANOTHER ROW?

$>Y$

ROW \#(I) $=$

$>6$

$>5$

$$
\text { TRI--OPTION\# (I) = }
$$

ROW 6 ELEMENT 1 TO 76

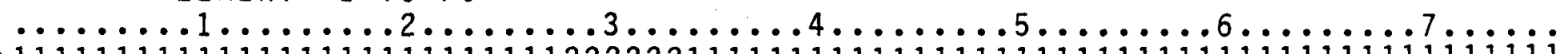

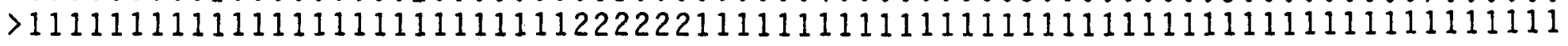

$>$ EDIT ANOTHER ROW?

$\underset{30 \mathrm{ROW}}{\operatorname{Ro}(I)=}$

$$
\text { TRI---OPTION\# (I) = }
$$

$>5$ 
ROW 7 ELEMENT 1 TO 76

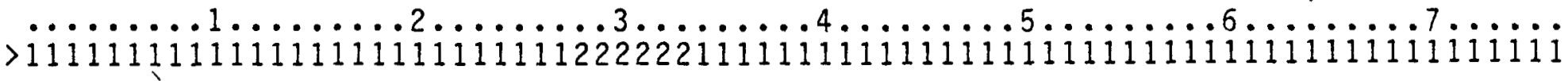

$\omega_{>Y}$ EDIT ANOTHER ROW?

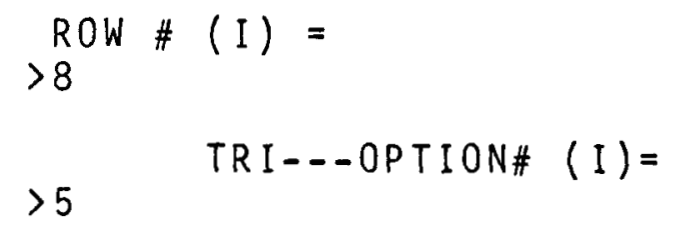

ROW 8 ELEMENT 1 TO 76

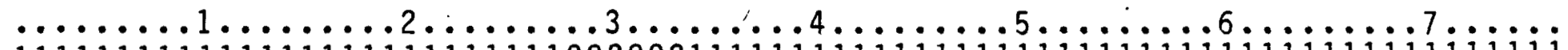

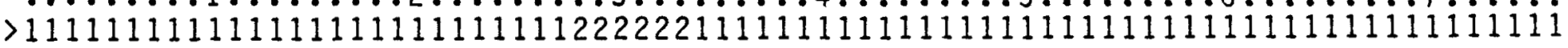

EDIT ANOTHER ROW?

$>\mathrm{N}$

$>0$

EDIT--OPTION\# (I) =

$\begin{array}{ll}\text { \# } & \text { OPTION } \\ 1 & \text { RETURN TO MASTER OPTIONS }\end{array}$

2 EDIT MESH CODE ELEMENTS

3 EDIT MESH CODE ROW'S

4 EDIT ENTIRE MESH CODE

5 EDIT \# OF MEDIA CODES

6 EDIT MEDIA RES

7 EDIT MEDIA PFE

8 EDIT MEASURED RES SEC.

9 EDIT MEASURED PFE SEC.

10 EDIT MESH GEOMETRY

11 EDIT TITLES

EDIT--OPTION\# (I)=

$>2$

$\underset{R O W}{>} \#(I)=$

(4)

ELEMENT \# (I) =

$>28$

${ }_{1}^{1} 1$ TRI--OPTION\# (I) $=$

$>5$

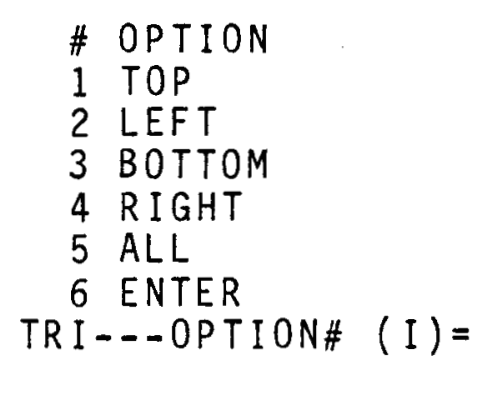


$>2$

NEW ELEMENT VALUE (I) =

EDIT ANOTHER ELEMENT?

$>1$ EDIT-OPTION\# (I) $=$

MASTR-OPTION\# (I) $=$
$>8$

(5)

NORMAL EXIT. TIME: 958 MILLISECONDS.

NORMAL EXIT. TIME: 3 MILLISECONDS.

*** IP2D (IP-RESISTIVITY 2-D) PROG.)

$>\mathrm{C}$

CALCULATE BOTH RESISTIVITY AND PFE?

IP2D DOCUMENTATION

SIMPLE MODEL

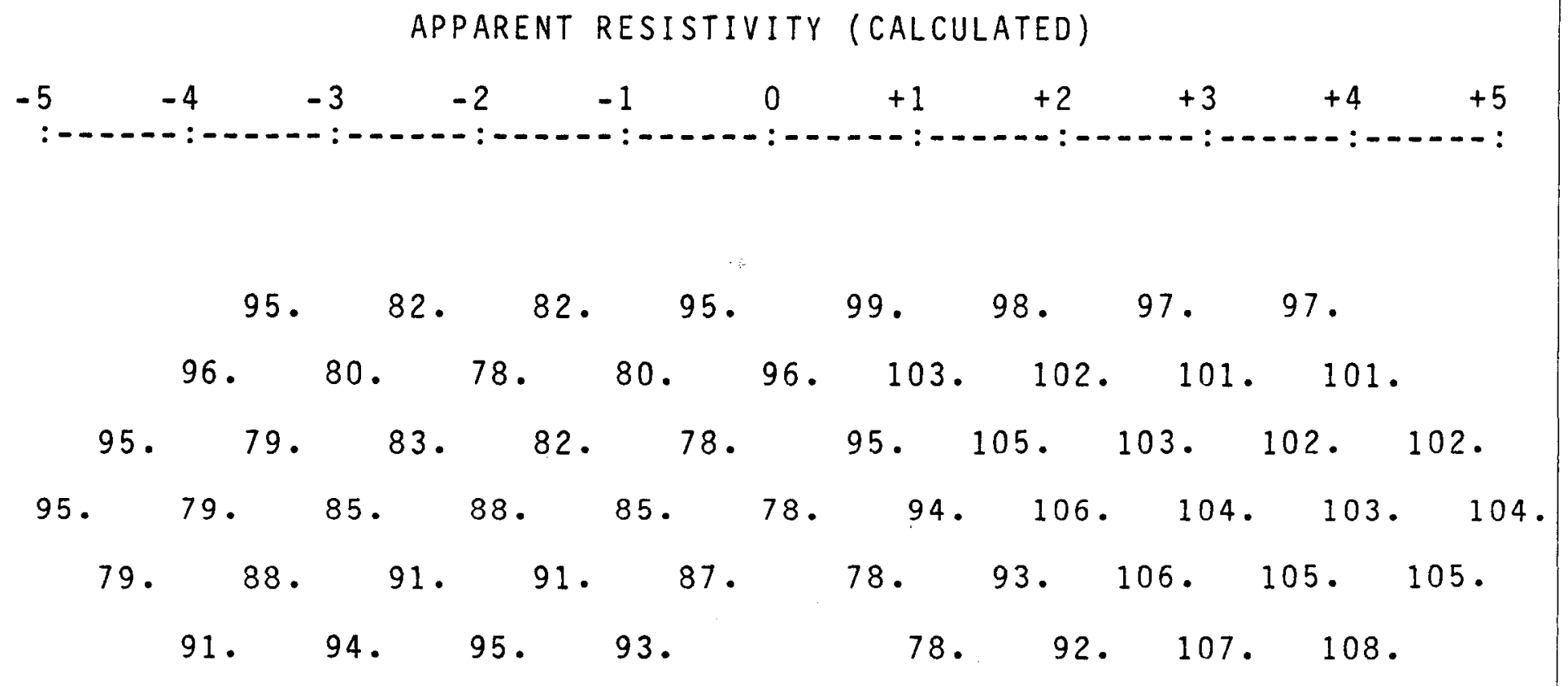

System warning - Max time IP2D DOCUMENTATION.

SIMPLE MODEL

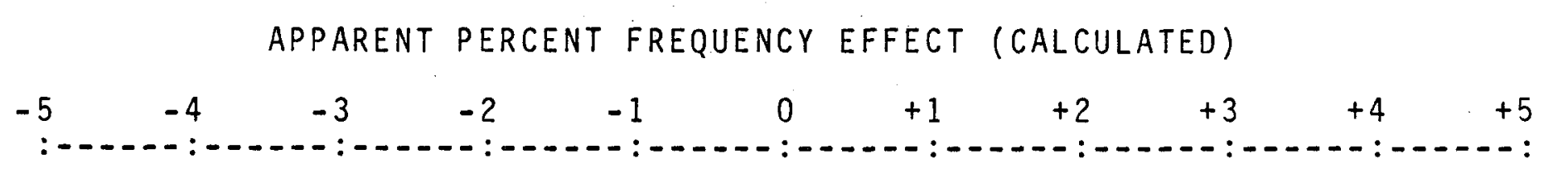

$$
\begin{array}{cccccccc}
10.49 & 14.58 & 14.58 & 10.49 & 9.51 & 9.84 & 9.94 & 9.98 \\
& & 0-15 & & & &
\end{array}
$$


$\begin{array}{lllllllll}11.14 & 16.84 & 17.35 & 16.84 & 11.14 & 9.19 & 9.66 & 9.86 & 9.94\end{array}$

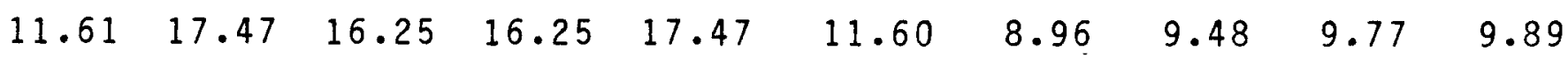
$\begin{array}{lllllllllll}11.99 & 17.71 & 15.43 & 14.60 & 15.44 & 17.71 & 11.99 & 8.81 & 9.33 & 9.68 & 9.84\end{array}$ $\begin{array}{llllllllll}17.80 & 14.80 & 13.72 & 13.73 & 14.81 & 17.79 & 12.32 & 8.73 & 9.21 & 9.60\end{array}$ $\begin{array}{llllllll}14.29 & 13.10 & 12.89 & 13.10 \quad & 17.80 & 12.61 & 8.69 & 9.11\end{array}$

NORMAL EXIT. $\star \star \star$ MASTER PROGRAM $* \star \star *$

MASTR-OPTION\# (I) =

$>5$

$>2$

RADIF-OPTION\# (I) =

(6)

RESISTIVITY RATIO SECTION (CALCULATED/MEASURED)

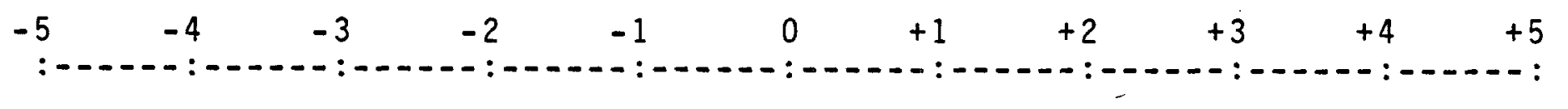

$\begin{array}{llllllll}1.04 & 1.39 & 1.39 & 1.04 & .96 & .99 & .99 & 1.00\end{array}$

$\begin{array}{lllllllll}1.08 & 1.85 & 2.12 & 1.85 & 1.08 & .93 & .97 & .99 & 1.00\end{array}$

$\begin{array}{llllllllll}1.10 & 2.02 & 2.12 & 2.12 & 2.01 & 1.10 & .91 & .95 & .98 & .99\end{array}$

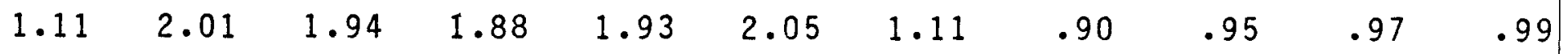
$\begin{array}{llllllllll}2.04 & 1.83 & 1.73 & 1.75 & 1.81 & 2.05 & 1.13 & .89 & .93 & .97\end{array}$ $\begin{array}{llllllll}1.71 & 1.62 & 1.60 & 1.61 & 2.00 & 1.13 & .88 & .93\end{array}$

$>3$

RADIF-OPTION\# (I) =

PFE DIFFERENCE SECTION (CALCULATED-MEASURED)

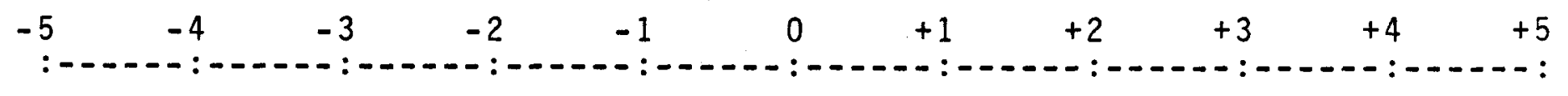

$\begin{array}{lllllllll}.34 & 3.14 & 3.14 & .34 & -.31 & -.10 & -.04 & -.01\end{array}$ $\begin{array}{llllllllll}.85 & 3.44 & 2.38 & 3.44 & .85 & -.48 & -.20 & -.08 & -.03\end{array}$ 
$\begin{array}{lllllllllll}1.30 & 3.48 & .88 & .88 & 3.48 & 1.28 & -.59 & -.30 & -.12 & -.05\end{array}$

$\begin{array}{llllllllllll}1.69 & 3.55 & .48 & -.36 & .49 & 3.55 & 1.68 & -.64 & -.37 & -.16 & -.07\end{array}$

$\begin{array}{lllllllllll}3.64 & .34 & -.68 & -.67 & .34 & 3.63 & 2.03 & -.64 & -.43 & -.20\end{array}$

$\begin{array}{llllllll}.26 & -.80 & -.98 & -.81 & 3.71 & 2.34 & -.62 & -.47\end{array}$

$>1$

RADIF-OPTION\# (I) =

MASTR-OPTION\# (I) =

$>3$

EDIT--OPTION\# (I)=

$>6$

RESISTIVITY OHM-METER

(7)

$1.000000+02 \quad 5.000000+01$

UPDATE PARAMETER \# (I) =

$>2$

$\# 2$ OLD $=5.000000+01 \quad \mathrm{NEW}=$

$>10$.

$1.000000+02 \quad 1.000000+01$

UPDATE PARAMETER \# (I) =

$>0$

EDIT--OPTION\# (I)=

8

$>7$

PFE PERCENT

$1.000000+01 \quad 3.000000+01$

UPDATE PARAMETER \# (I) = $>-1$

9

$\# 10.1$
$>10$

$\# 2$ OLD $=3.000000+01 \quad \mathrm{NEW}=$

$>20$.

EDIT-OPTION\# (I)=

$>1$

MASTR-OPTION\# (I) =

$>8$

NORMAL EXIT. TIME: 269 MILLISECONDS.

NORMAL EXIT. TIME: 3 MILLISECONDS.

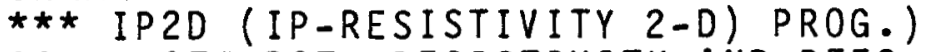

CALCULATE BOTH RESISTIVITY AND PFE?

$>Y$

IP2D DOCUMENTATION 
SIMPLE MODEL

\section{APPARENT RESISTIVITY (CALCULATED)}

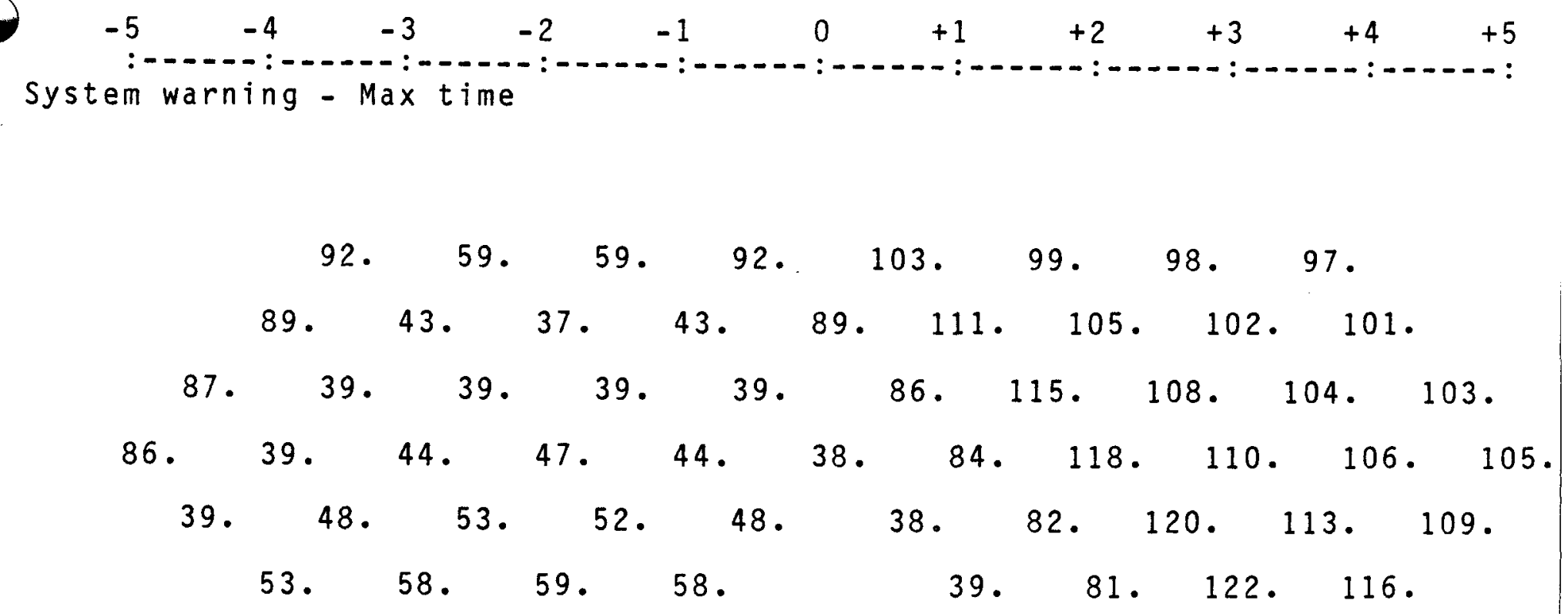

IP 2D DOCUMENTATION

SIMPLE MODEL

APPARENT PERCENT FREQUENCY EFFECT (CALCULATED)

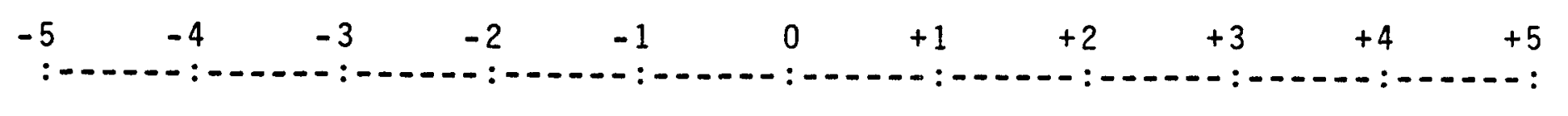

$$
\begin{array}{llllllll}
10.15 & 11.44 & 11.44 & 10.15 & 9.82 & 9.94 & 9.98 & 9.99
\end{array}
$$

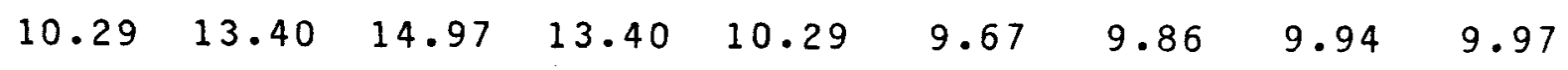

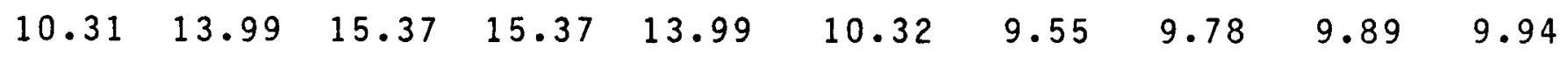

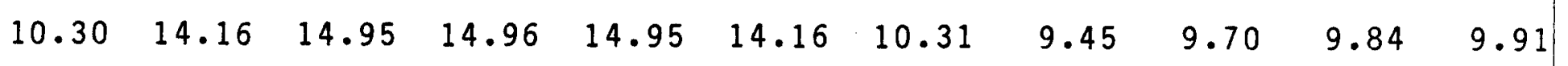

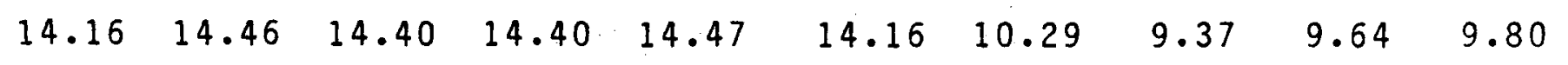

$$
\begin{array}{llllllll}
14.03 & 13.90 & 13.87 & 13.91 & 14.09 & 10.27 & 9.31 & 9.58
\end{array}
$$

\section{$\underset{\star N \text { NOMAL EXIT. }}{\text { TIME: }} \quad 65032$ MILLISECONDS.}

MASTR-OPTION\# (I) =

$>5$

$>2$

$$
\text { RADIF-OPTION\# (I)= }
$$




\section{RESISTIVITY. RATIO SECTION (CALCULATED/MEASURED)}

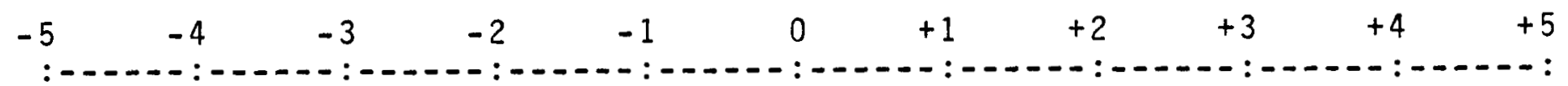

$\begin{array}{llllllll}1.00 & 1.00 & 1.00 & 1.00 & 1.00 & 1.00 & 1.00 & 1.00\end{array}$

$\begin{array}{lllllllll}1.00 & 1.00 & 1.00 & 1.00 & 1.00 & 1.00 & 1.00 & 1.00 & 1.00\end{array}$

$\begin{array}{llllllllll}1.00 & 1.01 & 1.01 & 1.01 & 1.01 & 1.00 & 1.00 & 1.00 & 1.00 & 1.00\end{array}$

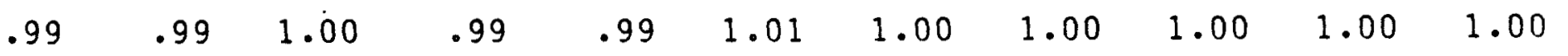
$\begin{array}{llllllllll}1.00 & 1.01 & .99 & 1.01 & 1.00 & 1.01 & 1.00 & 1.00 & 1.00 & 1.00\end{array}$ $\begin{array}{llllllll}1.00 & 1.00 & 1.00 & .99 & .99 & 1.00 & 1.00 & 1.00\end{array}$

RADIF-OPTION\# (I) =

$>3$

PFE DIFFERENCE SECTION (CALCULATED-MEASURED)

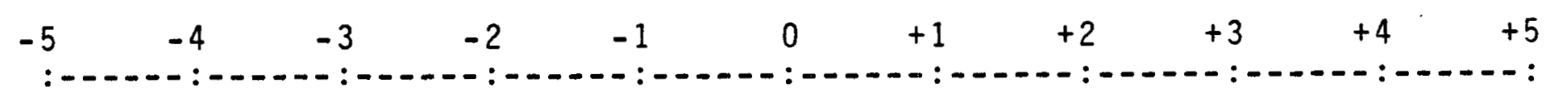

$$
\begin{aligned}
& \begin{array}{llllllllll}
.00 & -.00 & -.00 & .00 & -.00 & -.00 & -.00 & -.00
\end{array} \\
& \begin{array}{lllllllllll}
.00 & .00 & .00 & .00 & .00 & .00 & -.00 & -.00 & -.00
\end{array} \\
& \begin{array}{lllllllllll}
.00 & .00 & -.00 & -.00 & .00 & -.00 & -.00 & -.00 & .00 & .00
\end{array}
\end{aligned}
$$

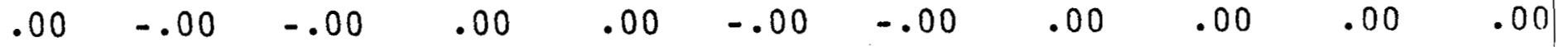

$$
\begin{aligned}
& \begin{array}{llllllllllll}
.00 & .00 & -.00 & -.00 & -.00 & .00 & .00 & .00 & -.00 & .00
\end{array} \\
& \begin{array}{lllllllll}
.00 & .00 & -.00 & -.00 & .00 & .00 & -.00 & -.00
\end{array}
\end{aligned}
$$

$>1$ RADIF-OPTION\# (I) $=$

MASTR-OPTION\# (I) =

$>4$

PLOT-OPTION\# (I) =

$\begin{array}{ll}\text { \# } & \text { OPTION } \\ 1 & \text { RETURN TO MASTER } \\ 2 \text { TEK MESH PLOT }\end{array}$

(11) 
3 TEK SECTION PLOT

4 CALCOMP MESH PLOT

5 CALCOMP SECTION PLOT

6 CALCOMP REPORT PAGE PLOT

7 CALCOMP SCALED PAGE

8 CALCOMP SCALED PSEUDO $S$.

PLOT--OPTION\# (I)=

$>6$

$>0$

$$
\text { PAGE-DPTION\# (I)= }
$$

$>4$

\# OPTION

I RETURN TO PLOT OPTIONS

2 COMPUTED RES. ONLY

3 COMPUTED \& OBSERVED RES.

4 COMPUTED RES. \& RATIO

5 COMPUTED PFE ONLY

6 COMPUTED \& OBSERVED PFE

7 COMPUTED PFE \& DIFF.

8 COMPUTED RES. AND PFE

PAGE--OPTION\# (I) =

NODEX $=77$ NODEZ $=12$

START $X$ NODE \#=

$>7$

END $X$ NODE \#=

$>71$

START Z NODE \#=

$>1$

END $Z$ NODE \#=

$>10$

PLOT TRIANGULAR ELEMENTS?
$>Y$

7 PAGE-OPTION\# (I) =

$>7$

NODEX $=77$ NODEZ $=12$

(12)

START $X$ NODE \#=

$>7$

END $X$ NODE \#=

$>71$

START Z NODE \#=

$>1$

END $Z$ NODE \#=

$>10$

() PLOT TRIANGULAR ELEMENTS?

PAGE- OPTION\# (I) = 
PLOT--OPTION\# (I)=

MASTR-OPTION\# (I)=

$>7$

$>8$

LIST--OPTION\# (I)=

PROJECT NAME:

IP2D DOCUMENTATION

MODEL NAME :

SIMPLE MODEL

\# OF $X$ NODES $=77$

\# OF $Z$ NODES $=12$

\# OF X ELEMENT GROUPS $=7$

$X$ ELEMENT GROUP \#S

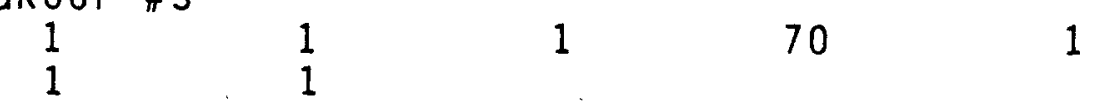

$X$ ELEMENT GROUP SPACINGS IN A-UNITS

$$
\begin{array}{ccccc}
30.00 & 15.00 & 2.00 & .25 & 2.00 \\
15.00 & 30.00 & & &
\end{array}
$$

\# OF Z ELEMENT GROUPS $=9$

$Z$ ELEMENT GROUP \#S

$\begin{array}{cccccc}1 & 1 & 1 & 1 & 2 \\ 2 & 1 & 1 & 1 & \end{array}$

$Z$ ELEMENT GROUP SPACINGS IN A-UNITS

$\begin{array}{rrrr}.10 & .20 & .30 & .40 \\ 1.00 & 2.00 & 4.00 & 8.00\end{array}$

ELECTRODE $X$ NODE LOCATIONS

$\begin{array}{lllllllllllllllll}7 & 11 & 15 & 19 & 23 & 27 & 31 & 35 & 39 & 43 & 47 & 51 & 55 & 59 & 63 & 67 & 71\end{array}$

ELECTRODE $Z$ NODE LOCATIONS

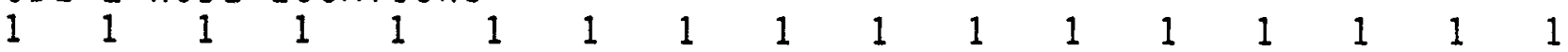

ELECTRODE LOCATIONS NODE \#S

$\begin{array}{lllllllllllllllll}73 & 121 & 169 & 217 & 265 & 313 & 361 & 409 & 457 & 505 & 553 & 601 & 649 & 697 & 745 & 793 & 841\end{array}$

MEDIA RESITIVITY (OHM-METERS)

MEDIA PFE (\%)

10.00

$$
10.00 \quad 20.00
$$

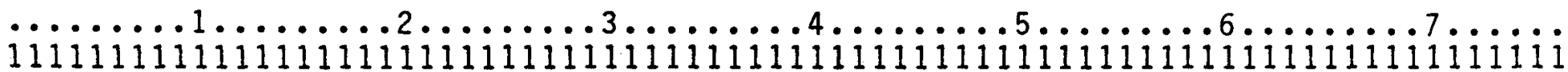

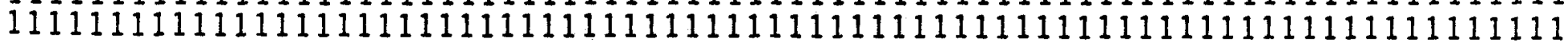
1111111111111111111111111111111111111111111111111111111111111111111111111111 1111111111111111111111111112222221111111111111111111111111111111111111111111 1111111111111111111111111112222221111111111111111111111111111111111111111111 1111111111111111111111111112222221111111111111111111111111111111111111111111 1111111111111111111111111112222221111111111111111111111111111111111111111111 1111111111111111111111111112222221111111111111111111111111111111111111111111 1111111111111111111111111111111111111111111111111111111111111111111111111111 1111111111111111111111111111111111111111111111111111111111111111111111111111 1111111111111111111111111111111111111111111111111111111111111111111111111111

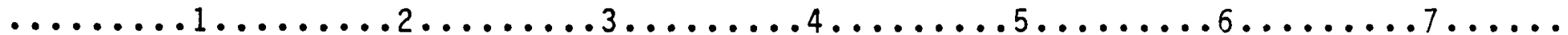




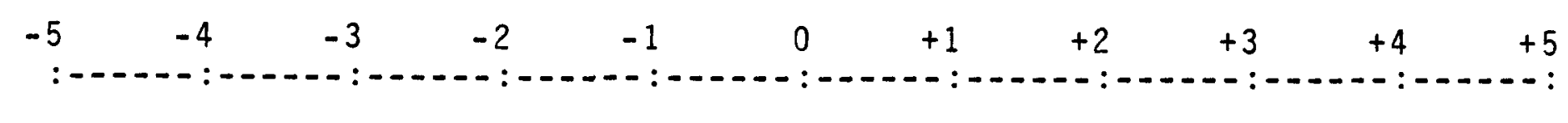

92. 59. 59. 92. $\quad$ 103. 99. 98.97. 89. 43. 37. 43. 89. 111. 105. 102. 101 . 87. 39. 39. 39. 39. 86. $315 . \quad 108 . \quad 104 . \quad 103$. 86. 39. 44. 47. 44. 38. 84. 118. 110. 106. 105 . 39. $\quad 48 . \quad 53 . \quad 52 . \quad 48 . \quad 38 . \quad 82 . \quad 120 . \quad 113 . \quad 109$. 53. 58. 59. 58. $\quad 39 . \quad 81 . \quad 122 . \quad 116$.

CALCULATED PFE (\%)

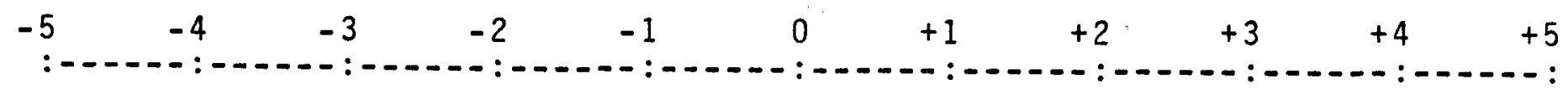

$\begin{array}{llllllll}10.15 & 11.44 & 11.44 & 10.15 & 9.82 & 9.94 & 9.98 & 9.99\end{array}$ $\begin{array}{lllllllll}10.29 & 13 . \dot{4} 0 & 14.97 & 13.40 & 10.29 & 9.67 & 9.86 & 9.94 & 9.97\end{array}$

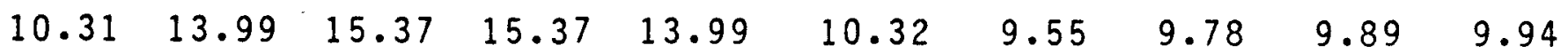

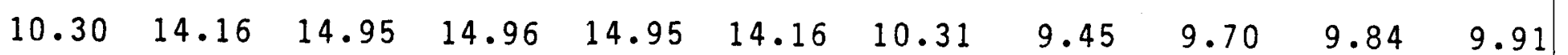
$\begin{array}{llllllllll}14.16 & 14.46 & 14.40 & 14.40 & 14.47 & 14.16 & 10.29 & 9.37 & 9.64 & 9.80\end{array}$ $\begin{array}{lllllllll}14.03 & 13.90 & 13.87 & 13.91 & 14.09 & 10.27 & 9.31 & 9.58\end{array}$

LIST--OPTION\# (I) =

MASTR-OPTION\# (I) =

$>6$

NORMAL EXIT. TIME: 5980 MILLISECONDS. ***DATA FILE SAVE-RESTORE PROGRAM*** $>0$ FMAIN-OPTION\# (I) =

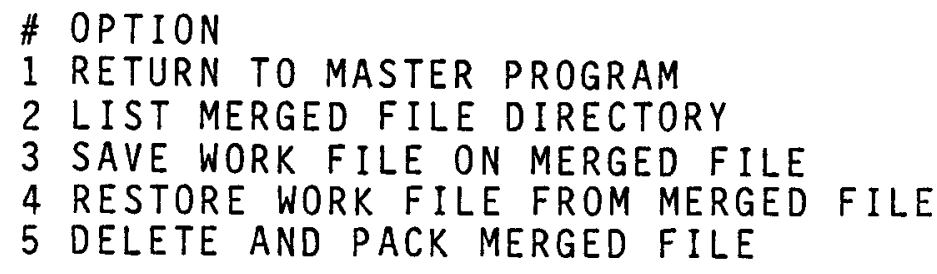


6 INITIALIZE WORK FILE

7 INITIALIZE MERGE FILE

FMAIN-OPTION\# (I)=

$>2$

MERGED FILE DIRECTORY

TOPOGRAPHIC STUDIES, MAY 1978

SUB FILE \# 1

IP2D DOCUMENTATION

SIMPLE MODEL

SUB FILE \# 2

TOPO EFFECT

FIELD CASE \# I

SUB FILE \# 3

BENCHMARK PRIME 400

HALF SPACE

FMAIN-OPTION\# (I)=

$>3$

WORK FILE SAVED AS SUB FILE \# 4

FMAIN-OPTION\# (I)=

$>2$

MERGED FILE DIRECTORY

TOPOGRAPHIC STUDIES, MAY 1978

SUB FILE \# 1

IP2D DOCUMENTATION

SIMPLE MODEL

SUB FILE\# 2

TOPO EFFECT

FIELD CASE \# 1

SUB FILE \# 3

BENCHMARK PRIME 400

HALF SPACE

SUB FILE \# 4

IP 20 DOCUMENTATION

SIMPLE MODEL

FMAIN-OPTION\# (I)=

$>4$

***EXECUTION OF THIS OPTION WILL OVERWRITE DATA FILE CONFIRM OPERATION $(Y, N)=$

$>Y$

SUB FILE \#=

$>3$

FMAIN-OPTION\# (I)=

$>1$

NORMAL EXIT.

$\star \star \star$ MASTER PROGRAM***

MASTR-OPTION\# (I)=

$>1$

NORMAL EXIT.

TIME :

13 MILLISECONDS.

Ready

Ready

2359 MILLISECONDS. 
An explanation of the program executions taking place near the circled numbers in the computer session is given below.

1 The interactive system is entered again by using the same add statement.

2 The user is able to pick up where execution was terminated. The ratio section has already been printed out and the user can continue by requesting a difference section.

3 After reviewing the results of the first calculation the user decides to widen the conducting body by recoding the mesh.

4 An error was made in coding row 5. Element \#28 should be coded with a 2 rather than a 1. This error is corrected using option 2 in the system editor.

5 The finite-element program is executed again with the new mesh code.

6 A look at the resistivity ratio section indicates that the resistivity of the conducting body is too high.

7 The resistivity of index 2 is reduced.

8 Exit is obtained from the updating routine by answering 0 to parameter number request.

9 The update routine can be used to systematically update all the parameters in a list by entering -1 to parameter number request.

10 Ratios of 1 and differences of 0 indicate that the model is producing values that are identical to the observed field values.

11 It is possible to obtain various plots of the final model through option selection.

12 The plot that the program produced at this point is shown in figure $\mathrm{D}-1$.

13 The plot that the program produced at this point is shown in figure $0-2$. 
Figure D-I Resistivity and Ratio Page

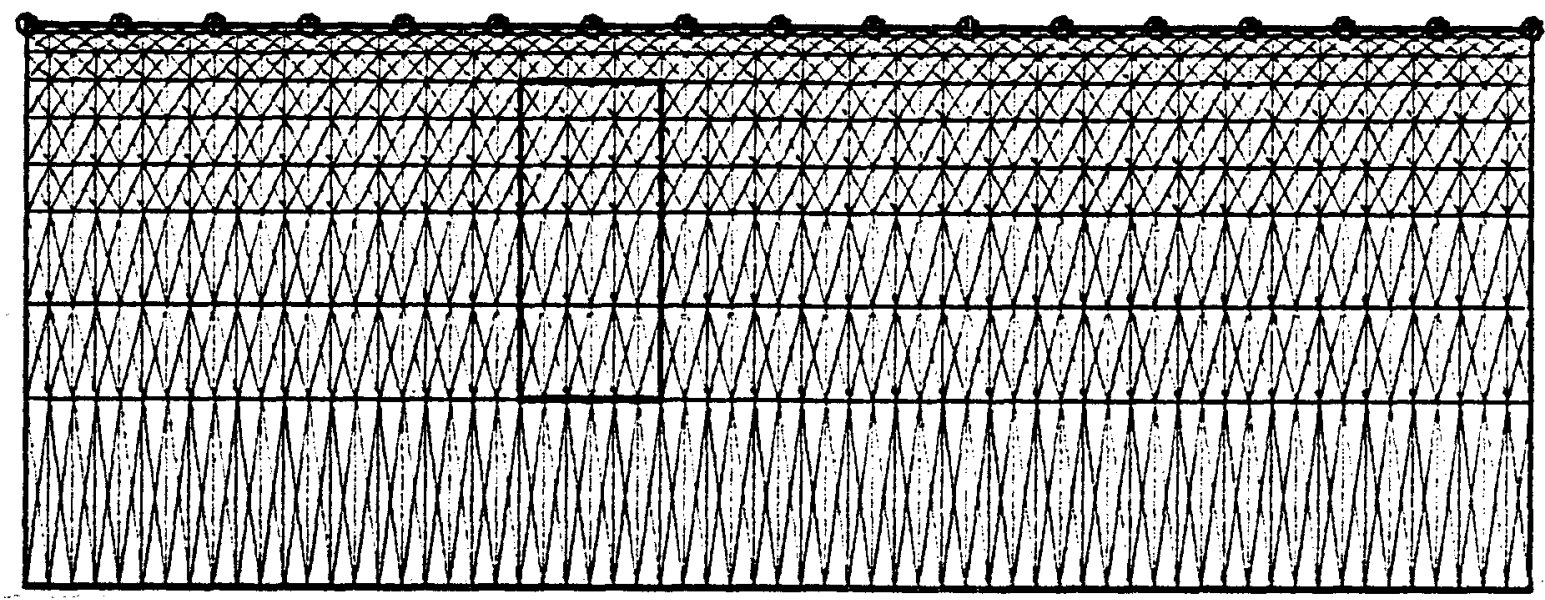

RATIO COMPUTED/OBSERVED

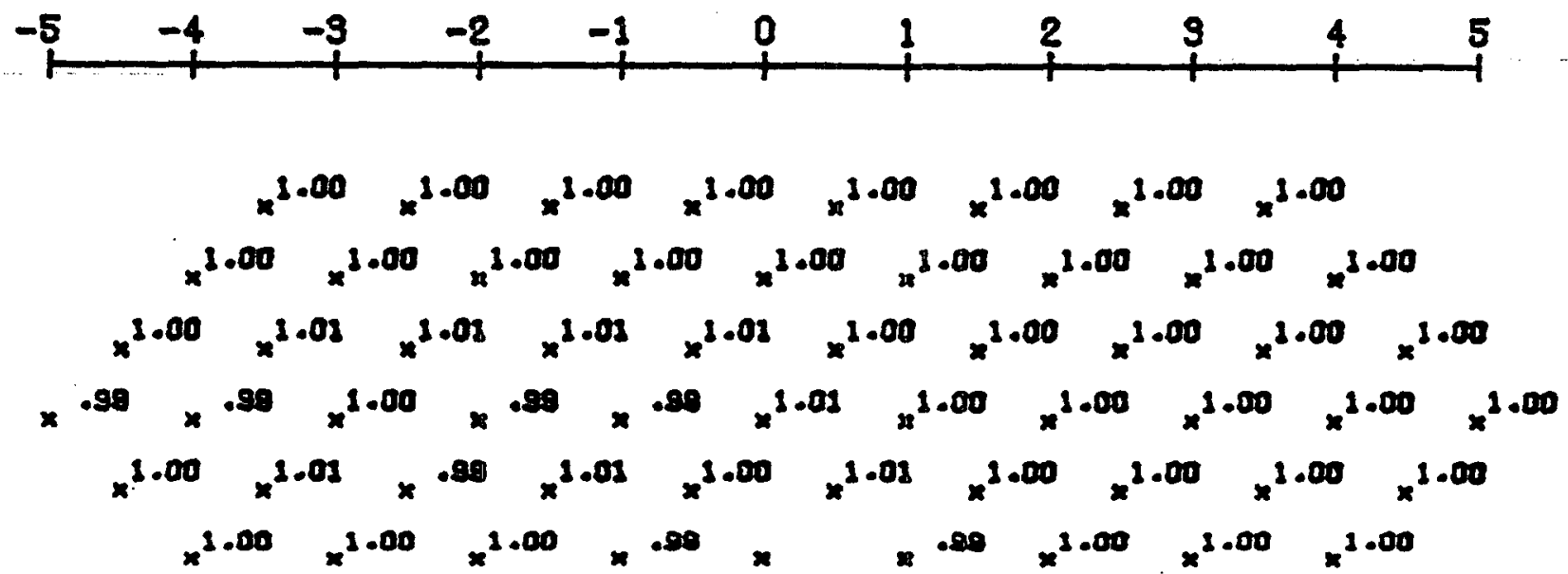

APPARENT RESISTIVITY - COMPUTED

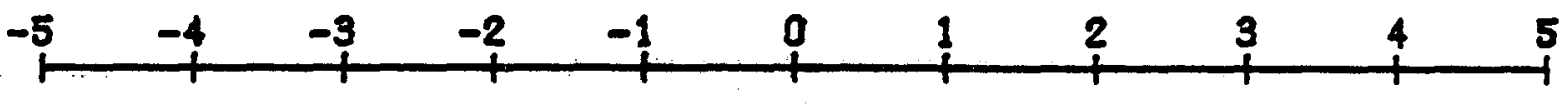

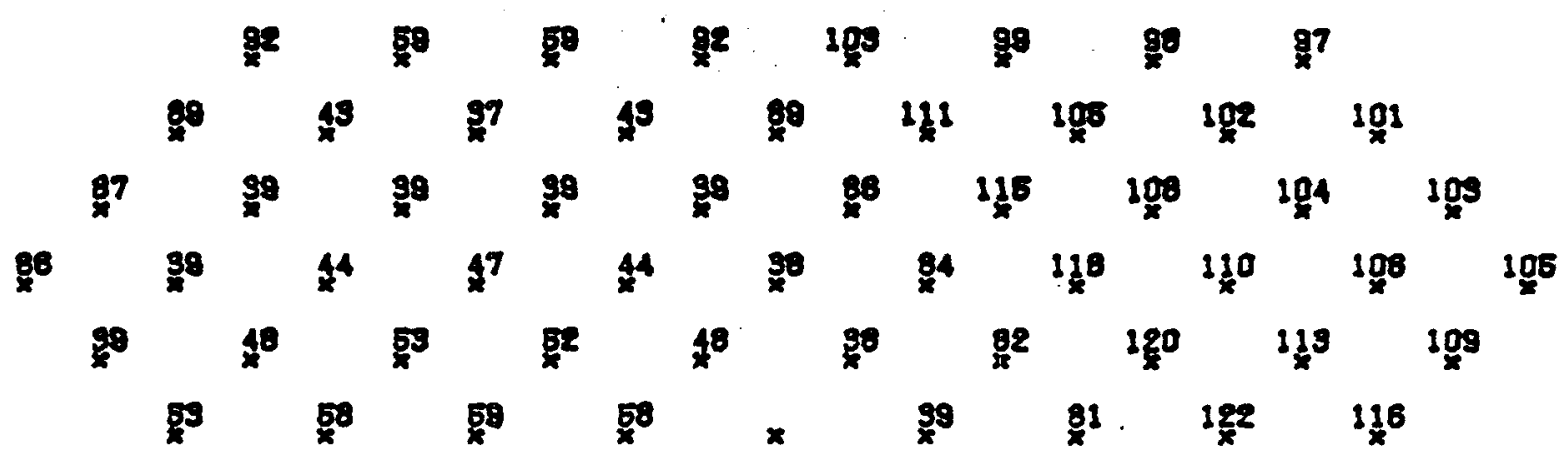


Figure D-2 PFE and Difference Page

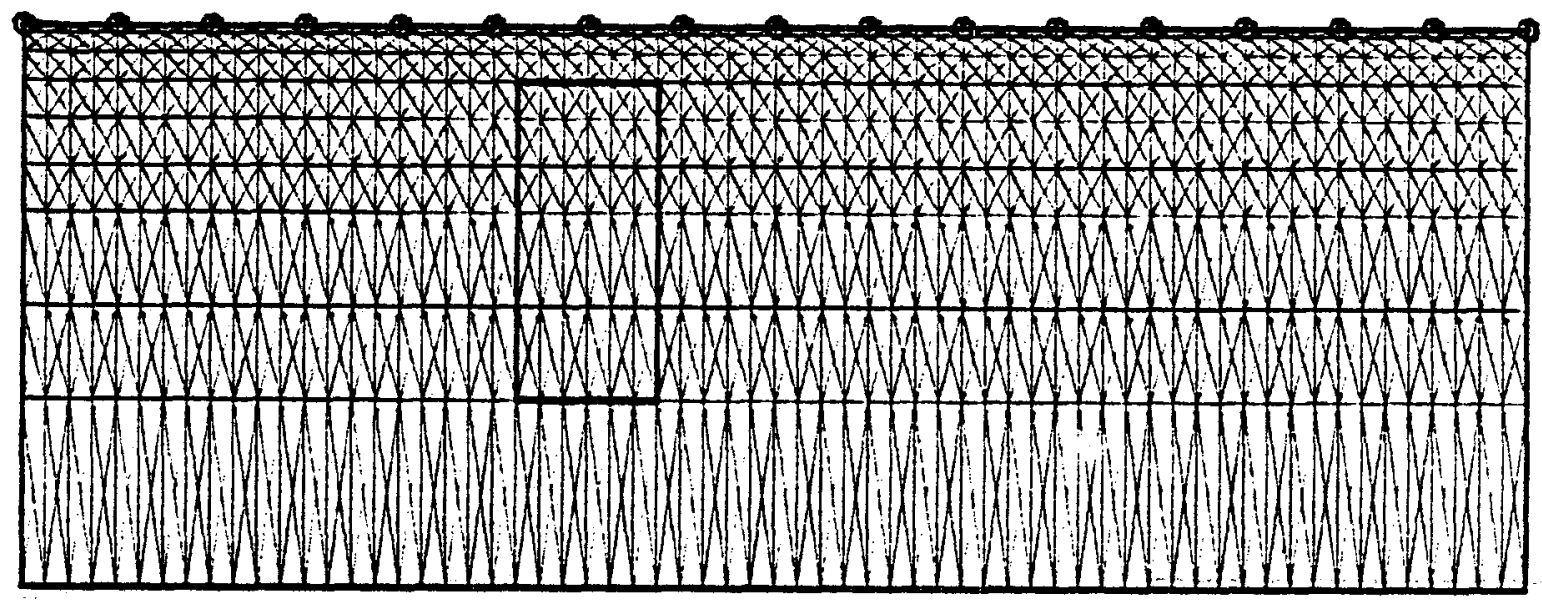

\section{DIFF. COMPUTED-OBSERVED}
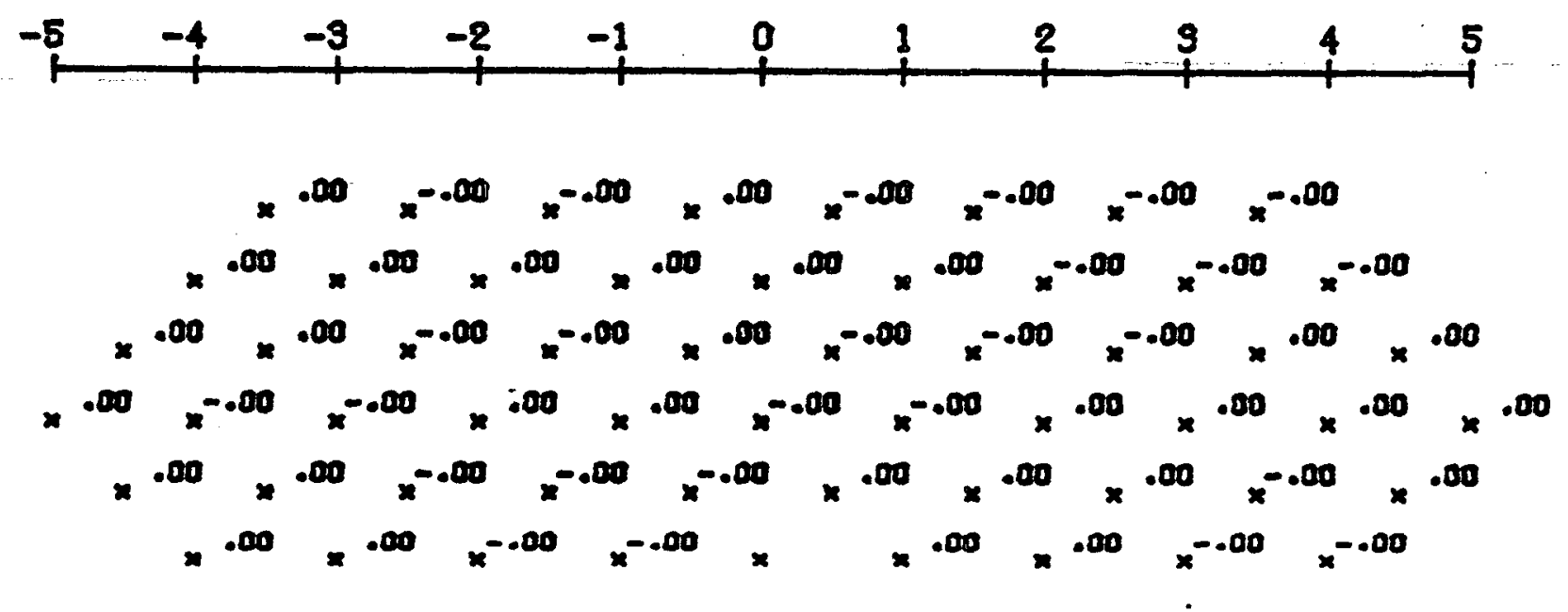

\section{PFE - COMPUTED}

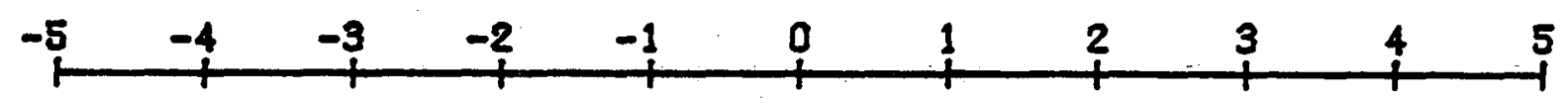

$19.2 \quad 18.4 \quad 11.4 \quad 19.2 \quad 8.8 \quad 9.9 \quad 10.0 \quad 10.0$

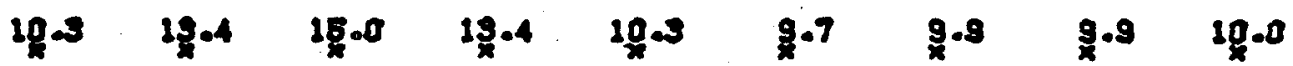

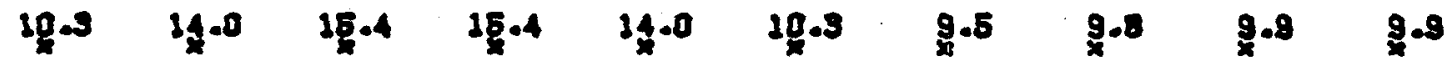

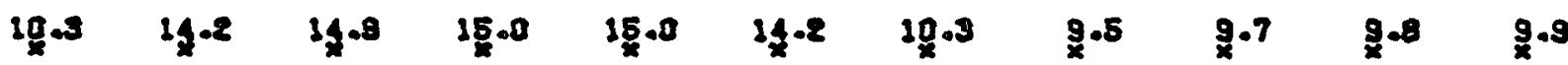

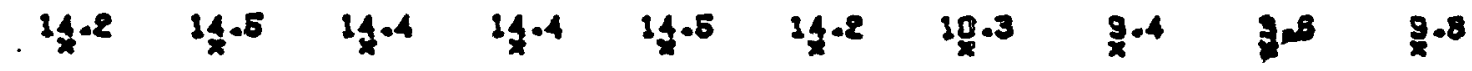

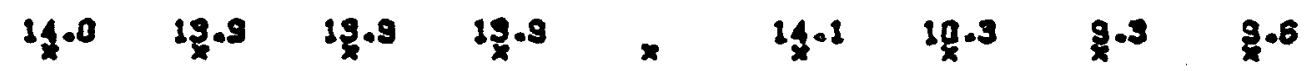


IP2D Computer Session \#3 Topographic Model 
GADD IP2D.XQT

FACILITY WARNING 102000000000 Ready

FACILITY WARNING 102000000000

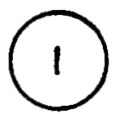

Ready

*** TERMINAL SELECTION PROGRAM***

TERM- -OPTION\# (I) =

$>1$

NORMAL EXIT TIME :

25 MILLISECONDS.

***MASTER PROGRAM***

MASTR-OPTION\# (I)=

$>0$

\# OPTION

1 EXIT FROM SYSTEM

2 INPUT MODEL PARAMETERS

3 EDIT MODEL PARAMETER FILE

4 PLOT MODEL MESH GEOMETRY

5 COMPUTE RATIO \& DIFF. SECTIONS

6 FILE MAINTENANCE SAVE \& RECALL

7 LIST MODEL PARAMETER FILE

8 EXECUTE RES. IP FINITE ELEMENT MASTR-OPTION\# (I)=

$>2$

$>0$

$$
\text { INPUT-OPTION\# (I)= }
$$

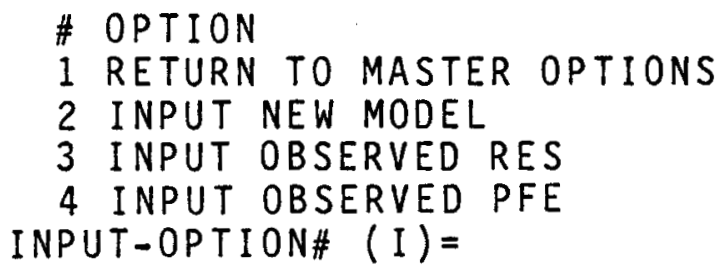

$>2$

PROJECT NAME $(60 \mathrm{~A})=$

$>$ TOPO EFFECT

MODEL NAME $(60 A)=$

$>$ FIELD CASE \# 1

USE DEFAULT MESH?

$>\mathrm{N}$

\#OF $X$ NODES (I) $=$

$>77$

\# OF $Z$ NODES (I) $=$

$>18$

\# OF $X$ ELEMENT GROUPS (I) $=$ $>13$

INPUT $13 \times$ ELEMENTS GROUP \#S (I)

$>1$ 


$$
\begin{aligned}
& >1 \# 2= \\
& \omega_{>1} \# 3= \\
& >1 \quad \# 4= \\
& >26 \# 5= \\
& >12^{\# 6}= \\
& >2 \quad \# 7= \\
& >3 \# 8= \\
& >8 \quad \# 9= \\
& >18 \# 10= \\
& >1 \# 11= \\
& >1 \# 12= \\
& >1 \# 13= \\
& \text { INPUT } 13 \times \text { GROUP SPACINGS (F) } \\
& >8 \text {. } \\
& >2 \text {. } \# 2= \\
& >1 \text {. } \# 3= \\
& >.55^{\# 4}= \\
& >.25^{\#} 5= \\
& \text { (6) } \begin{array}{l}
>.23^{\#} 6= \\
>.19^{\#} 7=
\end{array} \\
& \text { \# } 8=
\end{aligned}
$$


$>.18$
$>.22^{\# 9=}$

$\bigcup_{3}{ }^{\# 25^{10}=}$

$>.5 \# 11=$

$>2$. $\# 12=$

\# $13=$

$>8$.

\# OF $Z$ ELEMENT GROUPS (I) =

$>11$

INPUT $11 Z$ ELEMENT GROUP \#S

$>2 \# 1=$

$>2 \# 2=$

$>2 \# 3=$

$>2 \# 4=$

$>1 \# 5=$

$>3 \# 6=$

$>1 \# 7=$

$>1 \# 8=$

$>1 \# 9=$

$>1 \# 10=$

$>1 \# 11=$

INPUT $11 Z$ GROUP SPACINGS (F)

() $>.07^{\#} 1=$

$$
>.07^{\# \quad 2=}
$$


$>.1 \# 3=$

(3) $>12^{\# 4} 4=$

$>.09^{\# \quad 5}=$

$>.12^{\# 6}=$

$>.2^{\# 7=}$

$>.5 \# 8=$

71. $9=$

>2. \#10=

$>8$. $\# 811=$

INPUT 17 ELECTRODE POSITIONS (I)

$X$ NODE \# $1=$

$>7$

2 NODE \# $1=$

$>13$

(3)

$X$ NODE \# $2=$

$>11$

$Z$ NODE \# $2=$

$>13$

$X$ NODE \# $3=$

$>15$

Z NODE \# $3=$

$>13$

$X$ NODE \# $4=$

$>19$

2 NODE \# $4=$ $>13$

$X$ NODE\# $5=$ $>23$

(a) Z NODE\# $5=$ $>13$

$X$ NODE \# $6=$ 
$>27$

$Z$ NODE\# $6=$

$>13$

(3) NODE \# $7=$ $>31$

2 NODE \# $7=$ $>13$

$X$ NODE \# $8=$

$>35$

$Z$ NODE \# $8=$ $>10$

$X$ NODE \# $9=$

$>39$

Z NODE \# $9=$ $X$ NODE \# $10=$ $>43$

$Z$ NODE \# $10=$ $>3$

$X$ NODE \# $11=$ $>48$

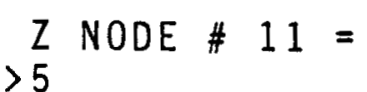
$X$ NODE \# $12=$ $>52$

9

*WAIT-Last input ignored* Z NODE \# $12=$ $>9$

$X$ NODE \#13= $>56$

2 NODE \# $13=$ $>13$

$X$ NODE \# $14=$ $>60$

$Z$ NODE \# $14=$ $>13$

XNODE \#15= $>64$

$Z$ NODE \# $15=$ 
$>13$

$X$ NODE \# $16=$ $>68$

Z NODE \# $16=$ $>13$

$X$ NODE \# $17=$

$>72$

Z NODE \# $17=$

$>13$

$\#$ OF DISTINCT MEDIA (I)= $>2$

INPUT 2 MEDIA RESISTIVITIES (F)

$>1000$.

$>100^{\#} .2=$

INPUT 2 MEDIA PFE (F)

$>0$.

$>0$.

DEFINE MESH AREA FOR INPUT

$X$ START NODE \# (I) $=$

$>30$

Z START NODE \#(I) =

$>1$

$\underset{>60}{X}$ END NODE \# (I) $=$

Z END NODE \# (I) =

$>14$

MEDIA MESH CODEING

ROW 1 ELEMENT 30 TO 59

$3 \ldots \ldots \ldots 4 \ldots \ldots \ldots . \ldots \ldots$

$>111111111111122111111111111 i$

ROW 2 ELEMENT 30 TO 59

$3 \ldots \ldots \ldots 4 \ldots \ldots \ldots 5 \ldots \ldots \ldots$

$>111111111111122221111111111111$

ROW 3 ELEMENT 30 TO 59

$3 \ldots \ldots \ldots 4 \ldots \ldots \ldots$............

$>1111111111122222211111111111$

ROW 4 ELEMENT 30 TO 59

3.......4...............

$>$ 1iiiiiiiin2222222iiliiiiii 
ROW 5 ELEMENT 30 TO 59

$3 \ldots \ldots \ldots 4 \ldots \ldots \ldots 5 \ldots \ldots \ldots$

$>111111111122222222211111111111$

ROW 6 ELEMENT 30 TO 59

$3 \ldots \ldots \ldots 4 \ldots \ldots \ldots 5 \ldots \ldots \ldots$.

$>111111111222222222221111111111$

ROW 7 ELEMENT 30 TO 59

$3 \ldots \ldots \ldots 4 \ldots \ldots \ldots 5 \ldots \ldots \ldots$

$>11 i 1111222222222222211111111$

ROW 8 ELEMENT 30 TO 59

3.....................

$>111111122222222222222211111111$

ROW 9 ELEMENT 30 TO 59

$3 \ldots \ldots \ldots . \ldots \ldots \ldots . \ldots \ldots$

$>11 i 11222222222222222221111111$

ROW 10 ELEMENT 30 TO 59

$3 \ldots \ldots \ldots 4 \ldots \ldots \ldots 5 \ldots \ldots \ldots$

$>111122222222222222222222111111$

ROW 11 ELEMENT 30 TO 59

$3 \ldots \ldots \ldots 4 \ldots \ldots \ldots 5 \ldots \ldots \ldots$

$>111222222222222222222222211111$

ROW 12 ELEMENT 30 TO 59

3 ......................

$>112222222222222222222222221111$

ROW 13 ELEMENT 30 TO 59

3 .....................

$>222222222222222222222222222222$

$>1$

INPUT-OPTION\# (I)=

MASTR-OPTION\# (I)= $>0$

\# OPTION

1 EXIT FROM SYSTEM

2 INPUT MODEL PARAMETERS

3 EDIT MODEL PARAMETER FILE

4 PLOT MODEL MESH GEOMETRY

5 COMPUTE RATIO \& DIFF. SECTIONS

6 FILE MAINTENANCE SAVE \& RECALL

7 LIST MODEL PARAMETER FILE

8 EXECUTE RES. IP FINITE ELEMENT MASTR-OPTION\# (I) =

$>7$

LIST--OPTION\# (I)=

\# OPTION

1 RETURN TO MASTER OPTIONS 


$\begin{array}{ll}2 & \text { LIST TITLES } \\ 3 & \text { LIST GEOMETRY PARAMETERS } \\ 4 & \text { LIST MEDIA CHARACTER. } \\ 5 & \text { LIST MESH CODE TRI. ELE. } \\ 6 & \text { LIST MESH CODE REC. ELE. } \\ 7 & \text { LIST PSEUDO SECTIONS } \\ 8 & \text { LIST FILE CONTENTS } \\ 9 & \text { SEND FILE CONTENTS TO PR } \\ 18 & \text { LIST-OOPTION\# }(I)=\end{array}$

PROJECT NAME:

TOPO EFFECT

MODEL NAME:

FIELD CASE \# 1

\# OF X NODES $=77$

$\#$ OF Z NODES $=18$

\# OF X ELEMENT GROUPS $=13$

$X$ ELEMENT GROUP \# $S$

$\begin{array}{ccccc}1 & 1 & 1 & 1 & 26 \\ 12 & 2 & 3 & 8 & 18 \\ 1 & 1 & 1 & & \end{array}$

$X$ ELEMENT GROUP SPACINGS IN A-UNITS

$\begin{array}{ccccc}8.00 & 2.00 & 1.00 & .50 & .25 \\ .23 & .19 & .18 & .22 & .25 \\ .50 & 2.00 & 8.00 & \end{array}$

\# OF Z ELEMENT GROUPS $=11$

$Z$ ELEMENT GROUP \#

$\begin{array}{ccccc}2 & 2 & 2 & 2 & 1 \\ 3 & 1 & 1 & 1 & 1 \\ 1 & & & \end{array}$

Z ELEMENT GROUP SPACINGS IN A-UNITS

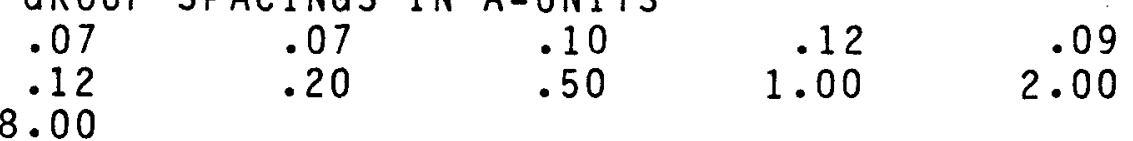

ELECTRODE $X$ NODE LOCATIONS

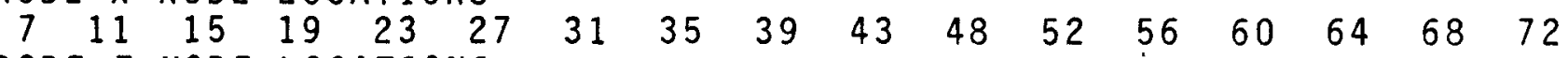

ELECTRODE Z NODE LOCATIONS

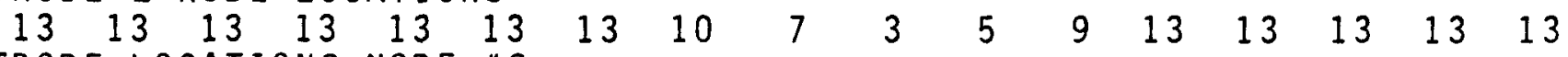

ELECTRODE LOCATIONS NODE \#S

$121 \quad 193265 \quad 337 \quad 40948155362269175985192710031075114712191291$

MEDIA RESITIVITY (OHM-METERS)

$1000.00 \quad 100.00$

MEDIA PFE $\quad \begin{array}{r}(\%) \\ .00\end{array}$

.00

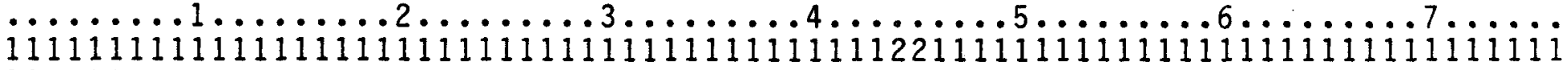

111111111111111111111111111111111111111111222211111111111111111111111111111

11111111111111111111111111111111111111112222221111111111111111111111111111

1111111111111111111111111111111111111111222222211111111111111111111111111111

1111111111111111111111111111111111111112222222221111111111111111111111111111

111111111111111111111111111111111111122222222222111111111111111111111111111 111111111111111111111111111111111122222222222221111111111111111111111 1111111111111111111111111111111111112222222222222221111111111111111111111111 1111111111111111111111111111111111122222222222222222111111111111111111111111

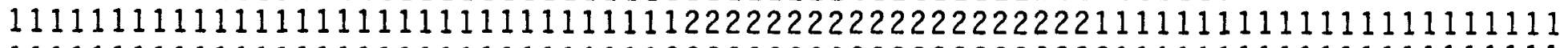
1111111111111111111111111111111122222222222222222222221111111111111111111111

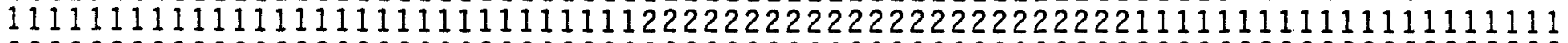
2222222222222222222222222222222222222222222222222222222222222222222222222222 
CALCULATED RESISTIVITY (OHM-METERS)

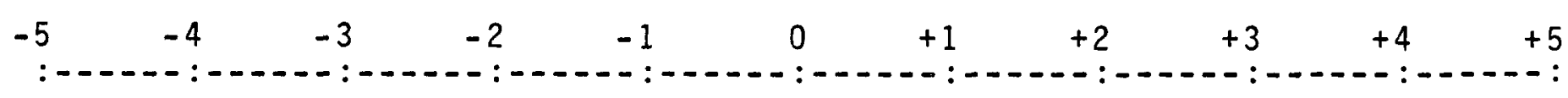

1. $1.1 . \quad 1 . \quad 1 . \quad 1 . \quad 1$.

1. 1. $1.1 . \quad 1.1 . \quad 1 . \quad 1 . \quad 1$.

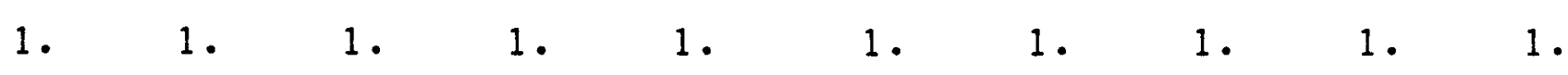

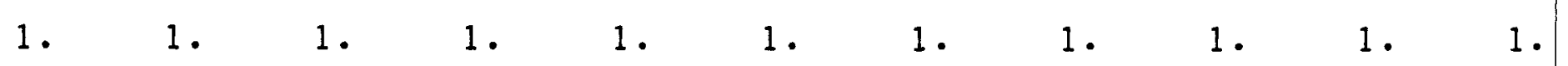

1. 1. 1. 1. 1. 1. 1. 1. 1. 1. 1 .

1. 1. 1. 1. 1.1 .1$.

CALCULATED PFE $(\%)$

\begin{tabular}{|c|c|c|c|c|c|c|c|c|c|c|}
\hline-5 & -4 & 3 & 2 & -1 & 0 & +1 & +2 & +3 & +4 & +5 \\
\hline & .00 & .00 & .00 & .00 & & .00 & .00 & .00 & .00 & \\
\hline & .00 & .00 & .00 & .00 & .00 & .00 & .00 & .00 & .00 & \\
\hline .00 & .00 & .00 & .00 & .00 & & .00 & .00 & .00 & .00 & .00 \\
\hline .00 & .00 & .00 & .00 & .00 & .00 & .00 & .00 & .00 & .00 & .00 \\
\hline .00 & .00 & .00 & .00 & .00 & & .00 & .00 & .00 & .00 & .00 \\
\hline & .00 & .00 & .00 & .00 & & .00 & .00 & .00 & .00 & \\
\hline
\end{tabular}

$>1 \quad$ LIST-OPTION\# (I) =

MASTR-OPTION\# (I)=

$>8$

NORMAL EXIT.

TIME :

2085 MILLISECONDS. 
NORMAL EXIT.

TIME :

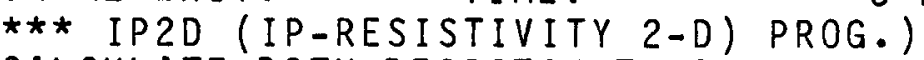

$>N$

CALCULATE BOTH RESISTIVITY AND PFE?

System warning - Max time

TOPO EFFECT

FIELD CASE \#I

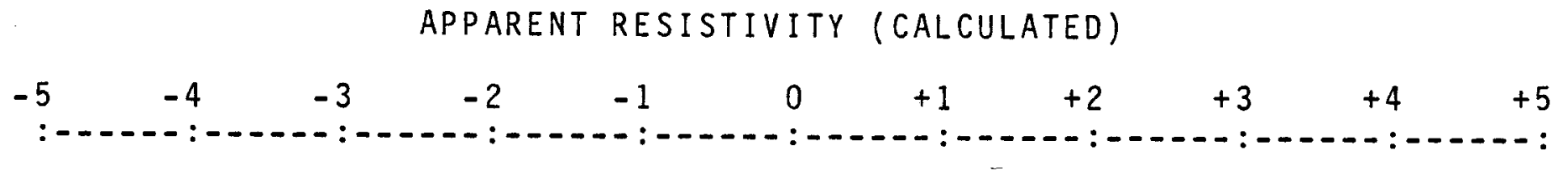

90. 84. 86. 81. $\quad 95 . \quad 146 . \quad 85 . \quad 86$.

97. 89. 86. 80. 82. $\quad$ 864. 142. $\quad 79.75$.

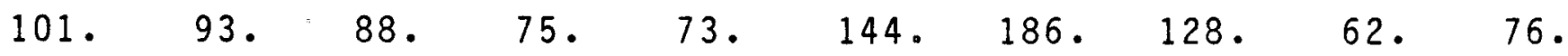

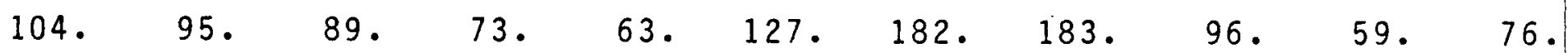

97. 89. $\quad$ 71. 59. 108. 168. 195. 140. 88. 57 .

89. 69. 56. 99. $6191 . \quad 154 . \quad 127 . \quad 83$.

NORMAL EXIT. TIME: 78811 MILLISECONDS.

***MASTER PROGRAM***

MASTR-OPTION\# (I) $=$

$>7$

$>8$

LIST--OPTION\# (I)=

PROJECT NAME:

TOPO EFFECT

MODEL NAME:

FIELD CASE \# 1

$\#$ OF $X$ NODES $=77$

\# OF $Z$ NODES $=18$

\# OF X ELEMENT GROUPS = 13

$X$ ELEMENT GROUP \# $S$

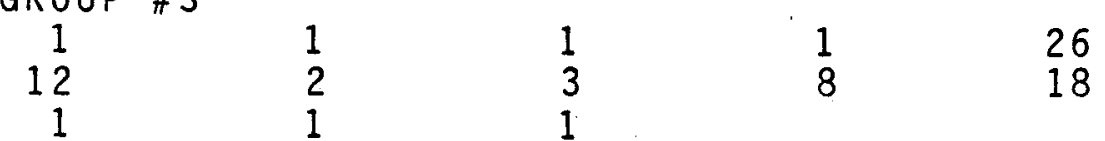

$X$ ELEMENT GROUP SPACINGS IN A-UNITS
8.00
.23
2.00
.19
1.00 .
$.50 \quad .25$
$.50 \quad 2.00$
.18
$.22 \quad .25$

\# OF Z ELEMENT GROUPS =

11

8.00

18

$Z$ ELEMENT GROUP \#S

$\begin{array}{lllll}2 & 2 & 2 & 2 & 1 \\ 3 & 1 & 1 & 1 & 1\end{array}$


Z ELEMENT GROUP SPACINGS IN A-UNITS
.07
.07
.10
.12
.09
.12
.20
.50
1.00
2.00

ELECTRODE X NODE LOCATIONS

$\begin{array}{llllll}7 & 11 & 15 & 19 & 23 & 27\end{array}$

ELECTRODE Z NODE LOCATIONS

$\begin{array}{llllll}13 & 13 & 13 & 13 & 13 & 13\end{array}$

ELECTRODE LOCATIONS NODE \#S

$\begin{array}{lllllllllll}31 & 35 & 39 & 43 & 48 & 52 & 56 & 60 & 64 & 68 & 72\end{array}$

$\begin{array}{lllllllllll}13 & 10 & 7 & 3 & 5 & 9 & 13 & 13 & 13 & 13 & 13\end{array}$

$121 \quad 19326533740948155362269175985192710031075114712191291$

MEDIA RESITIVITY (OHM-METERS)

$$
1000.00 \quad 100.00
$$

MEDIA PFE $(\%)$

.00

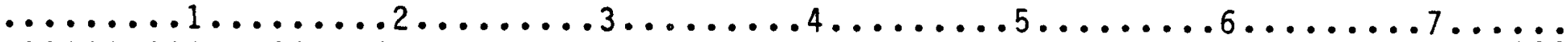
1111111111111111111111111111111111111111111221111111111111111111111111111 11111111111111111111111111111111111111112222111111111111111111111111111111 11111111111111111111111111111111111111122222211111111111111111111111111111 111111111111111111111111111111111111111222222211111111111111111111111111111 11111111111111111111111111111111111111122222222211111111111111111111111111 111111111111111111111111111111111111122222222222111111111111111111111111111 1111111111111111111111111111111111111222222222222211111111111111111111111111 111111111111111111111111111111111111222222222222222111111111111111111111111 111111111111111111111111111111111122222222222222222111111111111111111111111 111111111111111111111111111111111222222222222222222221111111111111111111111 1111111111111111111111111111111122222222222222222222221111111111111111111111 111111111111111111111111111111122222222222222222222222211111111111111111111 2222222222222222222222222222222222222222222222222222222222222222222222222222 2222222222222222222222222222222222222222222222222222222222222222222222222222 2222222222222222222222222222222222222222222222222222222222222222222222222222 2222222222222222222222222222222222222222222222222222222222222222222222222222 2222222222222222222222222222222222222222222222222222222222222222222222222222

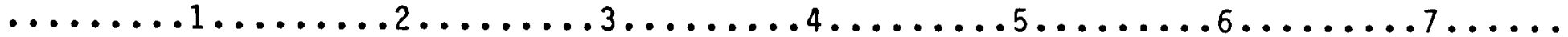

CALCULATED RESISTIVITY (OHM-METERS)

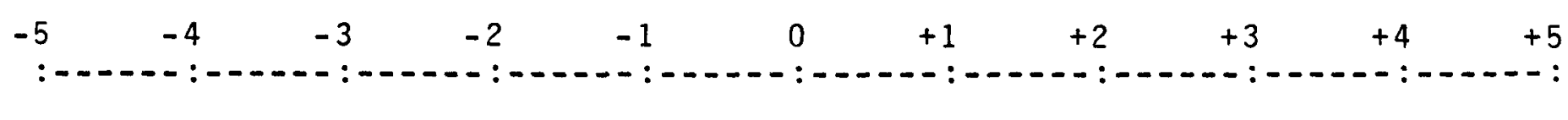

90. 84. 86. 81. 95. 146. 85. 86 .

97. 89. 86. 80. 82. 164. 142. 79. 75.

101. 93. 88. 75. 73. 144. 186. 128. 62. 76 .

104. 95. 89. 73. 63. 127. 182. 183. 96. 59. 76. 97. 89. 71. 59. 108. 168. 195. 140. 88. 57. 89. 69. 56. 99. 191. 154. 127. 83. 


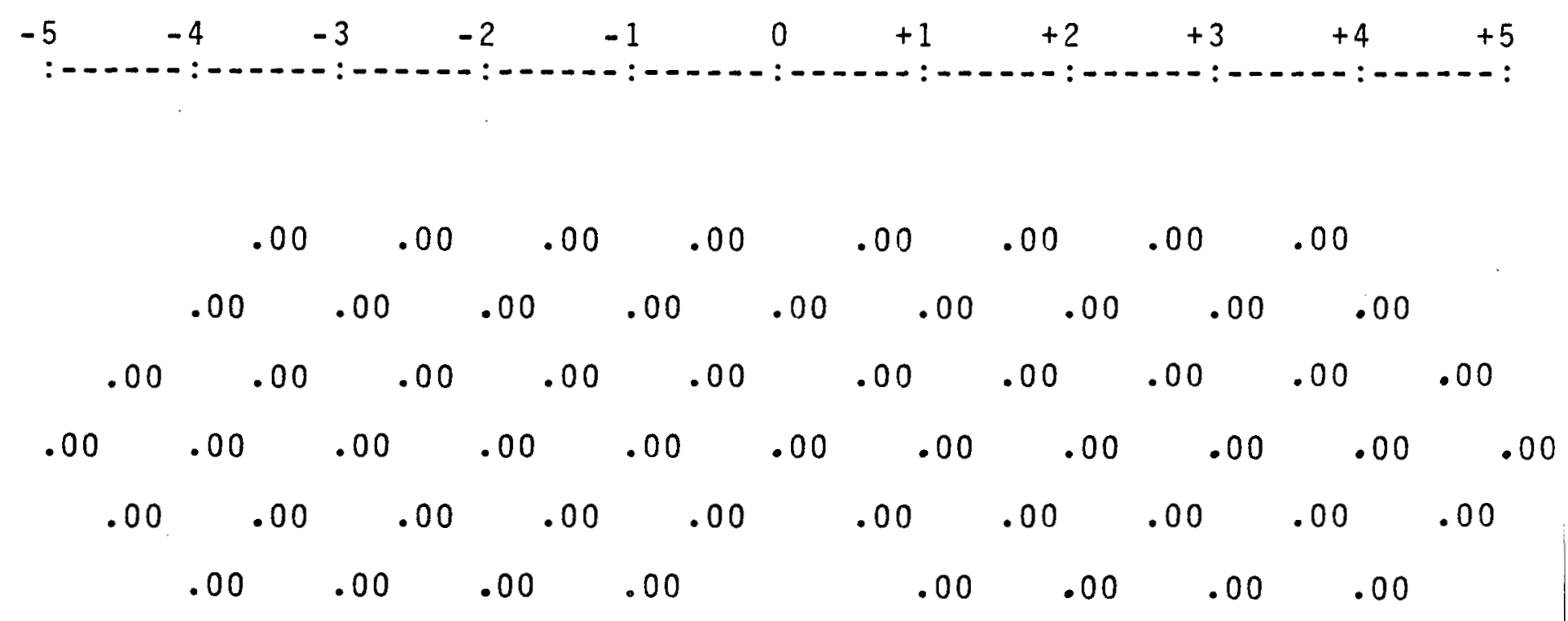

$>1$ LIST-OPTION\# (I) =

MASTR-OPTION\# (I)= $>4$

$>0$

PLOT--OPTION\# (I)=

\# OPTION

1 RETURN TO MASTER

2 TEK MESH PLOT

3 TEK SECTION PLOT

4 CALCOMP MESH PLOT

5 CALCOMP SECTION PLOT

6 CALCOMP REPORT PAGE PLOT

7 CALCOMP SCALED PAGE

8 CALCOMP SCALED PSEUDO $S$. $>6$ PLOT--OPTION\# (I) =

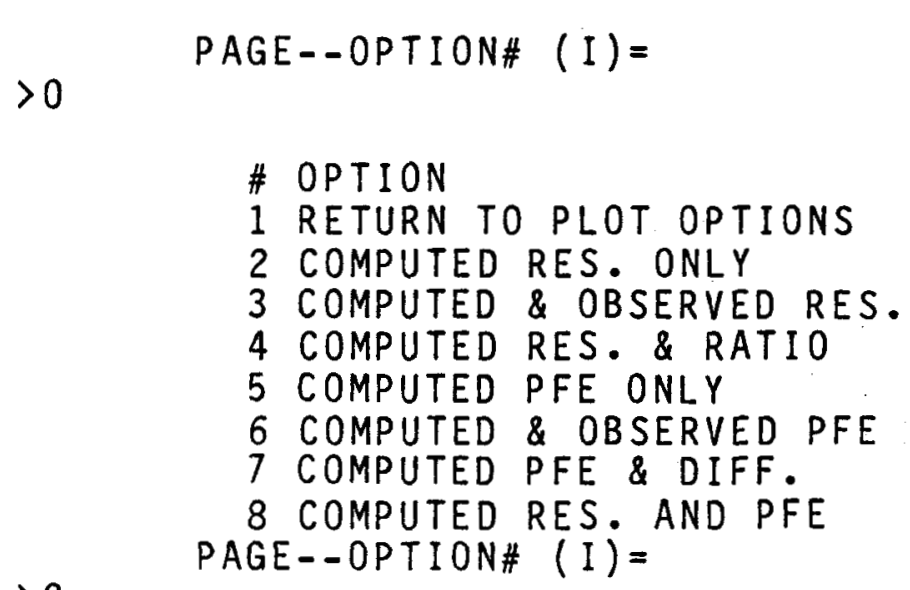

$>0$

$$
\text { PAGE--OPTION\# (I) = }
$$

\# OPTION

1 RETURN TO PLOT OPTIONS

2 COMPUTED RES. ONLY

3 COMPUTED \& OBSERVED RES.

4 COMPUTED RES. \& RATIO

5 COMPUTED PFE ONLY

6 COMPUTED \& OBSERVED PFE

7 COMPUTED PFE \& DIFF.

8 COMPUTED RES. AND PFE PAGE--OPTION\# (I)=

NODEX $=77$ NODEZ $=18$

START $X$ NODE \#= 
$>3$

END $X$ NODE \#= $>75$

$\omega_{>1}$ START Z NODE \#=

END Z NODE \#= $>17$

PLOT TRIANGULAR ELEMENTS?

$>Y$

$>1$

$$
\text { PAGE--OPTION\# (I) = }
$$

PLOT--OPTION\# (I)=

$>1$

MASTR-OPTION\# (I)= $>1$

NORMAL EXIT.

Ready

Ready

Ready

$>$

TIME :

4060 MILLISECONDS. 
An explanation of the program exections taking place near the circled numbers in the computer session is given below.

1 The facility warnings are given by the computer because the data files are still assigned to this run.

2 An answer of $\mathrm{N}$ to default mesh causes the program to request mesh parameters from the user. The mesh parameters are entered in the next five pages of session listing.

3 Note that the $z \& \times$ node locations are entered so that the electrodes reside on the air-earth boundary.

4 The plot that is produced at this point is shown in figure $0-3$. 
Figure D-3 Resistivity Section of a Topographic Model

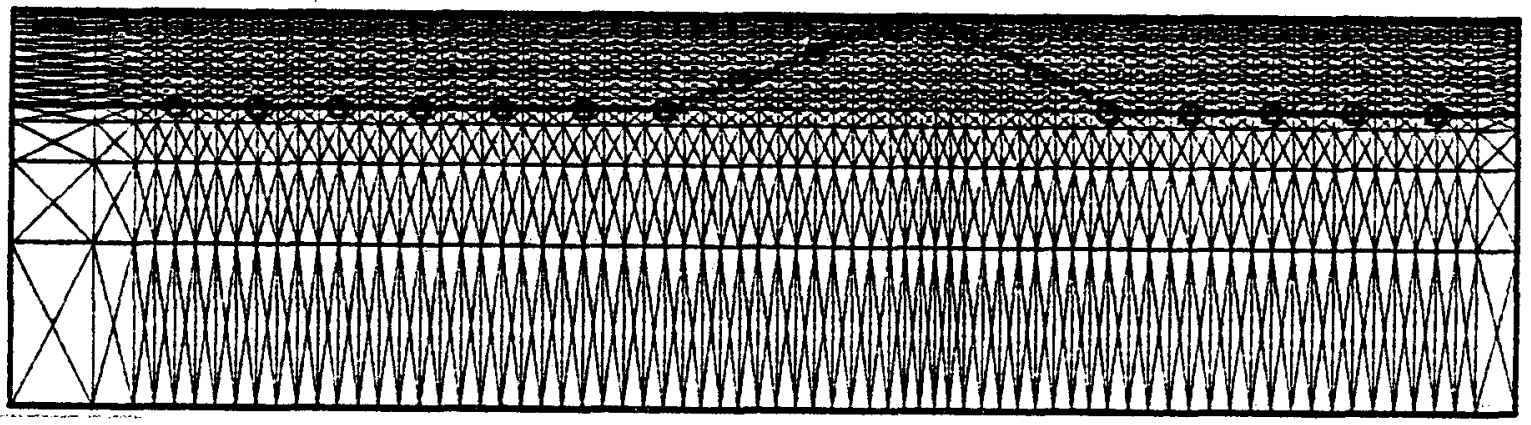

APPARENT RESISTIVITY - COMPUTED

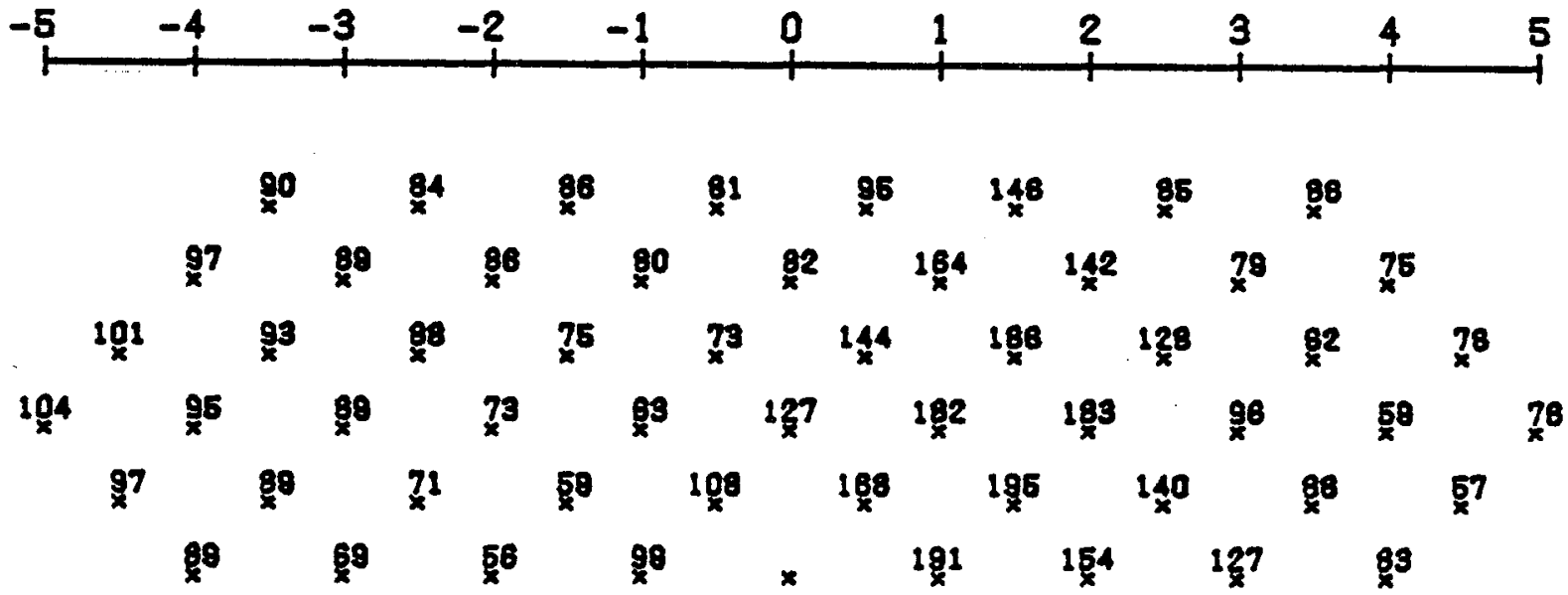




\section{3}

$\Theta$

Appendix E

Batch Modeling Users Guide 
It is possible to use the IP resistivity program in a batch mode. The interactive system is used to input models on the work file and to save the models on the merge file without having executed the finite-element algorithm. A card deck is then set up as a batch control file. The card deck can be submitted over the I/0 counter or can be started from a disk file. An explanation of how to set up the batch control file for use on the UNIVAC 1108 is given below.

(1) The cross section models that are to be executed on a lower priority are input into the work file using the interactive system. Each model is saved on the merge file without executing the finite-element algorithm. The user should make note of the subfile numbers underwhich the models are stored. For the sake of example, suppose that the file numbers were 11,12 , and 13 .

(2) A batch job deck is then set up either on cards or as a disk file as follows.

ORUN,W KILLPK,901900/ ,PROJECT $, 40,200$

@QUAL GEOPHY

QADD *IP2D.BATCH

11

N

11

12

N

12 
QFIN

(3) The card deck is then submitted to the computer over the I/0 counter or is started as a batch job from a remote terminal.

The qualifier of GEOPHY gives the user access to the interactive program file. The project name PROJECT that is used in the run card gives the user access to the work and merge file of a particular project. The subfile numbers appear as pairs of numbers in the card deck. The first number tells the program which subfile is to be moved into the work file. The $N$ in the card deck indicates that only the resisitivity pseudosection should be calculated. If both the resistivity and PFE pseudosections are to be calculated, the Ns in the card deck should be replaced with Ys. The second subfile number tells the program where to store the work file contents after the finite-element program has been run. A subfile number of 0 causes the batch system to return control to the 1108 operating system where the QFIN is encountered and the execution stops. The printout that is generated from the batch job can be picked up at the computer center at a later time. The priority of $W$ following the run card causes the program to be executed at night when the computer costs are the least. 


\section{REFERENCES}

Zienkiewicz, 0.C., 1971, The finite element method in engineerng science:

McGraw-Hill, N.Y., 521 p.

Rijo, Luiz, 1977, Modeling of electric and electromagnetic data: Ph.D. Dissertation, Univ. of Utah, Dept. of Geology \& Geophysics, 242 p. 